\title{
Cross-dehydrogenative coupling for the intermolecular C-O bond formation
}

\author{
Igor B. Krylov, Vera A. Vil' and Alexander O. Terent'ev§
}

\author{
Review \\ Address: \\ N. D. Zelinsky Institute of Organic Chemistry, Russian Academy of \\ Sciences, Leninsky Prospect 47, Moscow, 119991, Russia \\ Email: \\ Alexander O. Terent'ev* - alterex@yandex.ru \\ * Corresponding author \\ $\S$ Tel +7-916-385-4080 \\ Keywords: \\ acyloxylation; alkoxylation; C-H functionalization; C-O bond \\ formation; cross-dehydrogenative coupling; oxidative cross-coupling
}

\author{
Beilstein J. Org. Chem. 2015, 11, 92-146. \\ doi:10.3762/bjoc. 11.13 \\ Received: 14 October 2014 \\ Accepted: 31 December 2014 \\ Published: 20 January 2015 \\ Associate Editor: S. You \\ (C) 2015 Krylov et al; licensee Beilstein-Institut. \\ License and terms: see end of document.
}

\begin{abstract}
The present review summarizes primary publications on the cross-dehydrogenative $\mathrm{C}-\mathrm{O}$ coupling, with special emphasis on the studies published after 2000. The starting compound, which donates a carbon atom for the formation of a new $\mathrm{C}-\mathrm{O}$ bond, is called the $\mathrm{CH}$-reagent or the C-reagent, and the compound, an oxygen atom of which is involved in the new bond, is called the $\mathrm{OH}-$ reagent or the O-reagent. Alcohols and carboxylic acids are most commonly used as O-reagents; hydroxylamine derivatives, hydroperoxides, and sulfonic acids are employed less often. The cross-dehydrogenative $\mathrm{C}-\mathrm{O}$ coupling reactions are carried out using different $\mathrm{C}$-reagents, such as compounds containing directing functional groups (amide, heteroaromatic, oxime, and so on) and compounds with activated $\mathrm{C}-\mathrm{H}$ bonds (aldehydes, alcohols, ketones, ethers, amines, amides, compounds containing the benzyl, allyl, or propargyl moiety). An analysis of the published data showed that the principles at the basis of a particular cross-dehydrogenative $\mathrm{C}-\mathrm{O}$ coupling reaction are dictated mainly by the nature of the $\mathrm{C}$-reagent. Hence, in the present review the data are classified according to the structures of C-reagents, and, in the second place, according to the type of oxidative systems. Besides the typical cross-dehydrogenative coupling reactions of $\mathrm{CH}$ - and $\mathrm{OH}-$ reagents, closely related $\mathrm{C}-\mathrm{H}$ activation processes involving intermolecular $\mathrm{C}-\mathrm{O}$ bond formation are discussed: acyloxylation reactions with $\operatorname{Ar}\left(\mathrm{O}_{2} \mathrm{CR}\right)_{2}$ reagents and generation of $\mathrm{O}-$ reagents in situ from C-reagents (methylarenes, aldehydes, etc.).
\end{abstract}

\section{Introduction}

The development of methods for the cross-dehydrogenative coupling (CDC; or oxidative cross coupling) is an important field of modern organic chemistry. These terms commonly refer to reactions, in which two different molecules are linked by a new bond accompanied by the elimination of a hydrogen atom from each molecule (Scheme 1) [1-15]; however, these terms are also applied to a large number of various reactions with oxidants, which involve the intermolecular formation of new 
bonds between the starting molecules. For instance, such reactions involve the oxidation of several $\mathrm{C}-\mathrm{H}$ bonds, the elimination not only of hydrogen atoms but also of other moieties from the starting molecules, the addition at $\mathrm{C}-\mathrm{C}$ multiple bonds, and so on.

$$
\mathrm{A} \stackrel{!}{!} \mathrm{H}+\mathrm{H} \stackrel{!}{!} \mathrm{B} \stackrel{\text { oxidant }}{\longrightarrow} \mathrm{A}-\mathrm{B}
$$

Scheme 1: Cross-dehydrogenative coupling.

The cross-dehydrogenative coupling can be employed to form a new bond with high atomic efficiency and does not require additional synthetic steps for the introduction of functional groups (for example, such as -Hal, -OTf, - $\mathrm{BR}_{2},-\mathrm{SnR}_{3},-\mathrm{SiR}_{3},-\mathrm{ZnHal}$, -MgHal) into molecules necessary in other cross-coupling reactions. Therefore, the cross-dehydrogenative coupling is a promising approach to the minimization of byproduct formation and the reduction of the number of steps of the organic synthesis [1-15].

Studies of the cross-dehydrogenative coupling are not only of practical but also of fundamental interest because new aspects of the reactivity of organic compounds have to be found for the performance of these reactions. The prediction of the conditions necessary for the efficient cross-dehydrogenative coupling is an important problem that requires an understanding of the mechanisms of these processes.

Among cross-dehydrogenative coupling reactions, $\mathrm{C}-\mathrm{C}$ coupling reactions have been studied in most detail [1-14], whereas the $\mathrm{C}-\mathrm{O}$ coupling is less well-known (Scheme 2). We present the first systematic review of the main approaches to the cross-dehydrogenative $\mathrm{C}-\mathrm{O}$ coupling. The starting compound, which donates a carbon atom for the formation of a new $\mathrm{C}-\mathrm{O}$ bond, is called the CH-reagent or the C-reagent, and the compound, an oxygen atom of which is involved in the new bond, is called the OH-reagent or the O-reagent.

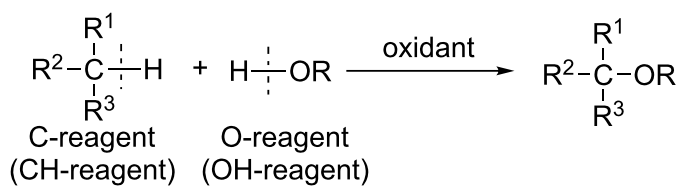

Scheme 2: Cross-dehydrogenative $\mathrm{C}-\mathrm{O}$ coupling.

Alcohols and carboxylic acids are most commonly used as O-reagents; hydroxylamine derivatives, hydroperoxides, and sulfonic acids are employed less frequently. In the case of
O-reagent $\mathrm{PhI}\left(\mathrm{O}_{2} \mathrm{CR}\right)_{2}$, dehydrogenated carboxylic acid $\mathrm{RCO}_{2} \mathrm{H}$ is preliminary included in the oxidant, so $\mathrm{C}-\mathrm{H}$ acyloxylation with $\mathrm{PhI}\left(\mathrm{O}_{2} \mathrm{CR}\right)_{2}$ can be considered as the second stage in a two-step cross-dehydrogenative $\mathrm{C}-\mathrm{O}$ coupling. The formation of a new $\mathrm{C}-\mathrm{O}$ bond generally takes place with the involvement of an O-nucleophile, an O-radical, or an O-electrophile. In the oxidative coupling with O-reagents as nucleophiles, electrophilic intermediates that are generated from $\mathrm{C}$-reagents are prone to side transformations. Therefore, O-reagents are often used in excess amounts. The $\mathrm{C}-\mathrm{O}$ coupling reactions involving $\mathrm{O}$-centered radicals are generally performed under severe conditions. In addition, O-radicals are highly reactive and unstable, and the reactions with these radicals are often nonselective and are accompanied by the formation of alcohols, carbonyl compounds, and fragmentation products. The examples of the $\mathrm{C}-\mathrm{O}$ bond formation between two molecules using $\mathrm{O}$-electrophiles are rare; electron-deficient peroxides with a specific structure can act as O-electrophiles [16-18]. These processes are not consistent with general Scheme 2 of the crossdehydrogenative $\mathrm{C}-\mathrm{O}$ coupling and are not considered in the present review.

The cross-dehydrogenative $\mathrm{C}-\mathrm{O}$ coupling reactions are carried out using different $\mathrm{C}$-reagents, such as compounds containing directing functional groups (amide, heteroaromatic, oxime, and so on) and compounds with activated $\mathrm{C}-\mathrm{H}$ bonds (aldehydes, alcohols, ketones, ethers, amines, amides, compounds containing a benzyl, allyl, or propargyl moiety). An analysis of the published data showed that the principles at the basis of a particular cross-dehydrogenative $\mathrm{C}-\mathrm{O}$ coupling reaction are dictated mainly by the nature of the C-reagent. Hence, in the present review the data are classified according to the structures of C-reagents, and, in the second place, according to the type of oxidative systems. Since structurally different $\mathrm{OH}$-reagents are often involved in $\mathrm{C}-\mathrm{O}$ coupling reactions of the same type, the classification according to the structures of O-reagents is inconvenient and was not applied.

Some cross-dehydrogenative $\mathrm{C}-\mathrm{O}$ coupling reactions are cursorily described in reviews on the oxidative $\mathrm{C}$-heteroatom bond formation without the use of metal compounds [15], the $\mathrm{Pd}(\mathrm{II})-$ catalyzed oxidative $\mathrm{C}-\mathrm{C}, \mathrm{C}-\mathrm{O}$, and $\mathrm{C}-\mathrm{N}$ bond formation [3], the transition metal-catalyzed etherification of unactivated $\mathrm{C}-\mathrm{H}$ bonds [19], the $\mathrm{Pd}(\mathrm{II})$-catalyzed oxidative functionalization at the allylic position of alkenes [20,21], the oxidative functionalization catalyzed by copper compounds to form $\mathrm{C}-\mathrm{C}, \mathrm{C}-\mathrm{N}$, $\mathrm{C}-\mathrm{O}, \mathrm{C}-\mathrm{Hal}, \mathrm{C}-\mathrm{P}$, and $\mathrm{N}-\mathrm{N}$ bonds $[10]$, the $\mathrm{Bu}_{4} \mathrm{NI} / t-\mathrm{BuOOH}$ oxidative system [22], selective functionalization of molecules [23], the oxidative esterification and oxidative amidation of aldehydes [24], and the transition metal-catalyzed radical oxidative cross-couplings [13]. 
The present review summarizes primary publications on the cross-dehydrogenative $\mathrm{C}-\mathrm{O}$ coupling, with special emphasis on the studies published after 2000. The focus is on the reactions described by general Scheme 2 .

\section{Review}

\section{$1 \mathrm{C}$-Reagents containing directing groups in cross-dehydrogenative $\mathrm{C}-\mathrm{O}$ coupling}

Nitrogen-containing moieties (amide, pyridine, oxime, etc.) are most commonly used as directing groups, which are responsible for the regioselectivity of the $\mathrm{C}-\mathrm{O}$ coupling. Most transformations of this type are catalyzed by $\mathrm{Pd}(\mathrm{II})$ compounds. Examples of the use of copper and ruthenium compounds as catalysts were also reported. It is commonly assumed that the reaction proceeds via the $\mathrm{C}-$ metal bond formation accompanied by the $\mathrm{C}-\mathrm{H}$ bond cleavage assisted by the directing group of the substrate, which forms a complex with the metal ion. The mechanism of this type of reactions was considered in detail in the publications [25-32].

\subsection{Reactions involving $\mathrm{C}\left(\mathrm{sp}^{2}\right)-\mathrm{H}$ bonds of aromatic C-reagents}

In one of the first publications on the preparative introduction of the -OR group into $\mathrm{CH}$-reagents containing directing groups, 8-methylquinoline, 2-arylpyridines, $\mathrm{N}$-phenylpyrazole, azobenzene, and benzylideneaniline were subjected to the acetoxylation using the $\mathrm{Pd}(\mathrm{OAc})_{2} / \mathrm{PhI}(\mathrm{OAc})_{2}$ system [33]. More recently, reactions involving the same and some other directing groups were studied in more detail. In most of the studies, $\mathrm{Pd}(\mathrm{OAc})_{2}$ was used as the catalyst, and $\mathrm{PhI}(\mathrm{OAc})_{2}$ or peroxides served as the oxidants.

The regioselectivity of the ortho-acetoxylation of meta-substituted arylpyridines and $\mathrm{N}$-arylamides 1 was studied [34]. The acetoxylation occurs mainly at the sterically more accessible para-position relative to the substituent $\mathrm{R}$ to form product $\mathbf{2}$.
The lowest regioselectivity $(\mathbf{2 : 3}=6: 1)$ was observed in the case of $\mathrm{R}=\mathrm{F}$ (Scheme 3).

The pyridine moiety served as the directing group in many works to accomplish the ortho-acyloxylation of arenes $\mathbf{4}$ giving products 5 (Table 1). The reactions were catalyzed by copper, palladium, or rhodium salts. Carboxylic acids or their salts, as well as aldehydes, methylarenes, arylethylenes, and arylacetylenes were used as precursors of the acyloxy fragment.

The cross-dehydrogenative $\mathrm{C}-\mathrm{O}$ coupling with 2-arylpyridines 4 proceeds also in the presence of the $\mathrm{Cu}(\mathrm{OAc})_{2} / \mathrm{O}_{2}$ system [40] and under electrochemical oxidation in the presence of $\mathrm{Pd}(\mathrm{II})$ salts [41].

The pyrimidine (acetoxylation of 6 to form 7) [42], benzoxazole (acetoxylation of $\mathbf{8}$ to form $\mathbf{9}$ ) [43], benzimidazole (alkoxylation of $\mathbf{1 0}$ to form 11) [44], and triazole (acyloxylation of $\mathbf{1 2}$ to form 13 [45], alkoxylation of 14 to form 15 [46]) moieties were also used as directing groups for the ortho-acyloxylation and alkoxylation of arenes (Scheme 4).

The pyridine, pyrimidine, or pyrazole moiety serves as the directing group in the oxidative ortho-alkoxylation of arenes $\mathbf{1 6}$ with the $\mathrm{Cu}(\mathrm{OAc})_{2} / \mathrm{AgOTf} / \mathrm{O}_{2}$ system giving coupling products 17 (Scheme 5) [47]. It is supposed that copper is inserted into the $\mathrm{C}-\mathrm{H}$ bond of arene, the resulting $\mathrm{Cu}$ (II) complex is oxidized by silver(I) ions to $\mathrm{Cu}$ (III) complex $\mathbf{1 8}$, and the $\mathrm{C}-\mathrm{O}$ bond is formed via reductive elimination. The drawbacks of this method are the use of large amounts of silver triflate and alcohol and the high temperature of the reaction.

The $\mathrm{Pd}(\mathrm{OAc})_{2} /$ persulfate system was used in the ortho-alkoxylation of arylnitriles 19-20 [48], $N$-methoxybenzamides 21 [49], and acetanilides 22 [50] and in the ortho-acetoxylation of acetanilides 22 [51] and sulfoximines 23 [52] to prepare cross-

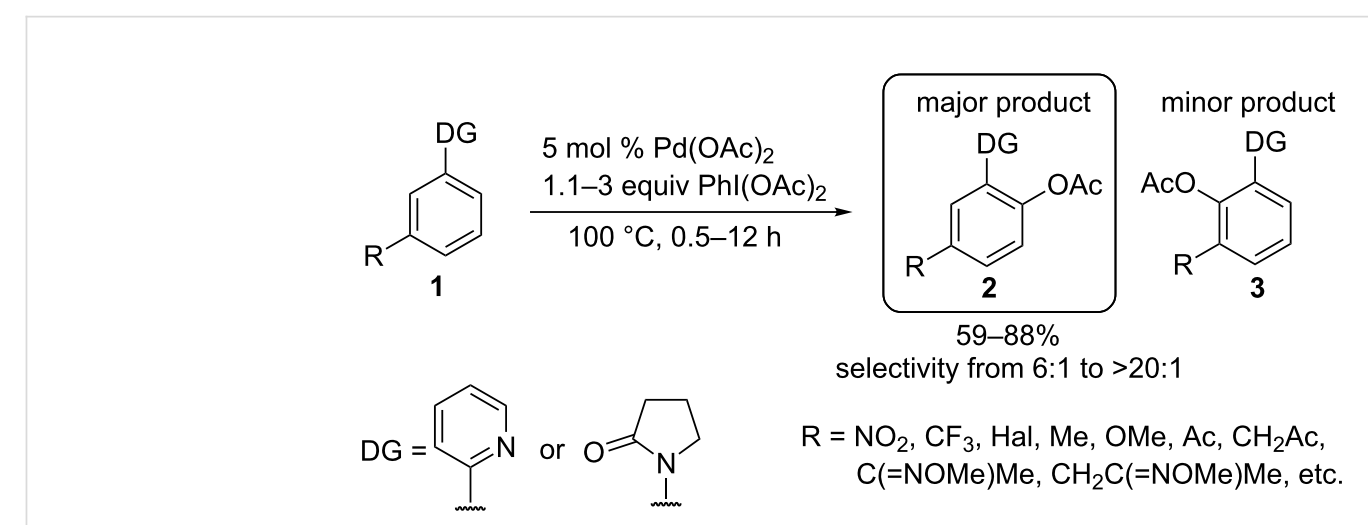


Table 1: ortho-Acyloxylation of arenes 4 directed by pyridine moiety.

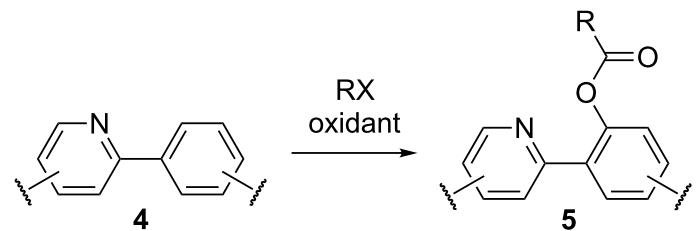

4

5

\begin{tabular}{|c|c|c|c|}
\hline Conditions & $\mathrm{RX}$ & Yield of $\mathbf{5}, \%$ & Ref. \\
\hline $\begin{array}{l}{[\mathrm{Rh}(\mathrm{cod}) \mathrm{Cl}]_{2}\left(5 \mathrm{~mol}^{\circ}\right)} \\
\mathrm{P}(\text { Cyclohexyl })_{3} \cdot \mathrm{HBF}_{4}(7.5 \mathrm{~mol} \%) \\
\text { Cul }(40 \mathrm{~mol} \%) \\
\text { phenanthroline }(10 \mathrm{~mol} \%) \\
N \text {-methylpyrrolidone, } 130{ }^{\circ} \mathrm{C}, 36 \mathrm{~h}\end{array}$ & $\begin{array}{l}\mathrm{RCOOH}(0.5 \text { or } 2 \text { equiv); } \mathrm{R}=\mathrm{Ar}, \mathrm{CH}=\mathrm{CHPh} \text {, } \\
\mathrm{Me}\end{array}$ & $43-85$ & [35] \\
\hline $\begin{array}{l}\mathrm{Pd}(\mathrm{OAc})_{2}(10 \mathrm{~mol} \%) \\
\mathrm{Cul}(1 \text { equiv) } \\
\mathrm{Ag}_{2} \mathrm{CO}_{3} \text { (1 equiv) } \\
\mathrm{O}_{2} \\
\text { dichloroethane, } 80^{\circ} \mathrm{C}\end{array}$ & $\mathrm{RCOOH} ; \mathrm{R}=\mathrm{Ar}, \mathrm{Me}$ & $53-78$ & [36] \\
\hline $\begin{array}{l}\mathrm{Cu}(\mathrm{OTf})_{2} \\
\mathrm{~K}_{2} \mathrm{~S}_{2} \mathrm{O}_{8} \\
\text { toluene, } 130^{\circ} \mathrm{C}, 24 \mathrm{~h}\end{array}$ & $\mathrm{RCOONa} ; \mathrm{R}=\mathrm{Ar}$ & $35-86$ & {$[37]$} \\
\hline $\begin{array}{l}\mathrm{Cu}(\mathrm{OAc})_{2}(10 \mathrm{~mol} \%) \\
t-\mathrm{BuOOH}(2-4 \text { equiv }) \\
\mathrm{PhCl} \text { or without a solvent, } 135^{\circ} \mathrm{C}, 24-40 \mathrm{~h}\end{array}$ & $\mathrm{RCHO}$ or $\mathrm{ArCH}_{3} ; \mathrm{R}=\mathrm{Ar}, n-\mathrm{Bu}, n-\mathrm{Pr}$ & $20-56$ & {$[38]$} \\
\hline $\begin{array}{l}\mathrm{Cu}(\mathrm{OAc})_{2}(20 \mathrm{~mol} \%) \\
t-\mathrm{BuOOH}(10 \text { moles per mole of arene }) \\
\mathrm{PhCl}, 120{ }^{\circ} \mathrm{C}, 10-22 \mathrm{~h}\end{array}$ & $\mathrm{ArCH}=\mathrm{CH}_{2}$ or $\mathrm{ArC} \equiv \mathrm{CH}$ (2 equiv) & $48-81$ & [39] \\
\hline
\end{tabular}

dehydrogenative $\mathrm{C}-\mathrm{O}$ coupling products $\mathbf{2 4 - 3 0}$ (Scheme 6). The alkoxylation of 1-naphthonitrile $\mathbf{2 0}$ occurs not at the orthoposition but at the 8-position of the aromatic system to give product 26. The acetoxylation takes place under more severe conditions compared with the alkoxylation. The acetoxylation employing the $S$-methyl-S-2-pyridylsulfoximine moiety as the bidentate directing group can be performed at lower temperature $\left(50{ }^{\circ} \mathrm{C}\right.$ instead of $100{ }^{\circ} \mathrm{C}$, as in the case of $\mathrm{CH}$-reagents 22 and 23) [53].

The ortho-acetoxylation and methoxylation of $O$-methyl aryl oximes 31 with $\mathrm{Pd}(\mathrm{OAc})_{2}$ combined with such oxidants as oxone, potassium persulfate, and (diacetoxyiodo)benzene (Scheme 7, coupling products $\mathbf{3 2}$ and $\mathbf{3 3}$ ) occur under similar conditions [54]. $N$-Phenylpyrrolidin-2-one (34) and (3-benzyl4,5-dihydroisoxazol-5-yl)methyl acetate (35) react in a similar fashion to afford products 36-38. Related ortho-acetoxylation reactions of the aryl group of methoxyimino-2-aryl acetates [55], 2-methoxyimino-2-arylacetamides [55], and $O$-acetyl aryl oximes [56] in the presence of the $\mathrm{Pd}(\mathrm{OAc})_{2} / \mathrm{PhI}(\mathrm{OAc})_{2}$ system were described.

The ruthenium-catalyzed ortho-acyloxylation of acetanilides 39 with carboxylic acids in the presence of $\mathrm{AgSbF}_{6}$ and ammonium persulfate afforded products 40 (Scheme 8) [57]. This method can be used for the selective replacement of one of the two hydrogen atoms in the ortho-position of acetanilide; the molar ratio of the $\mathrm{C}$ - and O-reagents is close to stoichiometric.

The acetoxylation (product 42) and methoxylation (product 43) of $N$-(2-benzoylphenyl)benzamides $\mathbf{4 1}$ at the ortho-position of the benzamide moiety of the substrate were performed using $\mathrm{Pd}(\mathrm{OAc})_{2}$ combined with $\mathrm{PhI}(\mathrm{OAc})_{2}$ as the oxidant (Scheme 9) [58]. The alkoxylation of $N$-tosylbenzamides 44 in the presence of the same oxidative system takes place at room temperature and gives products 45 [59]. The reactions of benzamides containing the nitro group at the ortho-position are most difficult to perform $[58,59]$.

The $\mathrm{Pd}(\mathrm{OAc})_{2} / \mathrm{PhI}(\mathrm{OAc})_{2}$ system was also employed to accomplish the ortho-alkoxylation of azoarenes 46 [60], 2-aryloxypyridines 47 [61], picolinamides 48 [62], and $N$-(1methyl-1-(pyridin-2-yl)ethyl)amides 49 [63], resulting in the formation of products 50-54 (Scheme 10).

The ortho-acetoxylation of compounds containing picolinamide and quinoline- 8 -amine moieties ( 55 and $\mathbf{5 6}$, respectively) with the $\mathrm{Pd}(\mathrm{OAc})_{2} / \mathrm{PhI}(\mathrm{OAc})_{2}$ system in a $\mathrm{AcOH} / \mathrm{Ac}_{2} \mathrm{O}$ mixture, resulting in the formation of products $\mathbf{5 7}, \mathbf{5 8}$, was performed at higher temperature $\left(150{ }^{\circ} \mathrm{C}\right.$, Scheme 11) 

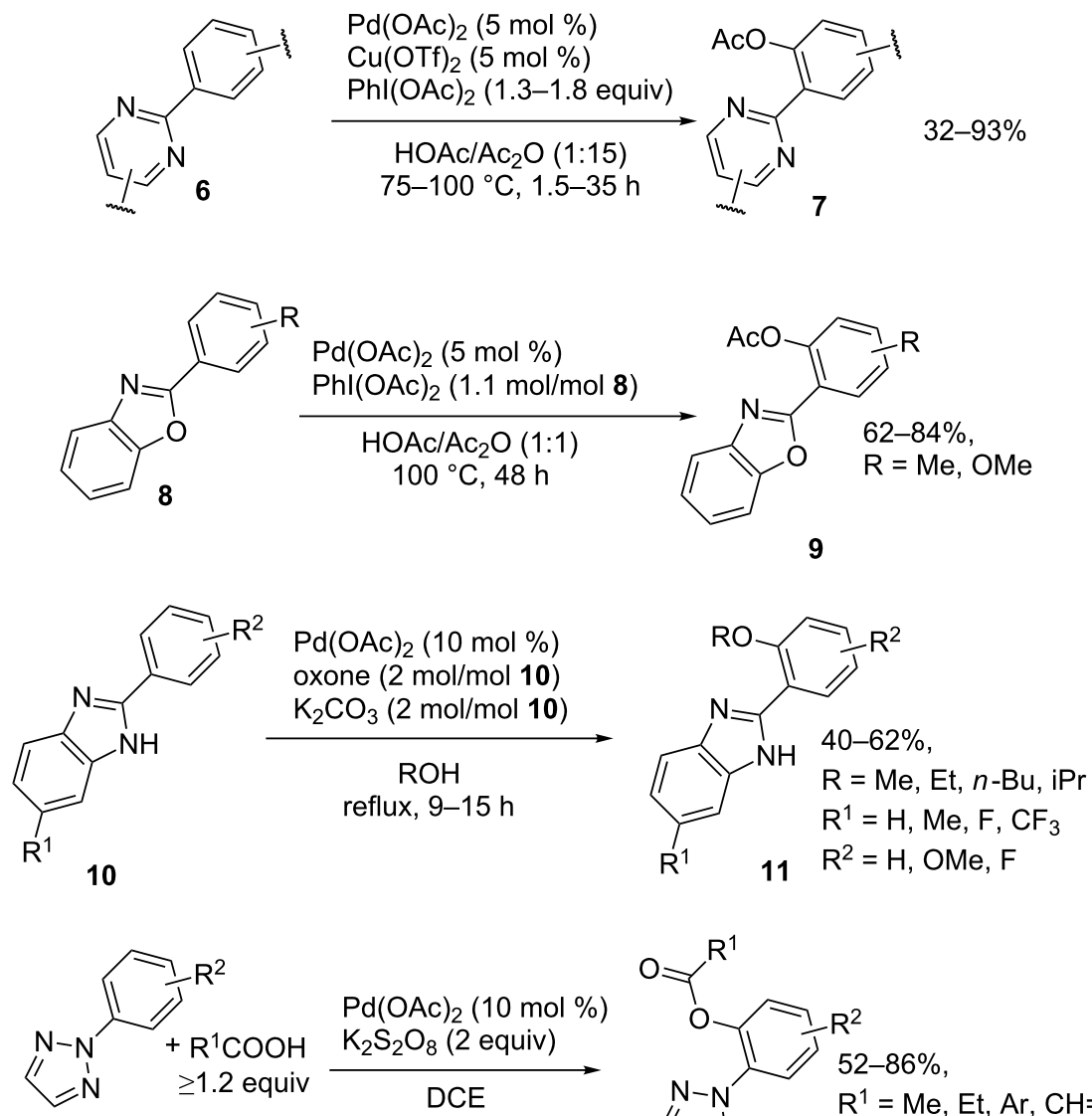

12

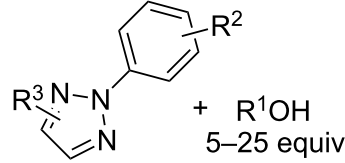

14
$\mathrm{Pd}(\mathrm{OAc})_{2}(10 \mathrm{~mol} \%)$

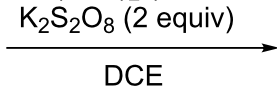

$120^{\circ} \mathrm{C}, 20 \mathrm{~h}$

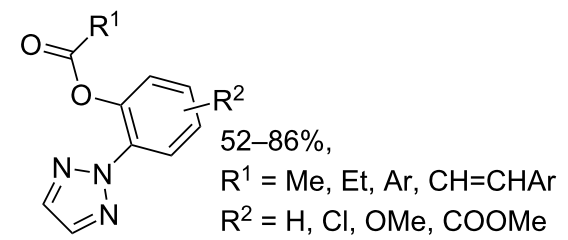

13

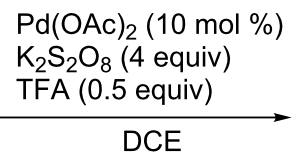

$80^{\circ} \mathrm{C}, 24 \mathrm{~h}$

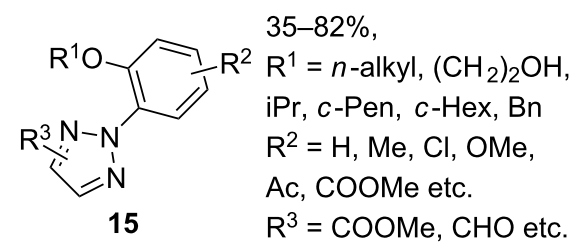

Scheme 4: ortho-Acyloxylation and alkoxylation of arenes directed by pyrimidine, benzoxazole, benzimidazole and triazole groups.

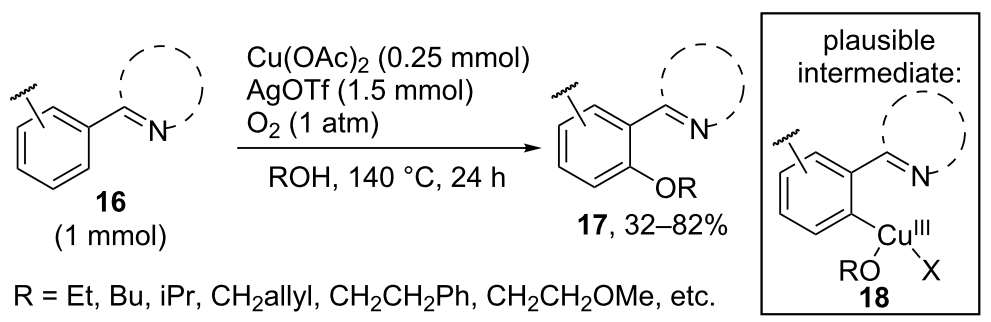

Scheme 5: $\mathrm{Cu}(\mathrm{OAc})_{2} / \mathrm{AgOTf} / \mathrm{O}_{2}$ oxidative system in the ortho-alkoxylation of arenes. 

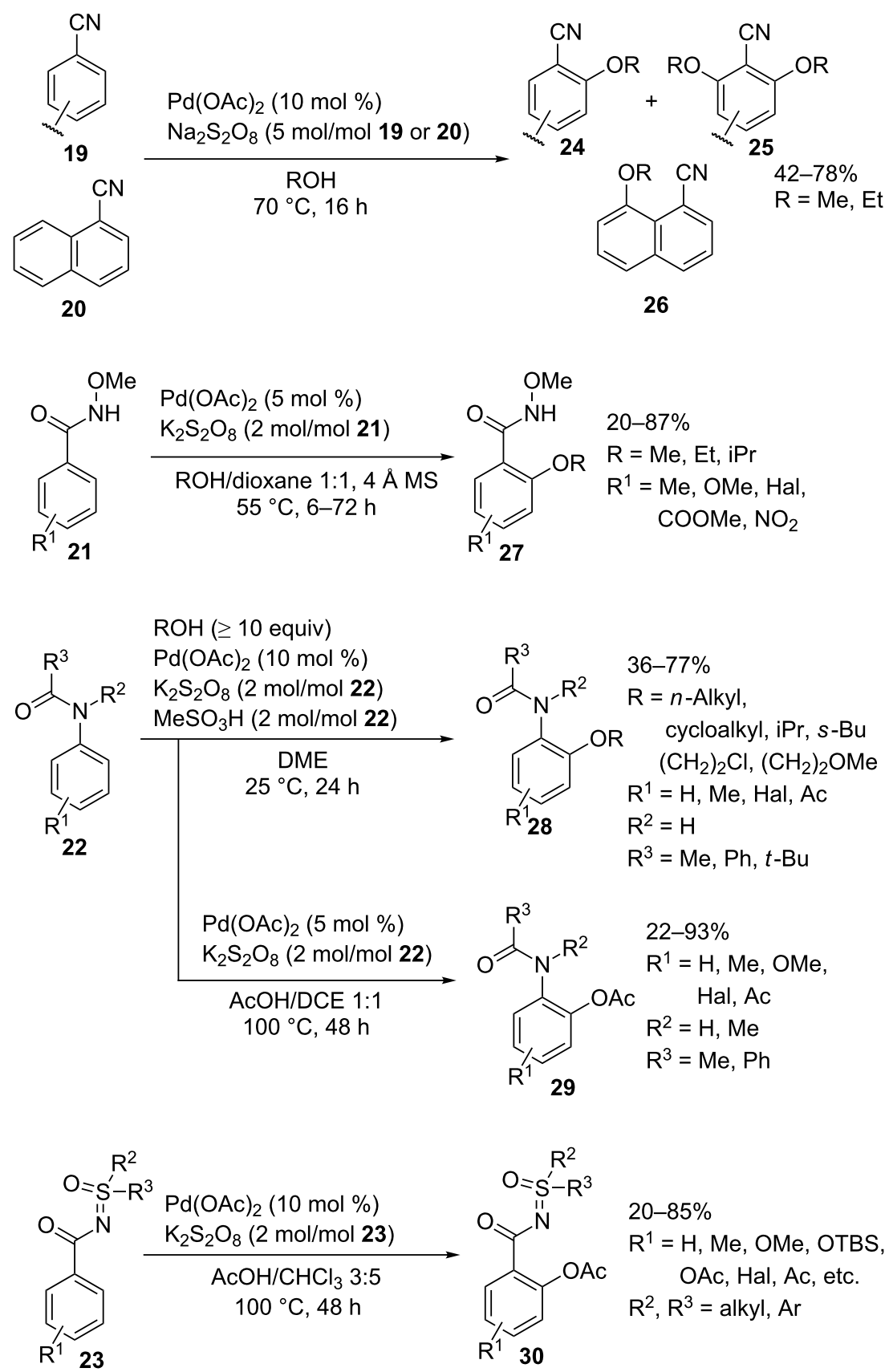

Scheme 6: $\mathrm{Pd}(\mathrm{OAc})_{2} /$ persulfate oxidative system in the ortho-alkoxylation and acetoxylation of arenes with nitrile, amide, and sulfoximine directing groups.

compared with the alkoxylation of structures 46-49 [64]. Under similar conditions, aryl phosphates and benzyl phosphonic monoacids were subjected to ortho-acetoxylation in the presence of the $\mathrm{Pd}(\mathrm{OAc})_{2} / \mathrm{PhI}(\mathrm{OAc})_{2}$ system; (diacetoxyiodo)benzene served as the source of the acetoxy group [65].

The quinoline-8-amine directing moiety was used for coppercatalyzed aerobic ortho-aryloxylation and alkoxylation of arenes 59 with electron donating or electron withdrawing substituents to afford products 60 [66] (Scheme 12). The method is applicable to a wide range of $\mathrm{OH}$-reagents; the molar ratio $\mathrm{OH}$-reagent/CH-reagent was 1:1 for aromatic $\mathrm{OH}$-reagents and 5:1 for aliphatic alcohols. Different organic and inorganic bases were used depending on the structures of substrates.

The cross-dehydrogenative coupling of phenols and arenes $\mathbf{6 1}$ with a directing group containing a pyridine $N$-oxide moiety occurs in the presence of $\mathrm{Cu}(\mathrm{OAc})_{2}$ under air atmosphere to 

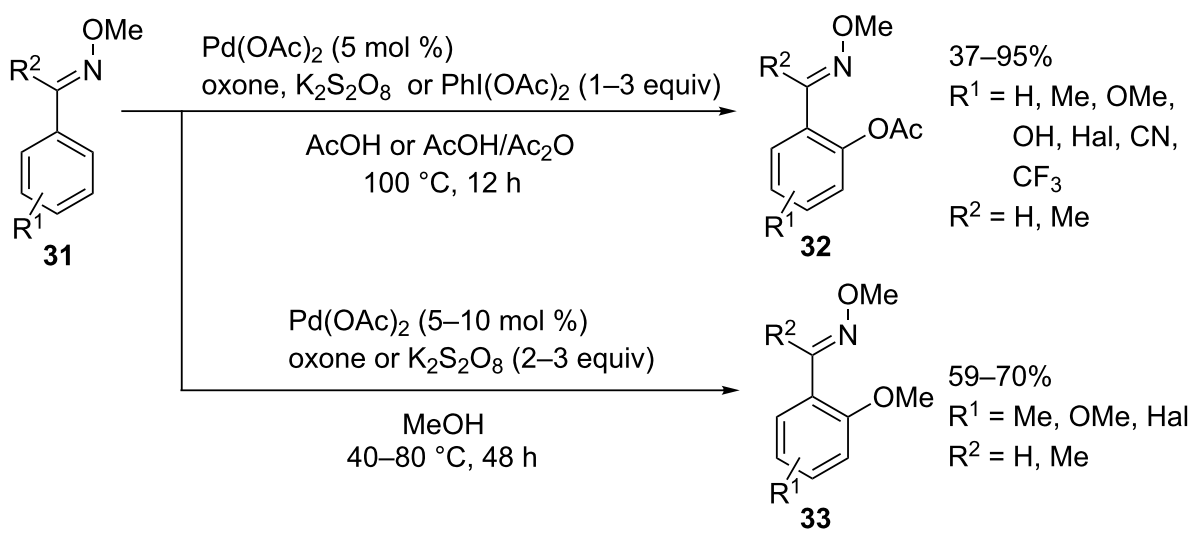<smiles>O=C1CCCN1c1ccccc1</smiles>

$\mathrm{Pd}(\mathrm{OAc})_{2}(5 \mathrm{~mol} \%)$

$\mathrm{K}_{2} \mathrm{~S}_{2} \mathrm{O}_{8}$ (1.5 equiv) or $\mathrm{Phl}(\mathrm{OAc})_{2}$ (1.2 equiv)

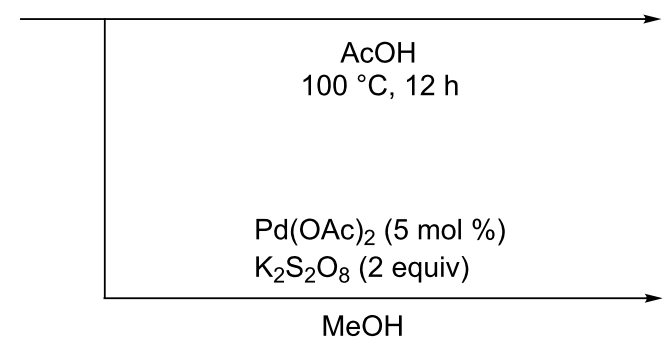

$\mathrm{rt}, 12 \mathrm{~h}$ then $40^{\circ} \mathrm{C}, 12 \mathrm{~h}$

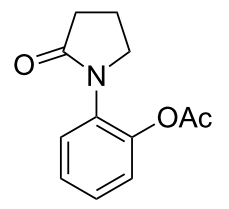

36, $75-77 \%$

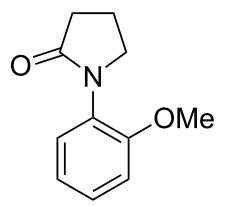

$37,72 \%$

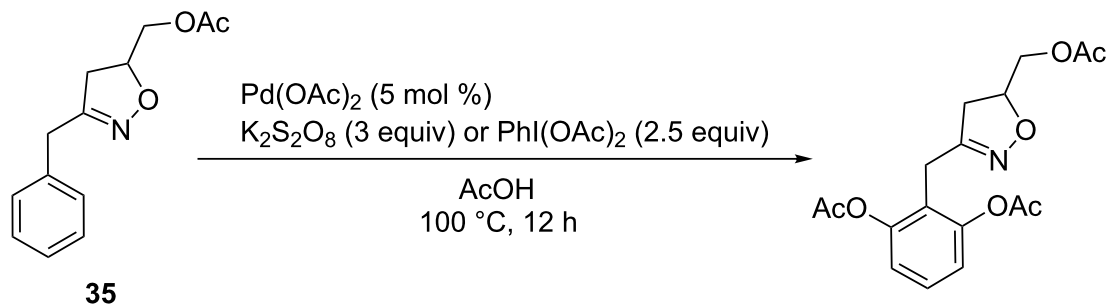

38, $53-72 \%$

Scheme 7: ortho-Acetoxylation and methoxylation of O-methyl aryl oximes, $\mathrm{N}$-phenylpyrrolidin-2-one, and (3-benzyl-4,5-dihydroisoxazol-5-yl)methyl acetate.
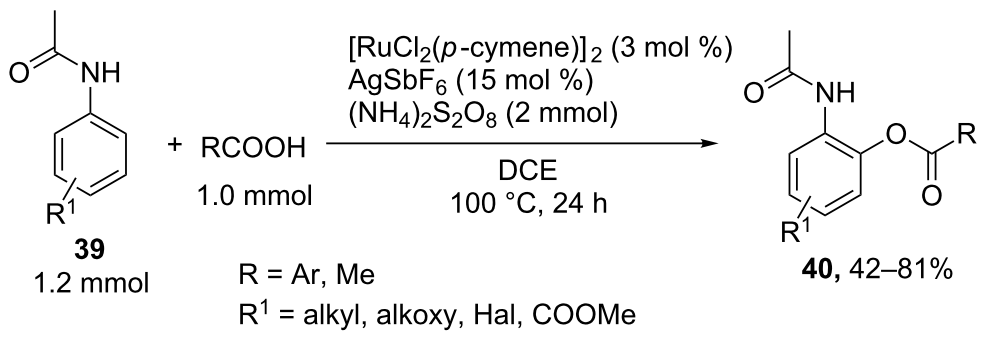

40, $42-81 \%$

Scheme 8: Ruthenium-catalyzed ortho-acyloxylation of acetanilides. 


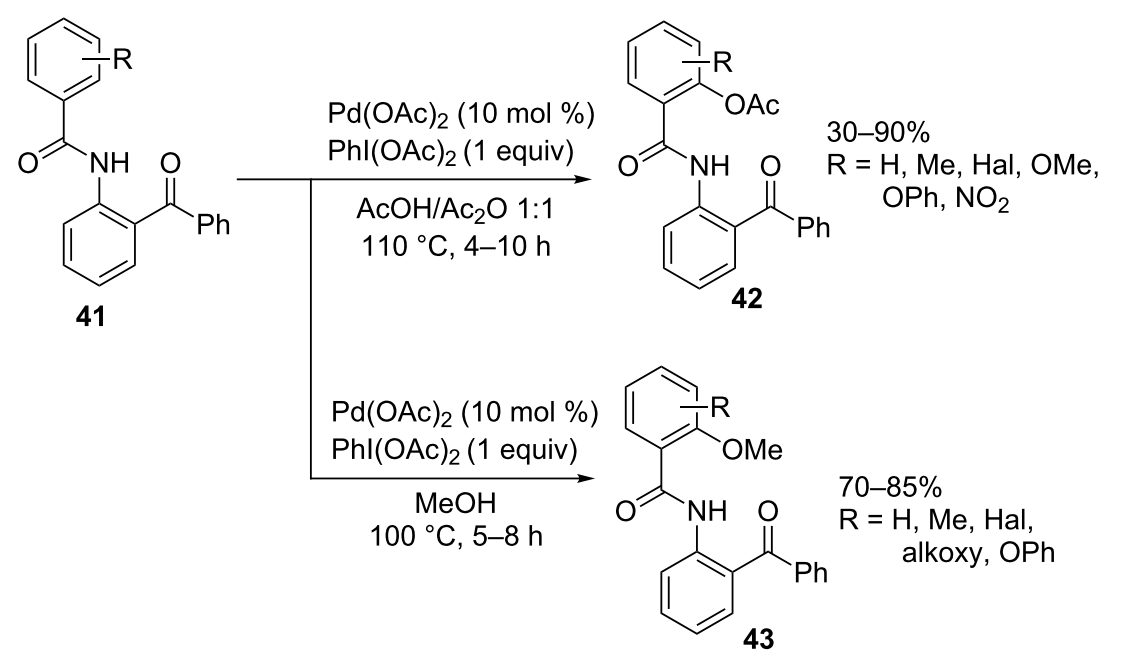<smiles>O=C(N[AsH3])c1[R1]cccc1</smiles>

44

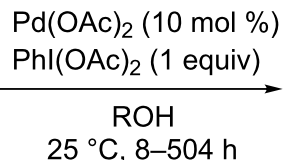

$25{ }^{\circ} \mathrm{C}, 8-504 \mathrm{~h}$

$\mathrm{R}=\mathrm{Me}, \mathrm{Et}, \mathrm{iPr}$

$\mathrm{R}^{1}=\mathrm{H}, \mathrm{Me}, \mathrm{OMe}, \mathrm{F}, \mathrm{Cl}, \mathrm{Br}, \mathrm{NO}_{2}, \mathrm{Ph}, \mathrm{CF}_{3}$<smiles>[R]Oc1ccc[R]c1C(=O)N[3H]</smiles>

$45,47-95 \%$

Scheme 9: Acetoxylation and alkoxylation of arenes with amide directing group using $\mathrm{Pd}(\mathrm{OAc})_{2} / \mathrm{Phl}(\mathrm{OAc})_{2}$ oxidative system.

form coupling products with one (product 62) or two (product 63) equivalents of phenol (Scheme 13) [67]. The same directing group was used for aerobic ortho-alkoxylation of arenes 64 in the presence of $\mathrm{CuCl}$ and $\mathrm{K}_{2} \mathrm{CO}_{3}$ to afford monoalkoxylated products 65 [68].

The 2-aminopyridine-1-oxide directing group was used in a rare example of a cobalt-catalyzed oxidative alkoxylation of arenes 66 and alkenes 67 to afford products 68 and 69 under mild contitions [69] (Scheme 14). The directing group can be removed to obtain the corresponding benzoic acid $\mathbf{7 1}$ from the cross-dehydrogenative coupling product 70 [69].

The majority of above mentioned directing groups cannot be easily removed or modified, thus limiting the scope of possible target products. To overcome these limitations, 2-pyridyldiisopropylsilyl (PyDipSi) [70,71] and 2-pyrimidyldiisopropylsilyl (PyrDipSi) [72,73] directing groups were proposed by the research group of Prof. V. Gevorgyan. The PyDipSi group was used for selective monoacetoxylation or pivaloyloxylation of the arene ortho-position [70,71], whereas the PyDipSi group allowed to achieve one-pot sequential acyloxylation of both ortho-positions affording, in particular, orthogonally protected resorcinol derivatives $\mathbf{7 3}$ in one step starting from PyrDipSi arenes 72 [72] (Scheme 15).

$\mathrm{Pd}(\mathrm{OAc})_{2}$ was used as catalyst with addition of $\mathrm{AgOAc}$ or LiOAc; $\mathrm{PhI}(\mathrm{OAc})_{2}$ or $\mathrm{PhI}(\mathrm{OPiv})_{2}$ were used as oxidants and sources of OAc and OPiv fragments, respectively, the syntheses were performed in dichloroethane at $80{ }^{\circ} \mathrm{C}$ for $1-168 \mathrm{~h}$. After ortho-acyloxylation step silyl directing group can be removed or substituted by a desirable moiety (-Aryl, -OH, -B(pin), -I, etc.).

Another example of an easily modifiable directing group is an $\mathrm{N}$-nitroso moiety that can be easily reduced to amine employing $\mathrm{Fe} / \mathrm{NH}_{4} \mathrm{Cl}$ [74]. $\mathrm{N}$-Nitroso directed $\mathrm{C}-\mathrm{H}$ alkoxylation of arenes 74 was realized using the $\mathrm{Pd}(\mathrm{MeCN})_{2} \mathrm{Cl}_{2} / \mathrm{PhI}(\mathrm{OAc})_{2}$ oxidative system to obtain products $\mathbf{7 5}$ [74] (Scheme 16).

\subsection{Reactions involving $\mathrm{C}\left(\mathrm{sp}^{3}\right)-\mathrm{H}$ bonds of \\ C-reagents with alkyl groups}

In some studies, directing groups were used to accomplish the $\mathrm{C}-\mathrm{O}$ coupling involving $\mathrm{sp}^{3}$-carbon atoms of C-reagents. Scheme 17 presents the alkoxylation of $\mathrm{CH}$-reagents 76, 77 and the acetoxylation of $\mathrm{CH}$-reagents $\mathbf{7 8}$. In these examples, the 

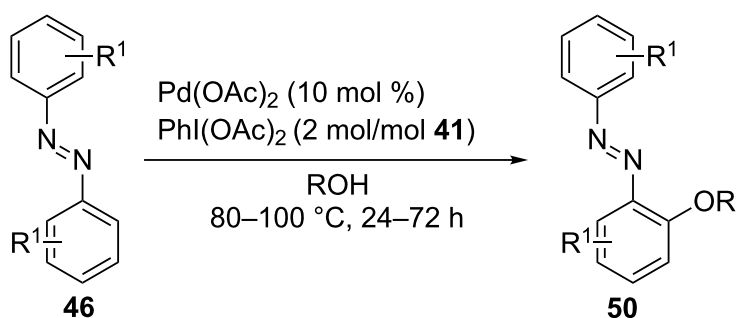
$35-77 \%$
$\mathrm{R}=\mathrm{Me}, \mathrm{Et}, \mathrm{Pr}$,
$\mathrm{iBu}, \mathrm{iPr}$

$\mathrm{R}^{1}=\mathrm{H}, \mathrm{Me}, \mathrm{OMe}$

$\mathrm{Hal}, \mathrm{Ac}$

50<smiles>[R1]1ccccc1Oc1ccccn1</smiles>

47
$\mathrm{Pd}(\mathrm{OAc})_{2}(10 \mathrm{~mol} \%)$

$\mathrm{Phl}(\mathrm{OAc})_{2}$ (2 equiv)

$\mathrm{AcOH}$ (0 or 10 equiv)

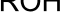

$90^{\circ} \mathrm{C}, 24 \mathrm{~h}$<smiles>[R][R1]1cccc([R])c1Oc1ccccn1</smiles>

51
35-83\%

$\mathrm{R}=\mathrm{Me}, \mathrm{Et}, n-\mathrm{Pr}, \mathrm{iPr}$

$\mathrm{R}^{1}=\mathrm{H}, \mathrm{Me}, \mathrm{OMe}$,

COOMe, $\mathrm{Ph}$, etc.

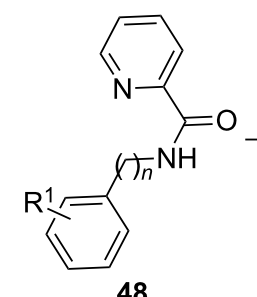

48<smiles>[R1]c1ccccc1C(=O)NC(C)(C)c1ccccn1</smiles>

49
$\mathrm{Pd}(\mathrm{OAc})_{2}(10 \mathrm{~mol} \%)$ $\mathrm{Phl}(\mathrm{OAc})_{2}$ (1.5-2.5 equiv)

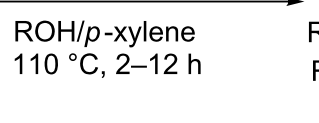<smiles>[R]OC1=CC=C2CCN=CC1=C[R20]2F</smiles>

52

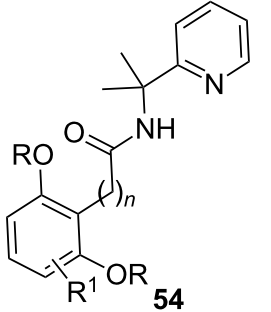

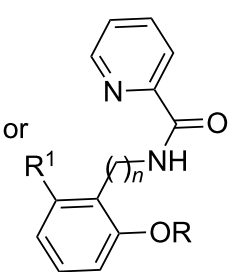

65-95\%

$\mathrm{R}=\mathrm{Me}, \mathrm{Cy}$,

$\mathrm{CH}_{2} \mathrm{CF}_{3}, \mathrm{Bn}$

$\mathrm{R}^{1}=\mathrm{OMe}, \mathrm{Cl}, \mathrm{CF}_{3}$ $n=1,2$

53

47-99\%

$\mathrm{R}=\mathrm{Me} \mathrm{Et}$, isopentyl,

$\mathrm{CH}_{2} \mathrm{CF}_{3}, \mathrm{iPr}$

$\mathrm{R}^{1}=\mathrm{H}, \mathrm{Me}, \mathrm{OMe}, \mathrm{Hal}, \mathrm{CF}_{3}$

$n=0,1$

Scheme 10: Alkoxylation of azoarenes, 2-aryloxypyridines, picolinamides, and N-(1-methyl-1-(pyridin-2-yl)ethyl)amides using the Pd(OAc) 2 $\mathrm{Phl}(\mathrm{OAc})_{2}$ oxidative system.<smiles>N/C=C(/N)c1ccccn1</smiles>

6

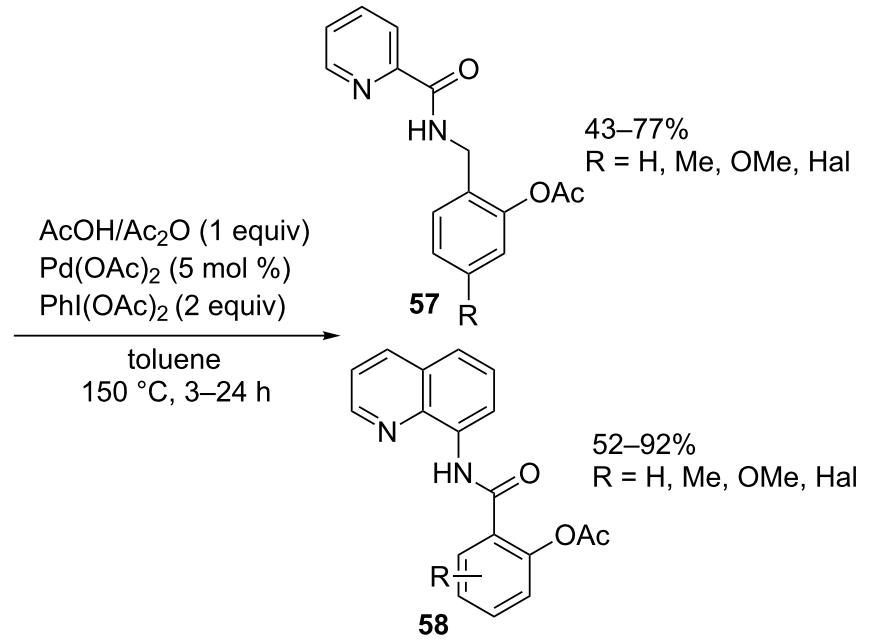

58 

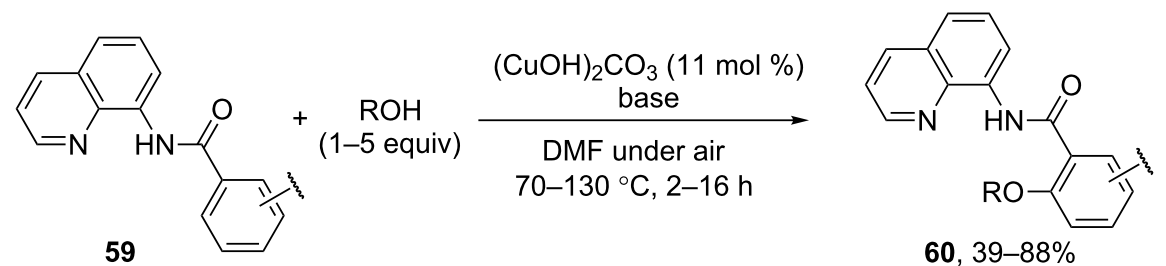

$60,39-88 \%$

$\mathrm{ROH}=\mathrm{ArOH}$, cyclopropylmethanol, $\mathrm{CF}_{3} \mathrm{CH}_{2} \mathrm{OH}$, allyl alcohol, cinchonine, ethyl lactate, carbitol base $=\mathrm{K}_{2} \mathrm{CO}_{3}, 1,1,3,3$-tetramethylguanidine, pyridine, $\mathrm{KOAc}, \mathrm{K}_{3} \mathrm{PO}_{4}$

Scheme 12: $(\mathrm{CuOH})_{2} \mathrm{CO}_{3}$ catalyzed oxidative ortho-etherification using air as oxidant.

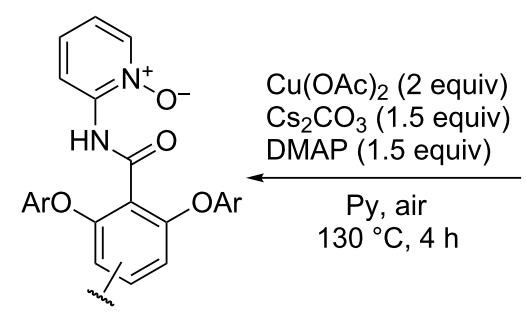

63

$36-88 \%$<smiles>O=C(Nc1cccc[n+]1[O-])c1ccc(Br)cc1</smiles>

61

mol 61
$\mathrm{Cu}(\mathrm{OAc})_{2}$ (1 equiv)

$\mathrm{Cs}_{2} \mathrm{CO}_{3}$ (1 equiv)

DMAP ( 0.5 equiv $)$

o-xylene, air

$130{ }^{\circ} \mathrm{C}, 8 \mathrm{~h}$

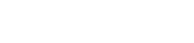

$54-82 \%$<smiles>CCCCOc1ccccc1C(=O)Nc1cccc[n+]1[O-]</smiles>

62<smiles>[R]c1cccc(C(=O)Nc2cccc[n+]2[O-])c1C(=O)Nc1cccc[n+]1[O-]</smiles>

$\mathrm{R}=n$-alkyl, iPr, $\mathrm{CH}_{2} \mathrm{CH}_{2} \mathrm{Ph}, \mathrm{CH}_{2}$ allyl, $\mathrm{CH}_{2} \mathrm{CH}_{2} \mathrm{OMe}$, etc.

$\mathrm{R}^{1}=\mathrm{H}, \mathrm{Me}, \mathrm{Hal}, \mathrm{CF}_{3}$, OMe, Ph, $t-\mathrm{Bu}$

Scheme 13: Copper-catalyzed aerobic alkoxylation and aryloxylation of arenes containing pyridine- $\mathrm{N}$-oxide moiety.

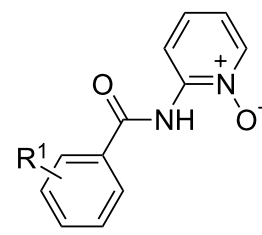

66

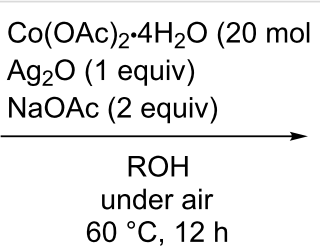

$60^{\circ} \mathrm{C}, 12 \mathrm{~h}$

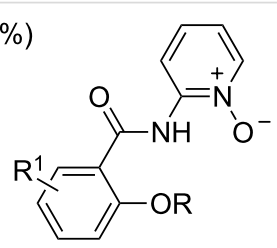

$68,34-88 \%$

$\mathrm{R}=n$-alkyl, Bn, $\mathrm{CH}_{2} \mathrm{CH}_{2} \mathrm{Ph}, \mathrm{CH}_{2} \mathrm{CH}_{2} \mathrm{OMe}, \mathrm{CH}_{2} \mathrm{CF}_{3}$, etc.

$\mathrm{R}^{1}=\mathrm{H}, \mathrm{Me}, \mathrm{Hal}, \mathrm{CF}_{3}, \mathrm{OMe} \mathrm{NMe}_{2}, \mathrm{Ph}, t-\mathrm{Bu}$

$\mathrm{Co}(\mathrm{OAc})_{2} \cdot 4 \mathrm{H}_{2} \mathrm{O}(20 \mathrm{~mol} \%)$

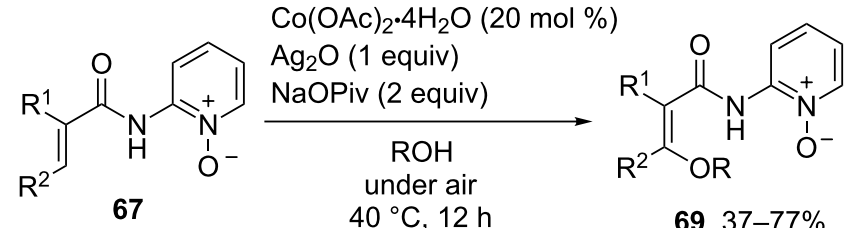

$\mathrm{R}=\mathrm{Me}, \mathrm{Et}$

$\mathrm{R}^{1}, \mathrm{R}^{2}=\mathrm{Me}, \mathrm{Me} ; \mathrm{Me}, \mathrm{Et} ;-\left(\mathrm{CH}_{2}\right)_{4}-;-\left(\mathrm{CH}_{2}\right)_{3} \mathrm{O}-$

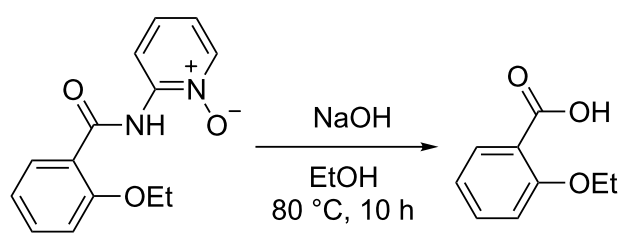

70

$71,81 \%$

Scheme 14: Cobalt-catalyzed aerobic alkoxylation of arenes and alkenes containing pyridine $\mathrm{N}$-oxide moiety. 


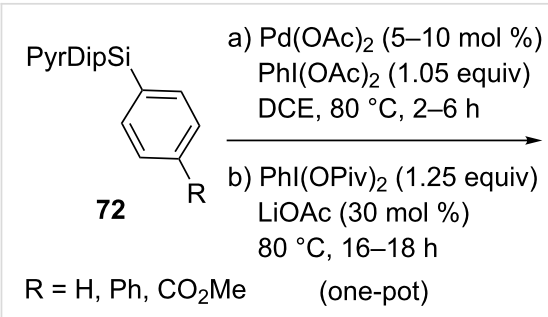

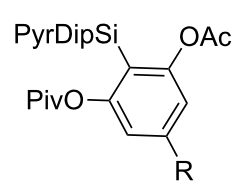

73, $60-75 \%$
Scheme 15: Non-symmetric double-fold C-H ortho-acyloxylation.

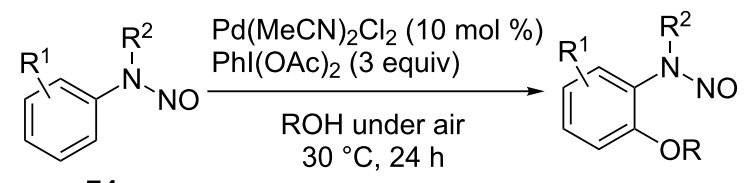

74

$\mathrm{R}=\mathrm{Me}, \mathrm{Et}, n-\mathrm{Pr}, \mathrm{iPr}$

$\mathrm{R}^{1}=\mathrm{H}, \mathrm{Me}, \mathrm{OMe}, \mathrm{Hal}, \mathrm{CO}_{2} \mathrm{Me}$

$\mathrm{R}^{2}=\mathrm{Me}, \mathrm{Et}, \mathrm{iPr}, \mathrm{Ph}$
$75,20-89 \%$
Scheme 16: $\mathrm{N}$-nitroso directed ortho-alkoxylation of arenes. reaction occurs at the methylene group of the molecule (with the $\mathrm{sp}^{3}$-carbon atom) rather than at the ortho-position of the aromatic system, which is also adjacent to the directing group. The $\mathrm{Pd}(\mathrm{OAc})_{2} / \mathrm{PhI}(\mathrm{OAc})_{2}$ oxidative system was employed in the methoxylation of dimethylcarbamoyltetrahydrocarbazoles 76 [75] and the acetoxylation of compounds containing the picolinamide directing group 78 [76,77]; the butoxylation of the methylene group of 2-benzylpyridine 77 took place in the presence of the $\mathrm{Cu}(\mathrm{OAc})_{2} / \mathrm{AgOTf} / \mathrm{O}_{2}$ system [47]. Cross-dehydrogenative $\mathrm{C}-\mathrm{O}$ coupling products $\mathbf{7 9 - 8 1}$ were obtained, despite the potential possibility of the more profound oxidation of the methylene group to the keto group.

The benzylic position of 2-alkylpyridines and related compounds 82 was acetoxylated using the $\mathrm{Pd}(\mathrm{OAc})_{2} / \mathrm{CuI}$ catalytic system in acetic acid under an oxygen pressure of 8 atm to prepare products 83 (Scheme 18) [78].

The acyloxylation of methyl or methylene groups of 8-methylquinoline and its derivatives in the presence of the $\mathrm{Pd}(\mathrm{OAc})_{2} / \mathrm{PhI}(\mathrm{OAc})_{2}[79]$ and $\mathrm{Pd}(\mathrm{OAc})_{2} /$ ligand $/ \mathrm{O}_{2}$ [80] oxidative systems was also described.

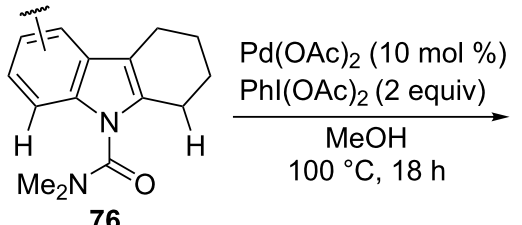

76

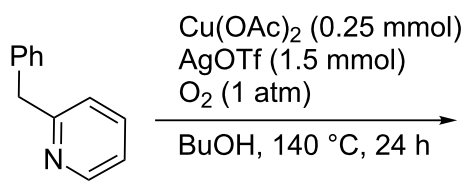

77

(1 mmol)<smiles>Cc1ccccc1NC(=O)c1nccc2c1I=CC=C2</smiles>

78

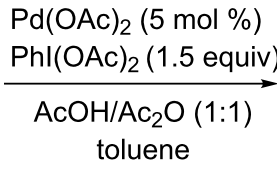

$\mathrm{Pd}(\mathrm{OAc})_{2}(5 \mathrm{~mol} \%)$ $\mathrm{Phl}(\mathrm{OAc})_{2}$ (1.5 equiv)

$\mathrm{AcOH} / \mathrm{Ac}_{2} \mathrm{O}(1: 1)$ toluene $110-130^{\circ} \mathrm{C}, 12-48 \mathrm{~h}$

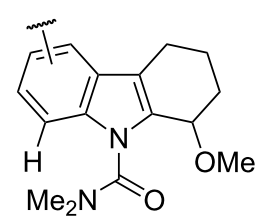

$79,51-86 \%$<smiles>CCCCOC(c1ccccc1)c1ccccn1</smiles>

$80,57 \%$

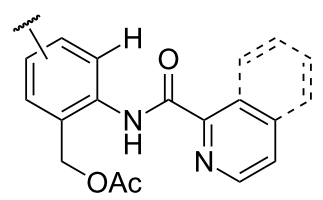

81, 49-85\%

Scheme 17: Selective alkoxylation and acetoxylation of alkyl groups.

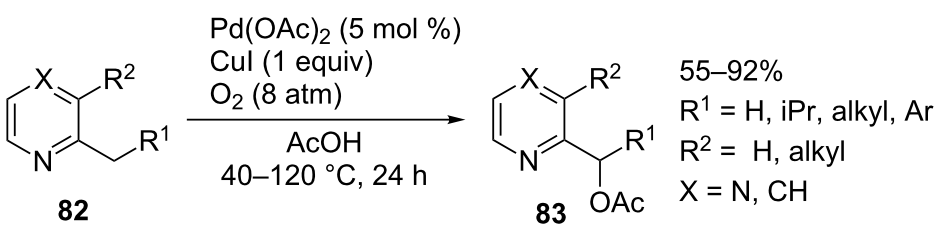


In the above considered examples, the oxidative $\mathrm{C}-\mathrm{O}$ coupling occurs with the involvement of methyl or methylene groups directly bonded to the aromatic ring. The $\mathrm{C}-\mathrm{O}$ coupling reactions involving unactivated alkyl groups of C-reagents are considered below.

The amide moiety was most commonly employed as the directing group. The alkoxylation of alkyl groups of $N$-(quinolin-8-yl)amides 84 [81], picolinamides 85 [62], and
$N$-(2-pyridin-2-yl)propan-2-yl)amides 86 [63], the trifluoroacetoxylation of amides 87 [82], and the acyloxylation of compounds containing the $S$-methyl-S-pyridylsulfoximine moiety $\mathbf{8 8}$ [83] were accomplished to prepare coupling products 90-95 (Scheme 19). In some cases, the latter reaction proceeds efficiently even at room temperature. Iodine(III) compounds $\mathbf{8 9}$, (diacetoxyiodo)benzene, or potassium persulfate served as oxidants. The former three reactions are applicable to a broad range of substrates and alcohols. The drawback is that a large

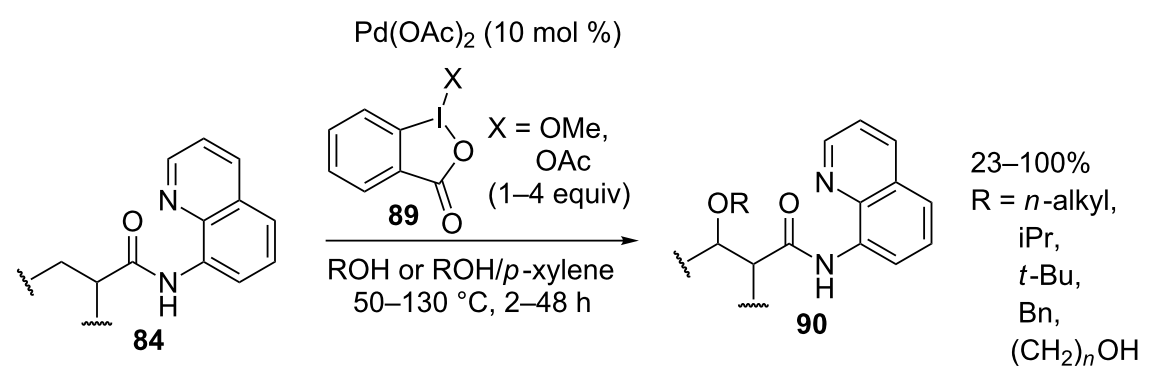

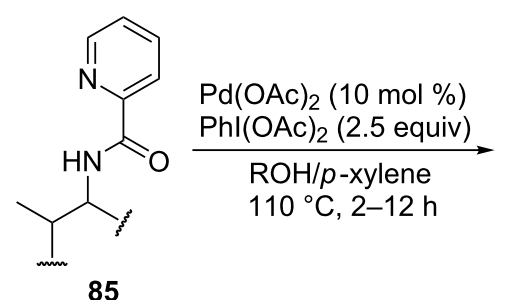<smiles>CC(C)C(NC(=O)c1ccccn1)C(C)C</smiles>

$42-95 \%$

$\mathrm{R}=n$-alkyl, sec-alkyl,

$t$-Bu, Bn, $\left(\mathrm{CH}_{2}\right)_{2} \mathrm{Ph}$<smiles>[R]C(CC)C(=O)NC(C)(C)C(=N)/C=C\C</smiles><smiles>[R]C(C)C([R20])C(=O)NC(C)(C)c1ccccn1</smiles>

$19-92 \%$

$\mathrm{R}=n$-alkyl, iBu, $\mathrm{CH}_{2} \mathrm{CF}_{3}, \mathrm{Bn}, \mathrm{iPr}$, 1,2-dimethylpropyl, 3-methylbut-2-enyl, etc.

92 $\mathrm{R}^{1}=\mathrm{H}, \mathrm{OMe}, \mathrm{OBn}$<smiles>[R1]NC(=O)C([R])([R])C</smiles>

$\mathrm{CF}_{3} \mathrm{COOH}$ (5 equiv) $\mathrm{Pd}(\mathrm{OAc})_{2}(10 \mathrm{~mol} \%)$ $\mathrm{K}_{2} \mathrm{~S}_{2} \mathrm{O}_{8}$ (2 equiv)

$80^{\circ} \mathrm{C}, 20 \mathrm{~h}$

87<smiles>[R]C([R])(C)C(=O)N=S(C)(=O)c1ccccn1</smiles>

$\mathrm{Pd}(\mathrm{OAc})_{2}(5 \mathrm{~mol} \%)$ $\mathrm{Phl}(\mathrm{OAc})_{2}$ (1.5-3 equiv)<smiles>[R1]NC(=O)C([R])([R])COC(=O)C(F)(F)F</smiles>

63-96\%

$\mathrm{R}^{1}=\mathrm{Bu}$, Cycloalkyl, 1-ethylpropyl, $t$-Bu, $\mathrm{CH}_{2} \mathrm{Ar}$
$\mathrm{RCOOH}$ rt-70 ${ }^{\circ} \mathrm{C}$ 14-60 h $\mathrm{R}^{2}, \mathrm{R}^{3}=\mathrm{Me}, \mathrm{Et}$

93<smiles>[R]OCC([R2])([R])C(=O)N=S(C)(=O)c1ccccn1</smiles>

35-90\%

$\mathrm{R}=\mathrm{Me}, \mathrm{Et}, \mathrm{Pr}, \mathrm{iPr}$

$\mathrm{R}^{1}, \mathrm{R}^{2}=\mathrm{Me}, \mathrm{Et}, \mathrm{CH}_{2} \mathrm{Hal}$, 
excess of alcohols is required. Unlike the alkoxylation of 84-86, the trifluoroacetoxylation of $\mathbf{8 7}$ was performed with structurally simple amides. This method is applicable only to $\alpha$-disubstituted amides. The reactions with amides containing hydrogen in the $\alpha$-position give coupling products 93 in substantially lower yields [82]. Similar limitations are encountered when performing the acyloxylation of $S$-methyl- $S$-pyridylsulfoximines $\mathbf{8 8}$.

Using the $N$-(quinolin-8-yl)amide directing group $\mathrm{Pd}(\mathrm{OAc})_{2}$ catalyzed the double $\mathrm{sp}^{3} \mathrm{C}-\mathrm{H}$ alkoxylation of $\mathbf{9 6}$ for the synthesis of symmetric acetals $\mathbf{9 7}$ and unsymmetric acetals [84] (Scheme 20). The method demonstrates good functional group tolerance and the applicability in the synthesis of products containing $\alpha$-hydrogen next to an amide moiety.

Copper-catalyzed acyloxylation of methyl groups of $\mathrm{N}$-(quinolin-8-yl)amides 99 was achieved [85] (Scheme 21, product 100); the reaction requires higher temperatures $\left(170{ }^{\circ} \mathrm{C}\right)$ then $\mathrm{Pd}(\mathrm{OAc})_{2}$ catalyzed alkoxylation of analogous substrates in the presence of iodine(III) oxidants $\left(50-130{ }^{\circ} \mathrm{C}\right.$, Scheme 19 and Scheme 20). Under similar conditions methyl groups of $\mathrm{N}$-(quinolin-8-yl)amides were acetoxylated using the $\mathrm{Cu}(\mathrm{OAc})_{2}$ catalyst (50 mol \%) and AgOAc (3 equiv) as acetoxylating agent.
The acetoxylation of alkyl groups of $O$-acetyl oximes $\mathbf{1 0 2}$ taking place in the presence of the $\mathrm{Pd}(\mathrm{OAc})_{2} / \mathrm{PhI}(\mathrm{OAc})_{2}$ system in a $\mathrm{AcOH} / \mathrm{Ac}_{2} \mathrm{O}$ mixture affords products $\mathbf{1 0 3}$ (Scheme 22) [56]. The acylation of oxime $\mathbf{1 0 1}$ and the $\mathrm{C}-\mathrm{H}$ acetoxylation of 102 are performed as a one-pot operation. In the acetoxylation of alkyl groups, the methyl group is more reactive than the methylene one.

The $O$-methyl oxime [54,86] or pyridine moieties [86] were employed as directing groups in the acetoxylation of alkyl groups using the $\mathrm{Pd}(\mathrm{OAc})_{2} / \mathrm{PhI}(\mathrm{OAc})_{2}$ system. The synthesis was carried out at $80-100{ }^{\circ} \mathrm{C}$ during a period of time from $5 \mathrm{~min}$ to $12 \mathrm{~h}$ in acetic acid, a $1: 1 \mathrm{AcOH} / \mathrm{Ac}_{2} \mathrm{O}$ mixture, or dichloromethane. More recently, a $\mathrm{Pd}(\mathrm{OAc})_{2} / \mathrm{NaNO}_{3} / \mathrm{O}_{2}$ catalytic system was developed for acetoxylation of unactivated $\mathrm{sp}^{3}-\mathrm{C}-\mathrm{H}$ bonds using the same directing groups [87]. Air or oxygen (1 atm) played a role of terminal oxidant and sodium nitrate was a redox co-catalyst; the reactions were performed in a $\mathrm{AcOH} / \mathrm{Ac}_{2} \mathrm{O}$ solvent mixture at $100-110^{\circ} \mathrm{C}$ for $18 \mathrm{~h}$.

The oxazole moiety also acts as the directing group in the acetoxylation of alkyl groups with $\mathrm{Pd}(\mathrm{OAc})_{2} / \mathrm{AcOO} t-\mathrm{Bu}$ or $\mathrm{Pd}(\mathrm{OAc})_{2} /$ lauroyl peroxide oxidative systems; in these reactions acetic anhydride served as the source of the acetoxy<smiles>[R]OC([R20])C([R])C(=O)Nc1cccc2cccnc12</smiles>

98, $49-60 \%$ a) $\mathrm{Pd}(\mathrm{OAc})_{2}(7.5 \mathrm{~mol} \%)$ $\mathrm{Ag}_{2} \mathrm{CO}_{3}$ ( 0.5 equiv) iodine(III) oxidant (1.5-2 equiv) $\mathrm{R}^{2} \mathrm{OH}, 70-80{ }^{\circ} \mathrm{C}, 2-6 \mathrm{~h}$

b) $\mathrm{Pd}(\mathrm{OAc})_{2}(7.5 \mathrm{~mol} \%)$ $\mathrm{Ag}_{2} \mathrm{CO}_{3}$ ( 0.5 equiv) iodine(III) oxidant ( $2-2.5$ equiv) $\mathrm{R}^{3} \mathrm{OH}, 120-130{ }^{\circ} \mathrm{C}, 2-6 \mathrm{~h}$

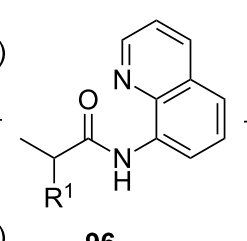

96
$\mathrm{Pd}(\mathrm{OAc})_{2}(15 \mathrm{~mol} \%)$

$\mathrm{Ag}_{2} \mathrm{CO}_{3}$ (1 equiv) iodine(III) oxidant (3.5-4 equiv) $80-130{ }^{\circ} \mathrm{C}, 4-12 \mathrm{~h}$<smiles>[R]OC([R])C([R])C(=O)Nc1cccc2cccnc12</smiles>

$97,34-71 \%$

$\mathrm{R}^{1}=\mathrm{H}, t-\mathrm{Bu}, \mathrm{iPr}$, cyclopentyl, OBn

$\mathrm{R}^{2}=n$-alkyl, iPr

$\mathrm{R}^{3}=n$-alkyl, $\mathrm{Bn}$

iodine(III) oxidant =<smiles>[X]I1OC(=O)c2ccccc21</smiles>

$\mathrm{R}=n$-alkyl, $\mathrm{Bn}, \mathrm{iPr}$

$\mathrm{R}^{1}=\mathrm{H}, t-\mathrm{Bu}, \mathrm{OMe}$, cyclopentyl, etc.

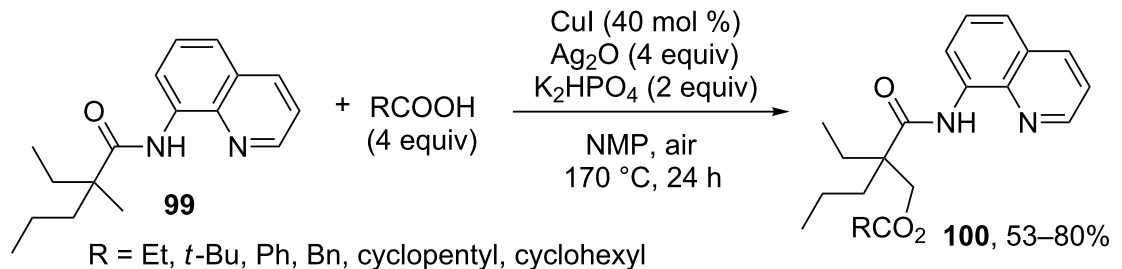




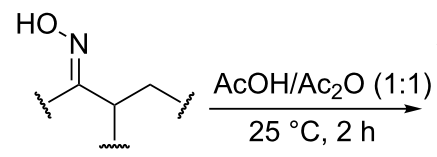

101 $\begin{gathered}80-100{ }^{\circ} \mathrm{C}, 4-12 \mathrm{~h} \\ \text { (one pot })\end{gathered}$
$\mathrm{Phl}(\mathrm{OAc})_{2}(1-3$ equiv)

$33-86 \%$

Examples of synthesized products, yields<smiles>CCC(=NOC(C)=O)C(CC)COC(C)=O</smiles>

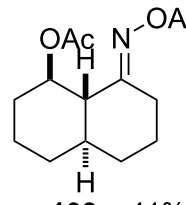

103c, $41 \%$<smiles>CC(=O)OCC1CCCCC1=NOC(C)=O</smiles>

$103 d, 66 \%$

Scheme 22: One-pot acylation and $\mathrm{sp}^{3} \mathrm{C}-\mathrm{H}$ acetoxylation of oximes.

groups [88]. Recently, $\mathrm{Cu}(\mathrm{OAc})_{2}$-mediated acetoxylation of unactivated methyl fragments using the $N$-(quinolin-8-yl)amide directing group and $\mathrm{AgOAc}$ as oxidant was achieved without a Pd catalyst [89].

\section{Aldehydes and alcohols as C-reagents in cross-dehydrogenative $\mathrm{C}-\mathrm{O}$ coupling}

There are numerous reactions, in which aldehydes are involved in the oxidative $\mathrm{C}-\mathrm{O}$ coupling with alcohols under the action of oxidizing agents to form esters. In some cases, primary alcohols are used instead of aldehydes. It is commonly assumed that, under these reaction conditions, primary alcohols are oxidized to aldehydes followed by cross-dehydrogenative $\mathrm{C}-\mathrm{O}$ coupling. These processes with aldehydes or primary alcohols as C-reagents giving esters are often referred to as oxidative esterification.

\subsection{Transition metal salt-catalyzed reactions using compounds with $\mathrm{C}=\mathrm{C}, \mathrm{C}=\mathrm{O}$, and $\mathrm{C}-\mathrm{Hal}$ bonds as oxidants}

One of the types of the oxidative esterification is based on the hydrogen transfer catalyzed by transition metal complexes. In these reactions, compounds with a double bond or a $\mathrm{C}-\mathrm{Hal}$ bond act as oxidants (hydrogen acceptors). Examples of these reactions with aldehydes or primary alcohols as $\mathrm{C}-\mathrm{H}$ reagents are given in Table 2 .

Table 2: Transition metal salt-catalyzed oxidative coupling of primary alcohols or aldehydes with alcohols using compounds with $\mathrm{C}=\mathrm{C}$, $\mathrm{C}=\mathrm{O}$, and C-Hal bonds as oxidants.

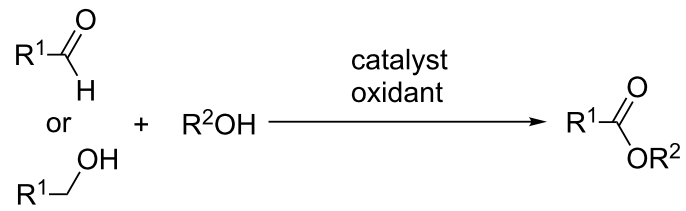

\begin{tabular}{|c|c|c|c|c|c|}
\hline $\mathrm{CH}$-reagent & $\begin{array}{l}\mathrm{R}^{2} \text { (amount of } \\
\left.\mathrm{R}^{2} \mathrm{OH}\right)\end{array}$ & Catalyst & Oxidant & Conditions; yields & Ref. \\
\hline $\begin{array}{l}\mathrm{R}^{1} \mathrm{CH}=\mathrm{O} \\
\mathrm{R}^{1} \mathrm{CH}_{2} \mathrm{OH}\end{array}$ & $\begin{array}{l}\text { Me } \\
\text { (excess) }\end{array}$ & $\begin{array}{l}\mathrm{RuH}_{2}(\mathrm{CO})\left(\mathrm{PPh}_{3}\right)_{3} / 4,5 \text {-bis(diphenyl- } \\
\text { phosphino)-9,9-dimethylxanthene }\end{array}$ & & $\begin{array}{l}\mathrm{MeOH} / \mathrm{PhMe}(1: 1) \\
4-48 \mathrm{~h}, 110^{\circ} \mathrm{C} ; \\
74-95 \%\end{array}$ & {$[90,91]$} \\
\hline $\mathrm{R}^{1} \mathrm{CH}_{2} \mathrm{OH}$ & $\begin{array}{l}\text { Me } \\
\text { (excess) }\end{array}$ & $\begin{array}{l}{[\mathrm{CplrCl}]_{2} / 2-\text { methylaminoethanol/ }} \\
\mathrm{Cs}_{2} \mathrm{CO}_{3}\end{array}$ & & $\begin{array}{l}\text { acetone, } 24 \mathrm{~h} \text {, room } \\
\text { temperature; } \\
23-92 \%\end{array}$ & [92] \\
\hline $\mathrm{R}^{1} \mathrm{CH}=\mathrm{O}$ & $\begin{array}{l}\text { Me, Et, iPr, } \\
\text { s-Bu, } \mathrm{CH}_{2} \mathrm{CF}_{3} \\
\text { (excess) }\end{array}$ & $\begin{array}{l}\mathrm{Pd}(\mathrm{OAc})_{2} / 2 \text {-dicyclohexylphosphino- } \\
2^{\prime}, 4^{\prime}, 6^{\prime} \text {-triisopropylbiphenyl/ } \mathrm{K}_{2} \mathrm{CO}_{3}\end{array}$ & & $\begin{array}{l}\text { acetone/ } \mathrm{R}^{2} \mathrm{OH} \\
2-24 \mathrm{~h} \text {, room } \\
\text { temperature-50 }{ }^{\circ} \mathrm{C} \text {; } \\
7-99 \%\end{array}$ & [93] \\
\hline $\mathrm{R}^{1} \mathrm{CH}=\mathrm{O}$ & $\begin{array}{l}\text { Et } \\
\text { (excess) }\end{array}$ & $\mathrm{Pd}\left(\mathrm{PPh}_{3}\right)_{4} / \mathrm{K}_{2} \mathrm{CO}_{3}$ & $\mathrm{BnCl}$ or $\mathrm{BnBr}$ & $\begin{array}{l}\text { EtOH, MW, } 30 \mathrm{~min} \\
90^{\circ} \mathrm{C} ; 65-93 \%\end{array}$ & [94] \\
\hline $\mathrm{R}^{1} \mathrm{CH}=\mathrm{O}$ & $\begin{array}{l}n \text {-alkyl, sec-alkyl, } \\
\text { Bn, etc. (1 equiv) }\end{array}$ & $\mathrm{PdCl}_{2}\left(\mathrm{PPh}_{3}\right)_{2} / \mathrm{K}_{2} \mathrm{CO}_{3}$ & $\mathrm{BnCl}$ & $\begin{array}{l}\mathrm{THF}, 20 \mathrm{~h}, 50{ }^{\circ} \mathrm{C} \text {; } \\
72-99 \%\end{array}$ & {$[95]$} \\
\hline
\end{tabular}


Crotononitrile, acetone, and benzyl halides were used as oxidants. Ruthenium, iridium, and palladium complexes acted as catalysts. In most cases, structurally simple alcohols, which are taken in a large excess relative to the $\mathrm{CH}$-reagent, served as OH-reagents. The exception is a study [95], in which the coupling was accomplished using an equivalent amount of alcohol.

\subsection{Oxidative systems based on noble metals and oxygen}

The oxidative coupling of benzyl alcohols with aliphatic alcohols in the presence of $\mathrm{Pd}(\mathrm{II})$ salt/ $\mathrm{Ag}(\mathrm{I})$ salt/base/oxygen system was proposed [96,97]. In the study [97], phosphine ligands were additionally employed. It is suggested that the coupling occurs through oxidation of benzyl alcohol to benzaldehyde. Alcohols (OH-reagents) are taken in a twofold molar excess [96] or are used as solvents [96,97]; the reaction time is $20-40 \mathrm{~h}$ at $45-80{ }^{\circ} \mathrm{C}$. The aerobic oxidative coupling of aldehydes or primary alcohols as $\mathrm{CH}$-reagents with low-molecular-weight alcohols was performed in the presence of heterogeneous catalysts, such as $\mathrm{Au} / \mathrm{TiO}_{2}$ [98-100], $\mathrm{Au} / \mathrm{\beta}-\mathrm{Ga}_{2} \mathrm{O}_{3}$ [101], $\mathrm{Au} /$ polymer [102], and $\mathrm{AuNiO}_{\mathrm{x}} / \mathrm{SiO}_{2}-\mathrm{Al}_{2} \mathrm{O}_{3}-\mathrm{MgO}$ [103]. In all the abovementioned processes in the presence of heterogeneous catalysts, low-molecular-weight alcohols are used as the solvents or are taken in a large excess relative to the $\mathrm{CH}$-reagent.

\subsection{Reactions catalyzed by $\mathrm{N}$-heterocyclic carbenes}

N-heterocyclic nucleophilic carbenes $\mathbf{1 0 5}$ have found use for the oxidative esterification. Scheme 23 shows, in a simplified way, the proposed mechanism of this type of cross-dehydrogenative $\mathrm{C}-\mathrm{O}$ coupling [104-113]. The aldehyde is subjected to the attack of N-heterocyclic nucleophilic carbene $\mathbf{1 0 5}$, which can be generated from the corresponding azolium salt 104. The resulting intermediate $\mathbf{1 0 6}$ is oxidized to $\mathbf{1 0 7}$ followed by the nucleophilic attack by the alcohol to form ester $\mathbf{1 0 8}$.

The mechanism of the aerobic oxidative coupling of benzaldehyde with methanol in the presence of the 4-ethyl-1-methyl-1H1,2,4-triazolium iodide/DBU system was studied in detail [114]. It was shown that the reaction proceeds via another mechanism, involving the formation of 2-hydroxy-1,2-diphenylethanone from benzaldehyde followed by the oxidation of this intermediate to 1,2-diphenylethanedione.

Scheme 24 shows an example of the oxidative coupling of aldehydes and alcohols, in which $\mathrm{CH}$ - and $\mathrm{OH}$-reagents are taken in equivalent amounts [104]. Thiazolium salt 109 combined with triethylamine acted as the catalyst, and azobenzene $\mathbf{1 1 0}$ served as the oxidizing agent. Esters 111 were prepared in 16-97\% yield.

The selective oxidative coupling of aldehydes $\mathbf{1 1 2}$ and alcohols 113 in the presence of amines 114 using 1,4-dimethyltriazolium iodide (115), DBU and quinone 116 afforded esters 117. This method was also applied to the synthesis of esters 117a-c from amino alcohols (Scheme 25) [115,116].

Different conditions were proposed for the cross-dehydrogenative $\mathrm{C}-\mathrm{O}$ coupling of aldehydes with alcohols and phenols catalyzed by N-heterocyclic carbenes $(\mathbf{1 1 8}, \mathbf{1 2 9})$ or their precursors, azolium salts (119-128), combined with bases (Table 3; the publications are summarized in chronological order). In most cases, alcohols were taken in an excess.

The oxidative esterification in the presence of azolium salts 119, 121, and 125 was performed with primary alcohols instead

$$
\begin{array}{cc}
\mathrm{X} \mathrm{N}^{+}-\mathrm{R} & \mathrm{X}=\mathrm{NR}{ }^{\prime}, \mathrm{S} \\
\mathrm{Hal} & \\
\mathrm{H} & \mathrm{Y}=\mathrm{N}, \mathrm{CR} "
\end{array}
$$<smiles>C=C[18O]</smiles>

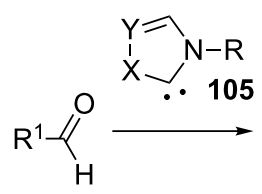

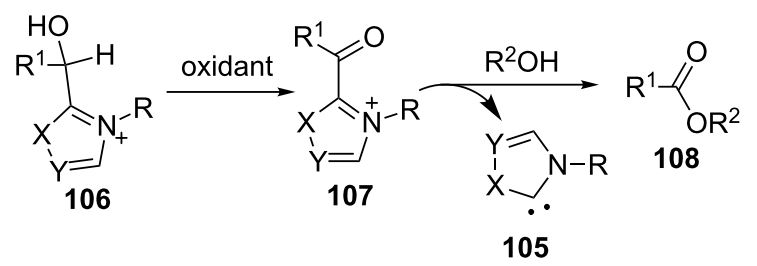




$$
\text { (1 equiv) }
$$

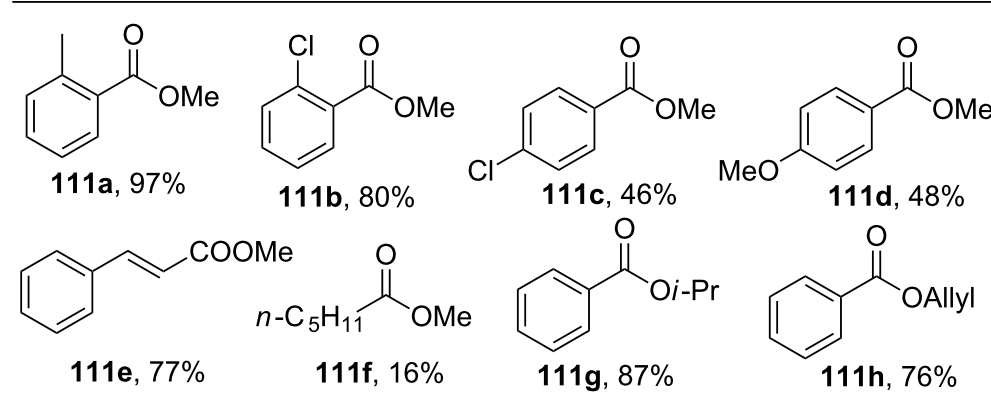

Scheme 24: Oxidative esterification employing stoichiometric amounts of aldehydes and alcohols.

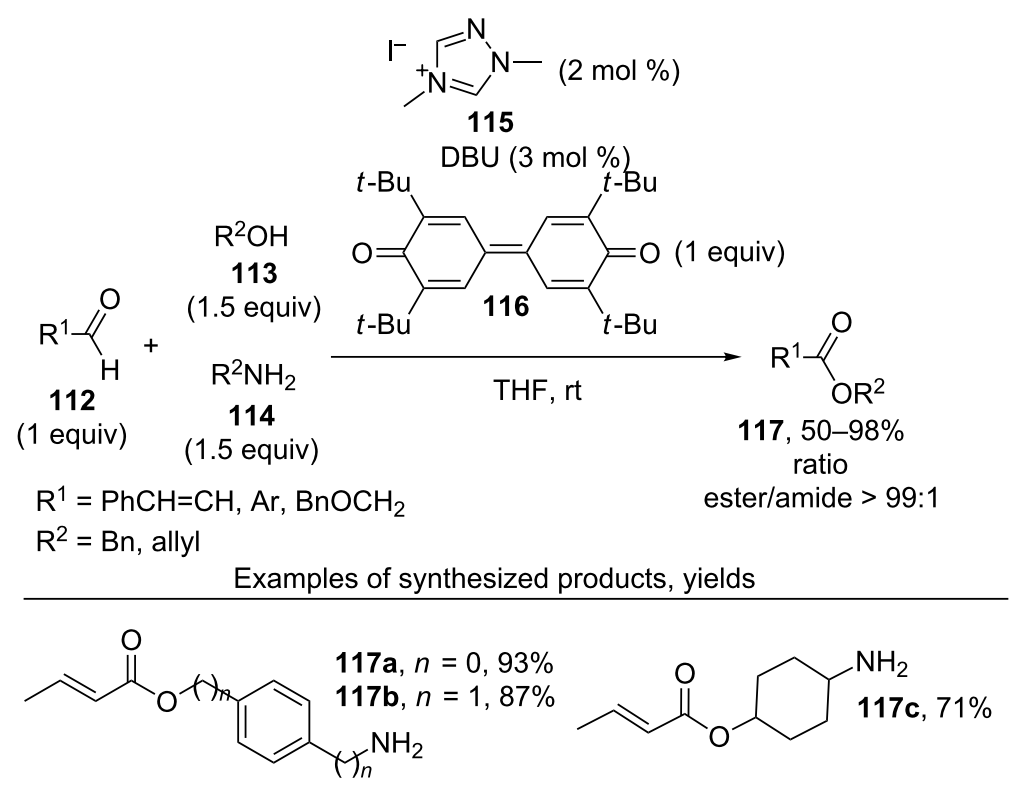

Scheme 25: Selective oxidative coupling of aldehydes with alcohols in the presence of amines.

of aldehydes (Table 4). It is supposed that under the reaction conditions primary alcohol is initially oxidized to aldehyde without the participation of $\mathrm{N}$-heterocyclic carbene $[106,113,123,124]$.

The oxidative esterification of aldehydes with racemic mixtures of alcohols catalyzed by chiral N-heterocyclic carbenes was used for the kinetic separation of enantiomers of alcohols $[125,126]$.

\subsection{Reactions using halogen-containing oxidative systems}

This section considers cross-dehydrogenative $\mathrm{C}-\mathrm{O}$ coupling reactions with aldehydes and primary alcohols as C-reagents in 
Table 3: Oxidative esterification of aldehydes with alcohols.

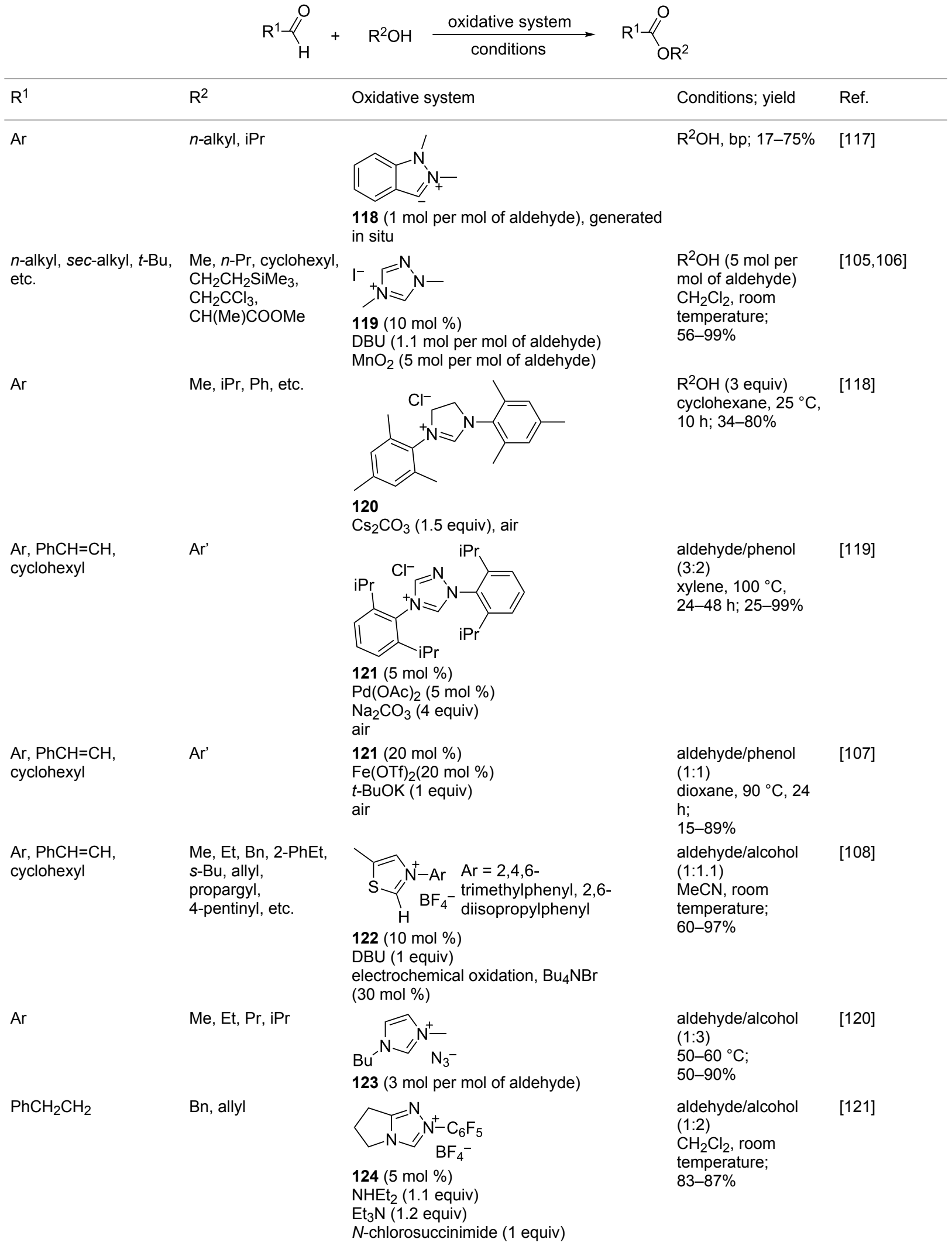


Table 3: Oxidative esterification of aldehydes with alcohols. (continued)

\begin{tabular}{|c|c|c|c|}
\hline $\mathrm{Ar}$ & $\begin{array}{l}\text { Me, Et, iPr, allyl, } \\
\text { propargyl, Bn }\end{array}$ & $\begin{array}{l}\text { DBU }(20 \mathrm{~mol} \%) \\
\text { oxygen }\end{array}$ & $\begin{array}{l}\text { aldehyde/alcohol } \\
(1: 1.2) \\
\text { THF } 25^{\circ} \mathrm{C} \text {; } \\
63-82 \%\end{array}$ \\
\hline $\begin{array}{l}\mathrm{Ar}, \mathrm{PhCH}=\mathrm{CH}, \\
\text { cyclohexyl }\end{array}$ & $\begin{array}{l}\text { Me, Et, } n-\mathrm{Pr}, \mathrm{Bn} \text {, } \\
\text { allyl, propargyl }\end{array}$ & $\begin{array}{l}\mathrm{BF}_{4}{ }^{-} / \\
126(2.5 \mathrm{~mol} \%) \\
{\left[\mathrm{Ru}(2,2 \text { '-bipyrazine })_{3}\right]\left(\mathrm{PF}_{6}\right)_{2}(5 \mathrm{~mol} \%) \text {, air }}\end{array}$ & $\begin{array}{l}\text { aldehyde/alcohol } \\
(1: 10) \\
\text { MeCN, room } \\
\text { temperature; } \\
15-81 \%\end{array}$ \\
\hline $\mathrm{Ar}, \mathrm{PhCH}_{2} \mathrm{CH}_{2}$ & $\begin{array}{l}\mathrm{Me}, \mathrm{Bn}, \text { allyl, } \\
\mathrm{CH}_{2} \mathrm{CCl}_{3}\end{array}$ & $\begin{array}{l}\Gamma^{+} \mathrm{N}= \\
127(15 \mathrm{~mol} \%) \\
\mathrm{DBU}(110 \mathrm{~mol} \%) \\
\text { air }\end{array}$ & $\begin{array}{l}\text { THF/ROH }(1: 1) \text { or } \\
3 \text { equiv } \mathrm{ROH} \text { in THF } \\
\text { room temperature; } \\
15-94 \%\end{array}$ \\
\hline Ar, $n$-alkyl & $\begin{array}{l}n \text {-alkyl, Bn, } \\
\mathrm{CH}_{2} \mathrm{CH}_{2} \mathrm{NEt}_{2}\end{array}$ & $\begin{array}{l}\mathrm{Bu}^{-\mathrm{N}^{-}} \\
128 \text { (solvent) } \\
\mathrm{DBU} \text { (1 equiv), } \mathrm{Cs}_{2} \mathrm{CO}_{3} \text { (3 equiv), } \mathrm{MnO}_{2} \\
\text { (3 equiv) }\end{array}$ & $\begin{array}{l}\text { aldehyde:alcohol } \\
(1: 3) \\
25^{\circ} \mathrm{C}, 24 \mathrm{~h} ; \\
25-91 \%\end{array}$ \\
\hline $\begin{array}{l}\mathrm{Ar}, \mathrm{CH}=\mathrm{CHPh}, \\
\mathrm{CH}=\mathrm{CH}\left(2-\mathrm{C}_{6} \mathrm{H}_{4} \mathrm{OMe}\right)\end{array}$ & $\begin{array}{l}\mathrm{Bn}, \mathrm{CH}=\mathrm{CHPh}, \mathrm{Et}, \\
\mathrm{Ph},\left(\mathrm{CH}_{2}\right)_{3} \mathrm{Ph}\end{array}$ & $\begin{array}{l}\text { iPr } \\
129(5 \mathrm{~mol} \%) \\
\text { TEMPO ( } 2 \text { equiv })\end{array}$ & $\begin{array}{l}\text { aldehyde:alcohol } \\
(1: 1.5) \\
\text { toluene, } 100{ }^{\circ} \mathrm{C} \text {, } \\
4-6 \mathrm{~h} \\
60-86 \%\end{array}$ \\
\hline
\end{tabular}

[109]

[110]

$$
\text { MeCN, room }
$$

THF/ROH (1:1) or 3 equiv $\mathrm{ROH}$ in THF, room temperature;

$$
\begin{aligned}
& (1: 3) \\
& 25^{\circ} \mathrm{C}, 24 \mathrm{~h} \text {; } \\
& 25-91 \%
\end{aligned}
$$

aldehyde:alcohol

$$
\text { TEMPO ( } 2 \text { equiv) }
$$

which halogens and their compounds, for example, molecular iodine, the $\mathrm{Bu}_{4} \mathrm{NI} / t$-BuOOH system, organic iodine(III or $\mathrm{V}$ ) compounds, bromides combined with oxidants, hypochlorite, and so on, acted as oxidants.

The oxidative coupling of primary alcohols $\mathbf{1 3 0}$ with methanol or trifluoroethanol and the oxidative coupling of aldehydes $\mathbf{1 3 2}$ with structurally diverse alcohols 133 were performed using molecular iodine in the presence of potassium carbonate (Scheme 26) [127]. In the former case, methanol or trifluoroethanol served as the solvent. In the latter case, the reaction was carried out in tert-butanol; the amount alcohol was nearly equivalent relative to aldehyde. It is suggested that the reaction proceeds through the formation of hemiacetal from alcohol and aldehyde, which is oxidized by iodine to ester $\mathbf{1 3 1}$ or 134. In the coupling of two alcohols, one of them is initially oxidized to aldehyde by iodine.

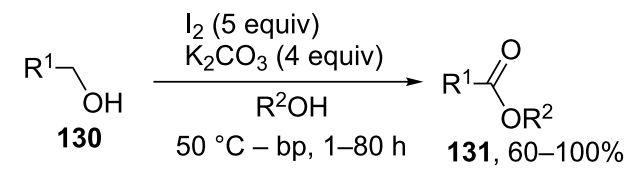

$\mathrm{R}^{1}=\mathrm{Ar}, \mathrm{ArCH}_{2} \mathrm{CH}_{2}, n$-alkyl, $\mathrm{Cy}, \mathrm{Ad}, \mathrm{PhC} \equiv \mathrm{C}, \mathrm{H}_{2} \mathrm{C}=\mathrm{CH}\left(\mathrm{CH}_{2}\right)_{8}$ $\mathrm{R}^{2}=\mathrm{Me}, \mathrm{CF}_{3} \mathrm{CH}_{2}$

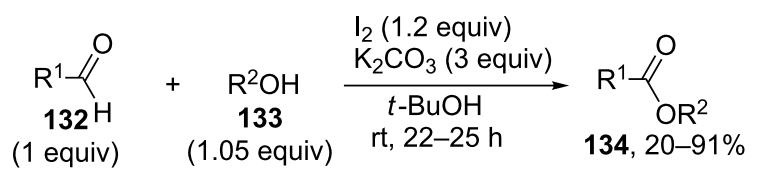

$\mathrm{R}^{1}=\mathrm{PhCH}_{2} \mathrm{CH}_{2}, n-\mathrm{Bu}, \mathrm{PhCH}\left(\mathrm{CH}_{3}\right), \mathrm{Ph}$, thiophen-2-yl

$\mathrm{R}^{2}=\mathrm{ArCH}_{2}, n$-alkyl, (tetrahydrofuran-2-yl)methyl, etc.

Scheme 26: lodine mediated oxidative esterification. 
Table 4: Oxidative esterification using primary alcohols as C-reagents.

\begin{tabular}{|c|c|c|c|c|}
\hline $\mathrm{R}^{1}$ & $\mathrm{R}^{2}$ & Oxidative system & Conditions; yield & Ref. \\
\hline $\begin{array}{l}\text { substituted vinyl, } \\
\text { alkynyl, } \mathrm{Ar}, \mathrm{Bn} \text {, etc. }\end{array}$ & $\begin{array}{l}\mathrm{Me}, \mathrm{Bu}, \mathrm{iPr}, \\
\mathrm{CH}_{2} \mathrm{CCl}_{3} \text {, } \\
\mathrm{CH}_{2} \mathrm{CH}_{2} \mathrm{OMe} \text {, } \\
\mathrm{CH}_{2} \mathrm{CH}_{2} \mathrm{OTMS} \text {, etc. }\end{array}$ & (10-50 mol \%), DBU (10-50 mol \%), & $\begin{array}{l}\mathrm{R}^{2} \mathrm{OH} \text { or } \mathrm{R}^{2} \mathrm{OH} \text { (5 equiv) in } \\
\text { toluene, } 23^{\circ} \mathrm{C} ; 65-95 \%\end{array}$ & [113] \\
\hline $\begin{array}{l}\mathrm{RCH}=\mathrm{CH}, \\
\mathrm{PhCH}=\mathrm{CMe}, \\
\mathrm{PhC} \equiv \mathrm{C}, \mathrm{Ar}\end{array}$ & Me, $n$-Bu, iPr & $\begin{array}{l}119(10 \mathrm{~mol} \%), \mathrm{DBU}(10-110 \mathrm{~mol} \%) \\
\mathrm{MnO}_{2}\left(15 \mathrm{~mol} \text { per mol of } \mathrm{R}^{1} \mathrm{OH}\right)\end{array}$ & $\begin{array}{l}\mathrm{R}^{2} \mathrm{OH} \text { or } \mathrm{R}^{2} \mathrm{OH}(3-5 \text { equiv) } \\
\text { in toluene, } 23^{\circ} \mathrm{C} ; 73-95 \%\end{array}$ & [106] \\
\hline $\mathrm{ArCH}_{2}$, allyl & $\mathrm{Ar}$ & $\begin{array}{l}121(10 \mathrm{~mol} \%), \mathrm{Pd}(\mathrm{OAc})_{2}(5 \mathrm{~mol} \%), \\
\mathrm{Na}_{2} \mathrm{CO}_{3}(0.5 \mathrm{~mol} \text { per mol of phenol), } \\
\text { oxygen }\end{array}$ & $\begin{array}{l}\mathrm{R}^{1} \mathrm{OH} / \mathrm{R}^{2} \mathrm{OH}(3: 2) \\
\text { xylene, } 130^{\circ} \mathrm{C}, 36 \mathrm{~h} \text {; } \\
35-95 \%\end{array}$ & [123] \\
\hline $\mathrm{ArCH}_{2}$, allyl, Bu & $\mathrm{Ar}$ & $\begin{array}{l}121(10 \mathrm{~mol} \%),\left[\mathrm{RuCl}_{2}(p \text {-cymene })\right]_{2} \\
(5 \mathrm{~mol} \%), \mathrm{Cs}_{2} \mathrm{CO}_{3}(10 \mathrm{~mol} \%) \text {, oxygen }\end{array}$ & $\begin{array}{l}\mathrm{R}^{1} \mathrm{OH} / \mathrm{R}^{2} \mathrm{OH}(3: 2) \\
\text { xylene, } 130^{\circ} \mathrm{C}, 24 \mathrm{~h} ; \\
50-95 \%\end{array}$ & [124] \\
\hline
\end{tabular}

In the oxidative coupling of aldehydes or primary alcohols, the second reagent (alcohol) usually served as the solvent. The oxidation was performed with halogen-containing reactants: $\mathrm{I}_{2} / \mathrm{KOH}$ [128], $\mathrm{KI}_{\text {cat }} / t$-BuOOH [129], $\mathrm{I}_{2 \text { cat }} / \mathrm{PhI}(\mathrm{OAc})_{2}$ [130], $\mathrm{I}_{2} / \mathrm{NaNO}_{2}$ [131], $\mathrm{NaBr} / \mathrm{PhI}(\mathrm{OAc})_{2}$ [132], $\mathrm{LiBr} / \mathrm{NaIO}_{4} / \mathrm{H}_{2} \mathrm{SO}_{4}$ [133], $\mathrm{Bu}_{4} \mathrm{NBr} / \mathrm{NaOCl}$ [134], $\mathrm{NaOCl} / \mathrm{AcOH}$ [135], $\mathrm{Py} \cdot \mathrm{HBr}_{3}$ [136], $N$-bromosuccinimide/pyridine [137], $N$-iodosuccinimide/ $\mathrm{K}_{2} \mathrm{CO}_{3}$ [138], and $N, N^{\prime}$-diiodo- $N, N^{\prime}$-1,2-ethanediylbis ( $p$ toluenesulfonamide) [139].

The oxidative $\mathrm{C}-\mathrm{O}$ coupling of benzyl alcohols $\mathbf{1 3 5}$ with alkylarenes 136 took place under the action of the $\mathrm{Bu}_{4} \mathrm{NI} / t-\mathrm{BuOOH}$ system in the presence of $\mathrm{NaH}_{2} \mathrm{PO}_{4}$ [140]. It was proposed that under the reaction conditions benzyl alcohol $\mathbf{1 3 5}$ is oxidized to carboxylic acid 138, while alkylarene gives iodide 139; the nucleophilic substitution between the carboxylate anion and benzyl iodide affords coupling product 137 [140] (Scheme 27).

This mechanism differs from that proposed in the study [141]. According to the latter mechanism, the benzylic carbocation rather than benzyl iodide is generated and this carbocation undergoes nucleophilic attack by carboxylic acid. This mecha- nism is confirmed by the fact that iodide is inert under the reaction conditions. The conditions of the oxidative coupling used in the study [140] differ from the conditions described in the work [141]. However, it should be noted that the formation of benzyl iodide was not experimentally confirmed in the study [140], and the presence of this species was proposed based on the literature data.

The coupling of methyl- and ethylarenes 141 with aromatic aldehydes 140 was performed with the $\mathrm{Bu}_{4} \mathrm{NI} / t$ - $\mathrm{BuOOH}$ system in the presence of an excess of either alkylarene 141 or aldehyde 140 [142]. It was supposed that the coupling occurs through the generation of tert-butoxyl radicals, which abstract a hydrogen atom from the benzylic position of the C-reagent to form the C-radical, which is oxidized to the carbocation; in turn, the aldehyde is oxidized to acid, which reacts with the carbocation to give the target coupling product 142 (Scheme 28).

It was shown that under the reaction conditions, tert-butyl perester is generated as an important intermediate from aldehyde and $t$ - $\mathrm{BuOOH}$, and this intermediate can serve as the source of acid and tert-butoxyl radicals [142]. 


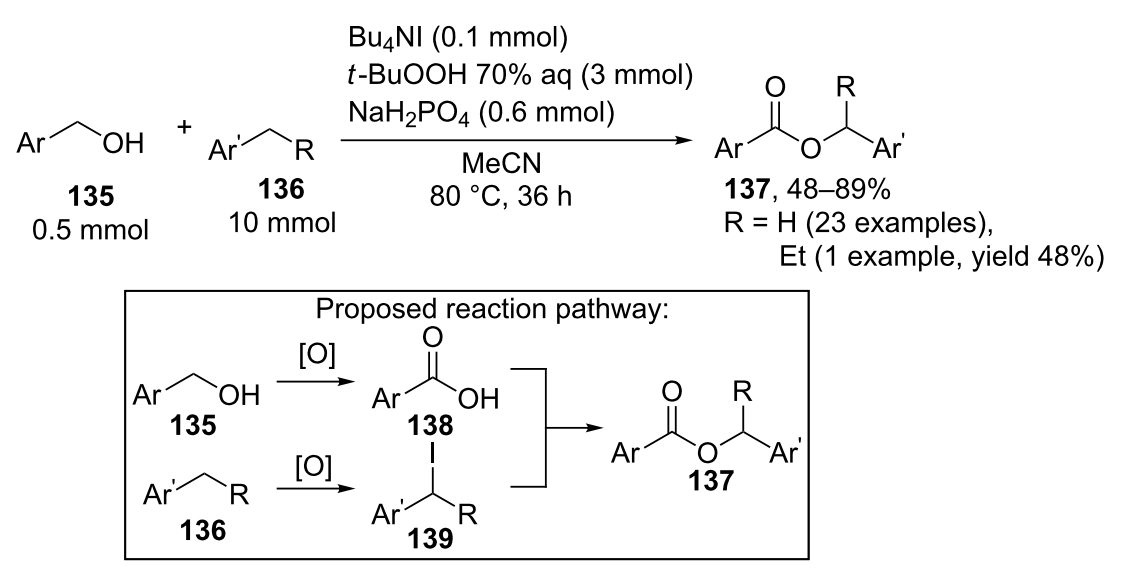

Scheme 27: Oxidative C-O coupling of benzyl alcohols with methylarenes under the action of $\mathrm{Bu}_{4} \mathrm{NI} / t-\mathrm{BuOOH}$ system in the presence of $\mathrm{NaH}_{2} \mathrm{PO}{ }_{4}$.

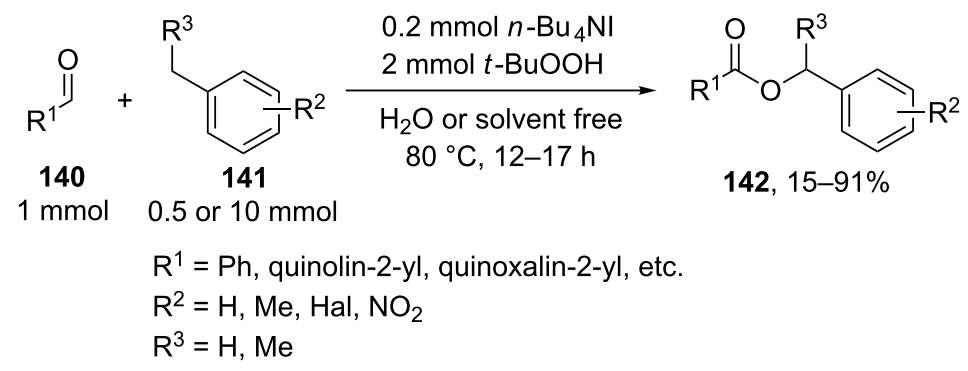

Scheme 28: Oxidative coupling of methyl- and ethylarenes with aromatic aldehydes under the action of $\mathrm{Bu}_{4} \mathrm{NI} / t-\mathrm{BuOOH}$ system.

tert-Butyl peresters 144 were synthesized on a preparative scale by the cross-dehydrogenative $\mathrm{C}-\mathrm{O}$ coupling of aldehydes 143 with $t$ - $\mathrm{BuOOH}$ in the presence of $\mathrm{Bu}_{4} \mathrm{NI}$ [143]. It is proposed that tert-butyl peresters 144 are produced as a result of the recombination of acyl radicals $\mathbf{1 4 5}$ and tert-butyl peroxide radicals. The radical reaction mechanism was confirmed by the experiment, in which acyl radicals generated from aldehyde $\mathbf{1 4 6}$ were trapped by the stable radical TEMPO, and trapping product 147 was obtained in an almost quantitative yield (Scheme 29).

The reaction of aldehydes $148 \mathrm{a}$ with ethers 149 in the presence of $\mathrm{Bu}_{4} \mathrm{NI}$ and $t$ - $\mathrm{BuOOH}$ generated corresponding $\alpha$-acyloxy ethers 150. Reactions between (hetero)aromatic aldehydes or cyclohexanecarbaldehyde $\mathbf{1 4 8 b}$ with arylalkyl ketones $\mathbf{1 5 1}$ under similar conditions resulted in $\alpha$-acyloxy ketones $\mathbf{1 5 2}$ [144] (Scheme 30). The plausible mechanism includes the formation of tert-butyl peresters from the aldehydes.

$\mathrm{N}$-Hydroxyimides 154 are efficient $\mathrm{OH}$-reagents in the coupling with aldehydes and primary alcohols. Their oxidative coupling products, so-called activated esters $\mathbf{1 5 5}$, readily react with nucleophiles, alcohols or amines, due to which they are employed for the preparation of esters and amides. This type of coupling was accomplished using iodine-containing oxidants. The proposed reaction mechanism involves the nucleophilic addition of $N$-hydroxyimides to aldehydes followed by the oxidation of the resulting adduct to form the activated ester. For example, the $\mathrm{C}-\mathrm{O}$ coupling of aldehydes 153 with $N$-hydroxyimides 154 was carried out in the presence of the $\mathrm{Bu}_{4} \mathrm{NHal} / t$ $\mathrm{BuOOH}$ system $(\mathrm{Hal}=\mathrm{I}$ or $\mathrm{Br})$ [145]. This method is applicable to the oxidative coupling of aldehydes 156 with hexafluoroisopropanol giving esters 157. One of the coupling components is added in a twofold excess (Scheme 31).

A similar oxidative coupling reaction was performed with primary alcohols 158 as CH-reagents and $N$-hydroxyimides 154a,b [146]. The coupling reaction with $N$-hydroxyphthalimide (154b) was carried out using the $\mathrm{NaI} /$ aqueous $t$ - $\mathrm{BuOOH} / \mathrm{KOH}$ system instead of $\mathrm{Bu}_{4} \mathrm{NI} / t-\mathrm{BuOOH}$ in decane [146]. The resulting activated esters $\mathbf{1 5 9}$ and $\mathbf{1 6 0}$ were isolated or used in the one-pot reaction with amines to prepare amides (Scheme 32).

The oxidative $\mathrm{C}-\mathrm{O}$ coupling of alcohols and aldehydes 161-164 with $N$-hydroxysuccinimide (154a) was performed in the pres- 


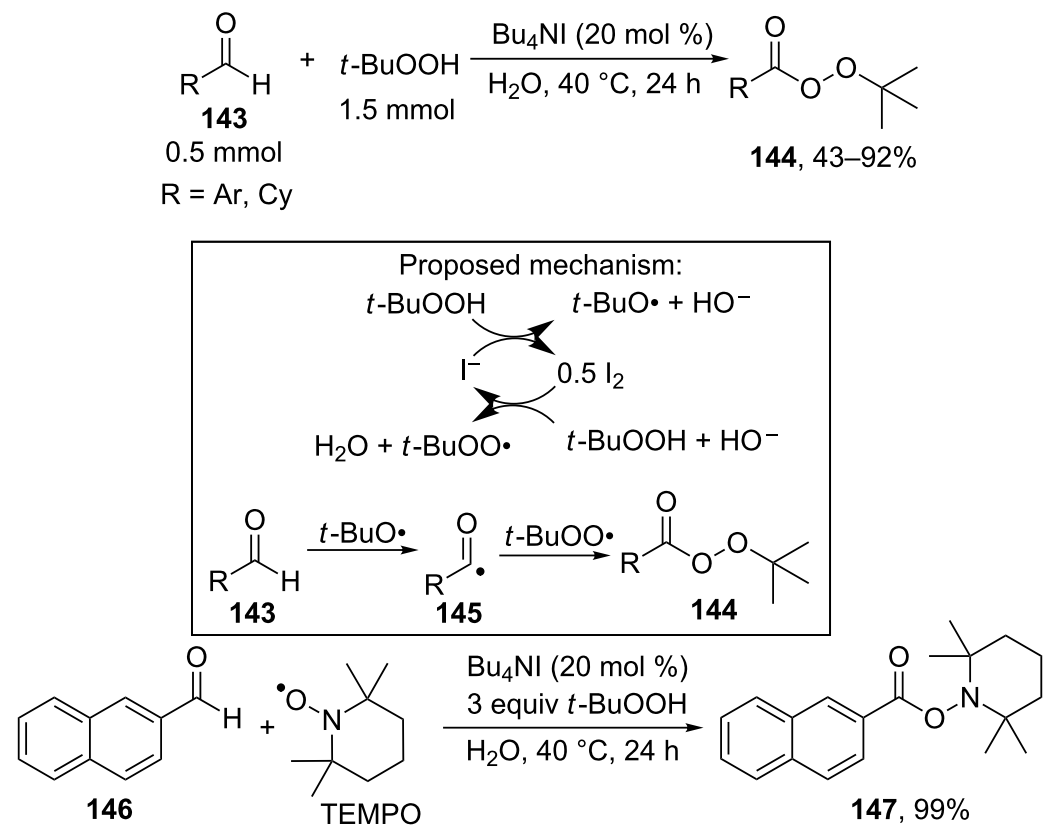

Scheme 29: Cross-dehydrogenative $\mathrm{C}-\mathrm{O}$ coupling of aldehydes with $t-\mathrm{BuOOH}$ in the presence of $\mathrm{Bu}_{4} \mathrm{NI}$.

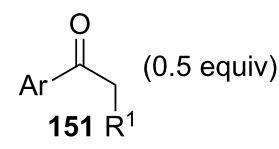

$\mathrm{Bu}_{4} \mathrm{NI}(20 \mathrm{~mol} \%)$<smiles>[R]C(=O)OC([R1])C(=O)[Te]</smiles>

$152,45-84 \%$

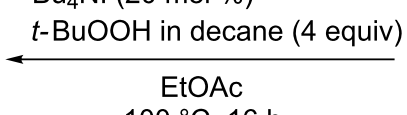

$100^{\circ} \mathrm{C}, 16 \mathrm{~h}$

148b: $R=A r, C y$ $\mathrm{R}^{1}=\mathrm{Me}, \mathrm{Et}$

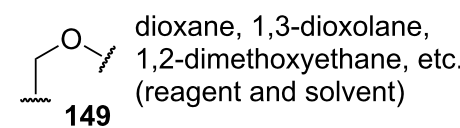

$\mathrm{Bu}_{4} \mathrm{NI}(20 \mathrm{~mol} \%)$

$t$-BuOOH in decane (8 equiv)<smiles>[R]C=C</smiles>
$100^{\circ} \mathrm{C}, 16 \mathrm{~h}$<smiles>[R]C(=O)OC(C)OCC</smiles>

148a,b 148a: $\mathrm{R}=\mathrm{Ar}, \mathrm{CH}=\mathrm{CHPh}, \mathrm{CH}_{2} \mathrm{Ar}$
$150,23-80 \%$

Scheme 30: $\mathrm{Bu}_{4} \mathrm{NI}$-catalyzed $\alpha$-acyloxylation reaction of ethers and ketones with aldehydes and $t-\mathrm{BuOOH}$.
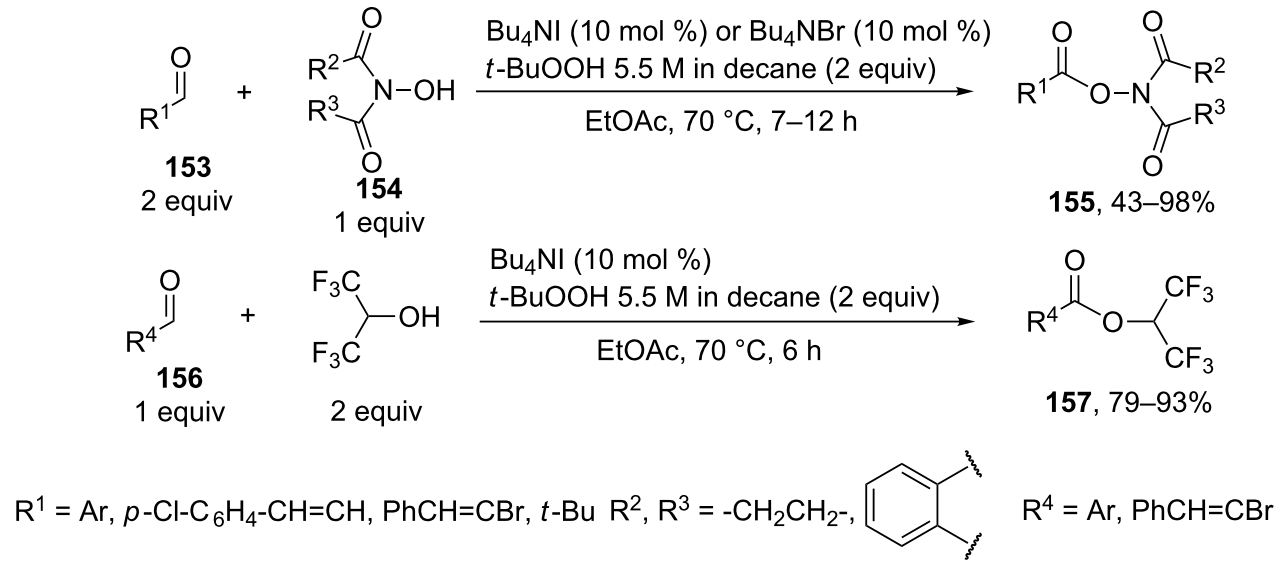


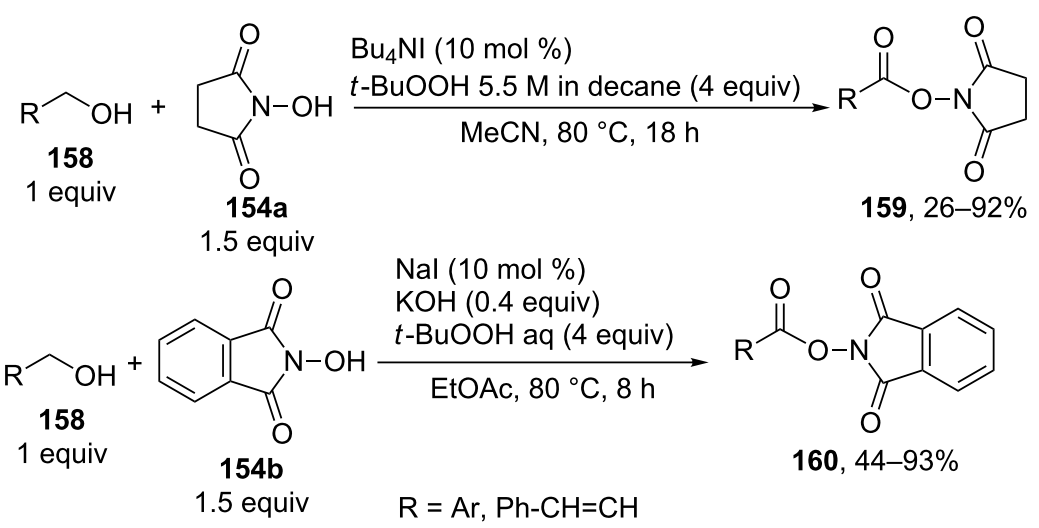

Scheme 32: Oxidative coupling of alcohols with $N$-hydroxyimides.

ence of (diacetoxyiodo)benzene [147] or iodoxybenzoic acid (IBX) [148] as the oxidant. The authors hypothesized that the reaction proceeds via the nucleophilic addition of $N$-hydroxysuccinimide (154a) to aldehyde followed by the oxidation of the adduct that formed with iodine(III) [147] or iodine(V) [148] compounds to form products 165,166 (Scheme 33).
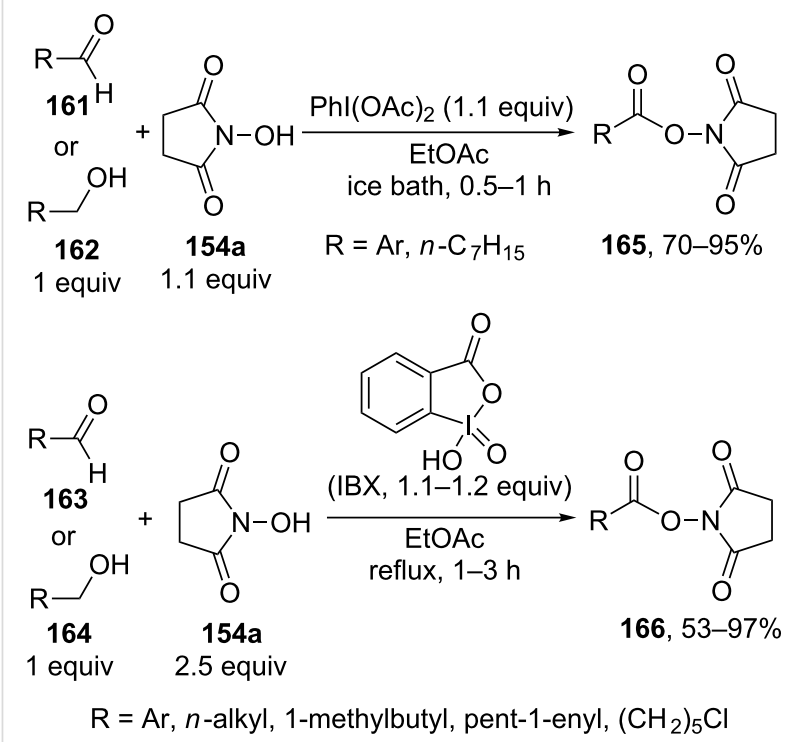

Scheme 33: Oxidative coupling of aldehydes and primary alcohols with $\mathrm{N}$-hydroxyimides using (diacetoxyiodo)benzene or iodoxybenzoic acid (IBX) as oxidants.

In the study [149], activated esters were synthesized by the oxidative coupling of aldehydes and $N$-hydroxysuccinimide in the presence of (diacetoxyiodo)benzene, and these compounds were subjected, without isolation, in the reaction with amines to prepare amides. The reaction was performed at room tempera- ture with $N$-hydroxysuccinimide (154a) taken in an equivalent amount or a small excess relative to aldehyde. Iodoxybenzoic acid (IBX) or the $\mathrm{Co}(\mathrm{OAc})_{2} \cdot 4 \mathrm{H}_{2} \mathrm{O} / \mathrm{O}_{2}$ system proved to be less efficient in the coupling reactions compared with (diacetoxyiodo)benzene. According to the proposed radical mechanism, $N$-hydroxysuccinimide (154a) adds to aldehyde to form intermediate $\mathbf{1 6 7}$ followed by the hydrogen atom abstraction from 167 by succinimide- $N$-oxyl radical 168 to give radical 169 and the oxidation of the latter resulted in the formation of coupling product 170 (Scheme 34). Radical intermediates 168 and 169 were detected by ESR spectroscopy [149].

The oxidative coupling of aldehydes 171 with pivalic acid (172) was performed using the $\mathrm{TEMPO}_{\text {cat }} / t$-BuOCl system; the coupling products, unsymmetrical anhydrides 173 , were employed in the synthesis of esters and amides $\mathbf{1 7 4}$ (Scheme 35) [150].

It is suggested that pivalic acid $\mathbf{1 7 2}$ adds to aldehyde $\mathbf{1 7 1}$ followed by the oxidation of the intermediate that formed with the oxoammonium salt, which is generated from TEMPO and $t$-BuOCl, to yield anhydride $\mathbf{1 7 3}$.

\subsection{Oxidative systems based on transition metal salts and peroxides}

Esters 177 were synthesized by the oxidative $\mathrm{C}-\mathrm{O}$ coupling of aldehydes 175 with alkylarenes 176 using the $\mathrm{Cu}(\mathrm{OAc})_{2} / t$ $\mathrm{BuOOH}$ system (Scheme 36) [151]. The coupling was performed with toluene, xylenes, 1,3,5-trimethylbenzene, 2,4dichlorotoluene, and ethylbenzene.

$\alpha$-Acyloxy ethers $\mathbf{1 8 0}$ were synthesized by the oxidative coupling of benzyl alcohols 178 with ethers 179 (dioxane, tetrahydropyran, tetrahydrofuran, 1,2-dimethoxyethane) using $\mathrm{Cu}(\mathrm{OAc})_{2} / t$-BuOOH system [152] (Scheme 37). 


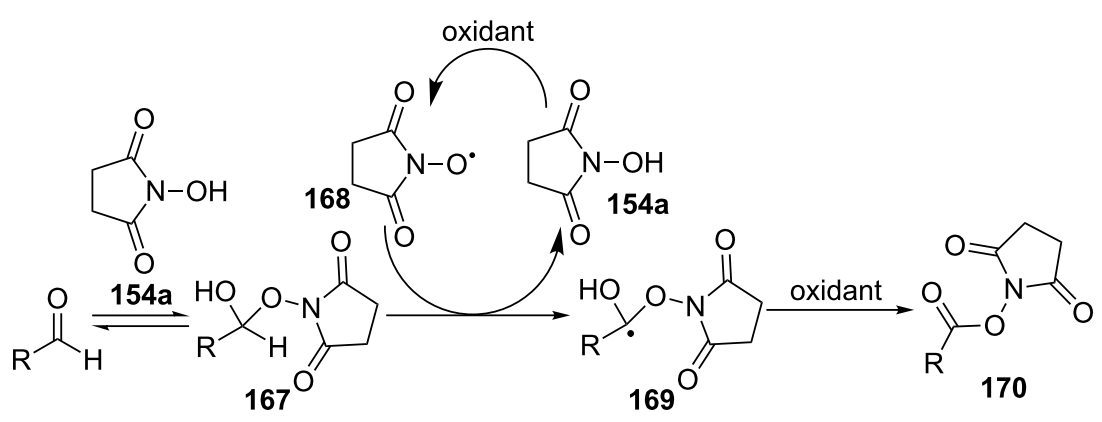

Scheme 34: Proposed mechanism of the oxidative coupling of aldehydes and $N$-hydroxysuccinimide under action of (diacetoxyiodo)benzene.

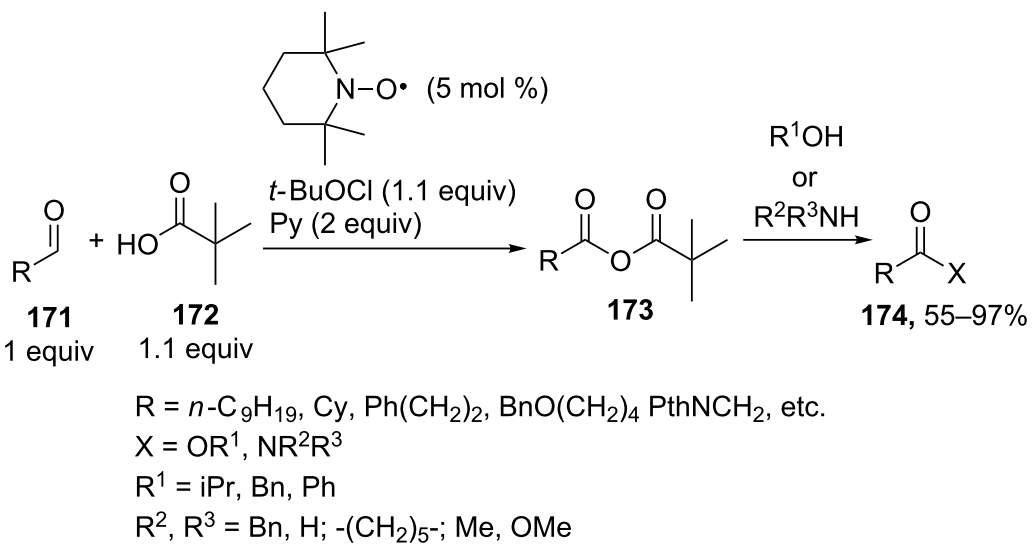

Scheme 35: Oxidative coupling of aldehydes with pivalic acid (172)

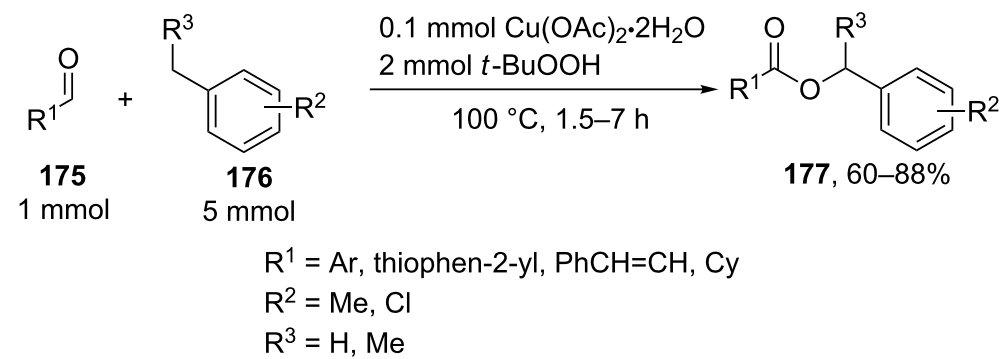

Scheme 36: Oxidative $\mathrm{C}-\mathrm{O}$ coupling of aldehydes with alkylarenes using the $\mathrm{Cu}(\mathrm{OAc})_{2} / t-\mathrm{BuOOH}$ system.

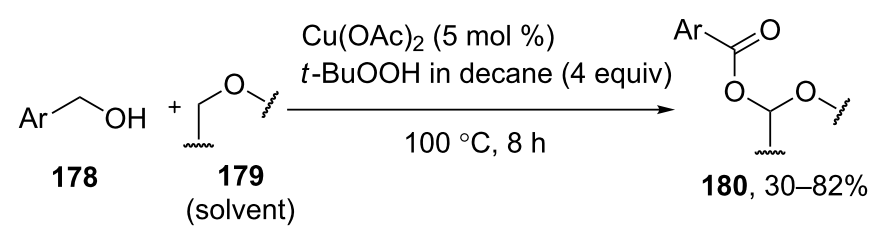

Scheme 37: Copper-catalyzed acyloxylation of $\mathrm{C}\left(\mathrm{sp}^{3}\right)-\mathrm{H}$ bond adjacent to oxygen in ethers using benzyl alcohols. 
In a series of works, the oxidative coupling of alcohols, aldehydes, or formamides with 1,3-dicarbonyl compounds or phenols was accomplished in the presence of tert-butyl hydroperoxide and copper salts (Table 5). In most cases, the range of phenols applicable to the coupling is limited to 2-acylphenols. However, 2-(benzothiazol-2-yl)phenol was used along with 2-acylphenols as the OH-reagent in the study [153].

In the coupling with aldehydes, the components are taken in a nearly stoichiometric molar ratio. In the coupling with

Table 5: Oxidative coupling of alcohols, aldehydes, or formamides with 1,3-dicarbonyl compounds or phenols in the presence of tert-butyl hydroperoxide and copper salts.
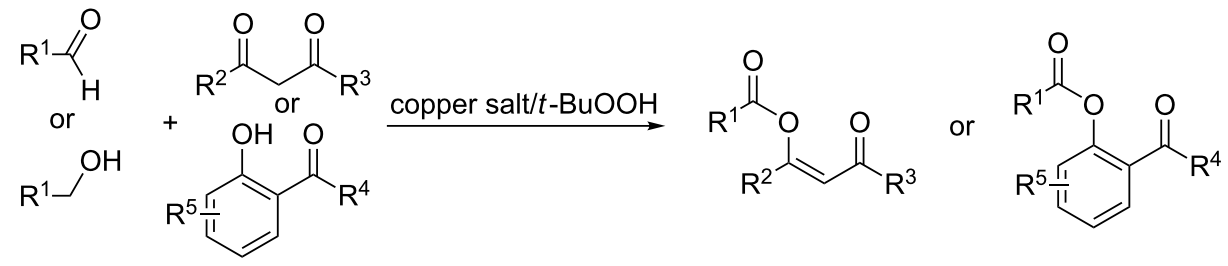

C-reagent
$\mathrm{R}^{1}{ }_{2}=$ di-Me, di-Et, di-iPr, $-\left(\mathrm{CH}_{2}\right)_{5-}$

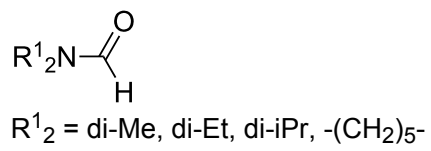

$\mathrm{R}^{1} \mathrm{OH}^{1-2}$

$\mathrm{R}^{1}=\mathrm{Ar}, n$-alkyl, cyclohexyl, $\mathrm{CH}_{2} \mathrm{CH}_{2} \mathrm{Ph}$,
Molar ratio C-reagent/O-reagent; conditions; yields

\section{1:1.1;}

$\mathrm{CuBr}(2.5 \mathrm{~mol} \%)$,

$t$-BuOOH (5.5 $\mathrm{M}$ in decane, 1.5 equiv),

$\mathrm{R}^{2}=\mathrm{Me}, \mathrm{Et}, \mathrm{CH}_{2} \mathrm{Cl}, \mathrm{Ph}$

$\mathrm{R}^{3}=\mathrm{Me}, \mathrm{Et}, \mathrm{OMe}, \mathrm{OEt}$<smiles>[R]C(=O)C([R])C([R])=O</smiles>

$\mathrm{R}^{2}, \mathrm{R}^{4}=$ alkyl, $\mathrm{Ph},-\left(\mathrm{CH}_{2}\right)_{4^{-}} ; \mathrm{R}^{4}$ may be $\mathrm{H}$;

$\mathrm{R}^{3}=$ alkoxy, $\mathrm{BnO}$<smiles>[R]C(=O)C([Z1])C([R])C([R])=O</smiles>

$\mathrm{R}^{2}, \mathrm{R}^{4}=$ alkyl, $\mathrm{Ph},-\left(\mathrm{CH}_{2}\right)_{4^{-}} ; \mathrm{R}^{4}$ may be $\mathrm{H}$;

$\mathrm{R}^{3}=$ alkoxy, $\mathrm{BnO}$

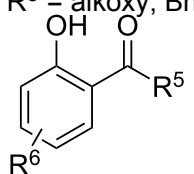

$\mathrm{R}^{5}=\mathrm{Me}, \mathrm{OMe}, \mathrm{Ph}, \mathrm{NHPh}$

$\mathrm{R}^{6}=\mathrm{H}$, OMe, Hal<smiles>[R]C(=O)c1cb[13cH]cc1O</smiles>

$\mathrm{R}^{4}=\mathrm{Me}, \mathrm{OMe}, \mathrm{OEt}, \mathrm{OBn}, \mathrm{Ph}$

$\mathrm{R}^{4}=\mathrm{MH}$

$80^{\circ} \mathrm{C}, 16 \mathrm{~h} ; 57-89 \%$

Formamide as the solvent;

$\mathrm{CuBr}_{2}$ or $\mathrm{Cu}(\mathrm{OAc})_{2}(5 \mathrm{~mol} \%)$,

$t$-BuOOH ( $70 \%$ aq, 1.5 equiv),

$80{ }^{\circ} \mathrm{C}, 3 \mathrm{~h}$;

$62-86 \%$

Ref.

[154] 
Table 5: Oxidative coupling of alcohols, aldehydes, or formamides with 1,3-dicarbonyl compounds or phenols in the presence of tert-butyl hydroperoxide and copper salts. (continued)

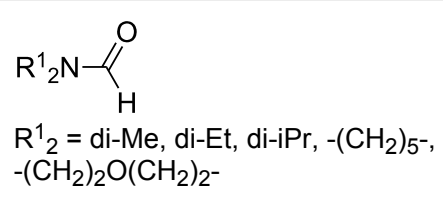<smiles>[R14]NC=O</smiles>

$\mathrm{R}^{1}{ }_{2}=\mathrm{di}-\mathrm{Me}, \mathrm{di}-\mathrm{Et}$

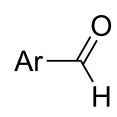<smiles>O=Cc1ccccc1O</smiles>
$\mathrm{R}^{5}=\mathrm{H}, \mathrm{Me}, t-\mathrm{Bu}, \mathrm{OMe}, \mathrm{NEt}_{2}$, $\mathrm{Cl}, \mathrm{Br}$, etc.<smiles>[R]C(=O)CC([R])=O</smiles>
$\mathrm{R}^{2}=\mathrm{Me}, \mathrm{Ph}, n-\mathrm{Pr}$, etc. $\mathrm{R}^{3}=\mathrm{Me}, \mathrm{OMe}, \mathrm{OEt}, \mathrm{Bn}$, allyl, etc.

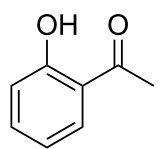

Formamide as the solvent; $\mathrm{CuCl}(1-2 \mathrm{~mol} \%)$, $t$-BuOOH (70\% aq, 6 equiv), $80{ }^{\circ} \mathrm{C}, 15-90 \mathrm{~min}$; 26-99\%

Formamide as the solvent; $\mathrm{CuO} / \mathrm{a}-\mathrm{Fe}_{2} \mathrm{O}_{3} /$ carbon nanotubes, $t$-BuOOH ( $70 \%$ aq, 1.5 equiv), $80{ }^{\circ} \mathrm{C}, 4 \mathrm{~h} ; 40-80 \%$

$1: 1$

$\mathrm{CuO} / \mathrm{\alpha}-\mathrm{Fe}_{2} \mathrm{O}_{3} /$ carbon nanotubes, $t$-BuOOH ( $70 \%$ aq, 1.5 equiv), DMSO, $80^{\circ} \mathrm{C}, 10 \mathrm{~h} ; 20-82 \%$
[157] formamides, the latter served as the solvent. In the studies $[155,156], 1,3$-cyclohexanedione was used as the OH-reagent along with 1,3-ketoesters. However, the reaction with 1,3cyclohexanedione gave products in low yields (19-26\%). The coupling of a number of substituted salicylaldehydes with formamides was performed; the aldehyde group, which is prone to oxidation, remaining intact [157].

The coupling of aldehydes and formamides with 2-substituted phenols was carried out in the presence of heterogeneous catalysts, such as $\mathrm{CuO}$ on $\alpha-\mathrm{Fe}_{2} \mathrm{O}_{3}$-modified carbon nanotubes (a magnetically separable catalyst) [158] and the metal-organic framework $\mathrm{Cu}_{2}$ (4,4'-biphenyldicarboxylate) ${ }_{2}$ (4,4'-bipyridine) [159].

Aldehydes were oxidized to esters in alcohols with $\mathrm{V}_{2} \mathrm{O}_{5}$ / $\mathrm{H}_{2} \mathrm{O}_{2 \mathrm{aq}} / \mathrm{HClO}_{4}$ [160], $\mathrm{V}_{2} \mathrm{O}_{5} /$ percarbonate, sodium perborate/ $\mathrm{HClO}_{4}$ [161], $\mathrm{VO}(\mathrm{acac})_{2} / \mathrm{H}_{2} \mathrm{O}_{2 \mathrm{aq}}[162], \mathrm{Cu}\left(\mathrm{ClO}_{4}\right)_{2} / t$-BuOOH in decane $/ \mathrm{InBr}_{3}$ [163], $\mathrm{Fe}\left(\mathrm{ClO}_{4}\right)_{3} / \mathrm{H}_{2} \mathrm{O}_{2 \mathrm{aq}}$ [164], $\gamma-\mathrm{Fe}_{2} \mathrm{O}_{3}-\mathrm{SiO}_{2}-$ supported heteropoly acids combined with $\mathrm{H}_{2} \mathrm{O}_{2 \mathrm{aq}}$ [165], silica gel-immobilized manganese phthalocyanine $/ \mathrm{H}_{2} \mathrm{O}_{2 \mathrm{aq}}$ [166], a $\mathrm{Ni}(\mathrm{II})$ complex $/ \mathrm{H}_{2} \mathrm{O}_{2 \mathrm{aq}}$ [167], and $\mathrm{ZnBr}_{2} / \mathrm{H}_{2} \mathrm{O}_{2}$ [168].

The oxidative $\mathrm{C}-\mathrm{O}$ coupling of aromatic aldehydes 181 with cycloalkanes 182 was accomplished in the presence of the $\mathrm{Cu}(\mathrm{OAc})_{2} / t-\mathrm{BuOOH}$ system to prepare products 183 . This reaction is unusual in that it involves the cleavage of four $\mathrm{C}-\mathrm{H}$ bonds, including unactivated $\mathrm{C}-\mathrm{H}$ bonds of cycloalkane, and the formation of two $\mathrm{C}-\mathrm{O}$ bonds and one $\mathrm{C}=\mathrm{C}$ double bond [169]. The yields of products $\mathbf{1 8 3}$ were not higher than $53 \%$. However, the transformation is a rare example of the oxidative coupling with the participation of inert $\mathrm{CH}$-reagents, cycloalkanes, to form a product, which can be subjected to higher oxidation under the conditions of oxidative coupling (Scheme 38).

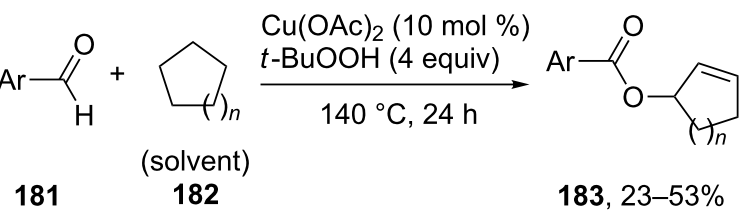

\footnotetext{
$\mathrm{Ar}=\mathrm{Ph}$, thiophen-2-yl, 4-Et- $\mathrm{C}_{6} \mathrm{H}_{4}, 4-\mathrm{MeO}-\mathrm{C}_{6} \mathrm{H}_{4}$, $4-\mathrm{Br}_{-} \mathrm{C}_{6} \mathrm{H}_{4}, 4-\mathrm{O}_{2} \mathrm{~N}-\mathrm{C}_{6} \mathrm{H}_{4}$, etc.

$n=1-3$
}

Scheme 38: Oxidative C-O coupling of aromatic aldehydes with cycloalkanes.

Related oxidative $\mathrm{C}-\mathrm{O}$ coupling reactions of alkanes with methylarenes and carboxylic acids are discussed in sections 4.1 and 6, respectively. Different radical mechanisms were proposed, the common feature is the generation of alkene via the radical dehydrogenation of alkane.

\subsection{Other oxidative systems}

Esters were synthesized from aldehydes and methanol (6 equiv excess relative to aldehyde) using pyridinium dichromate in DMF [170]. Methyl esters were synthesized also from aromatic aldehydes, $\alpha, \beta$-unsaturated aldehydes, or allylic alcohols in the presence of the DDQ (2,3-dichloro-5,6-dicyanobenzoquinone)/ amberlyst-15 system in a methanol/toluene mixture under microwave irradiation [171]. Methyl, ethyl, and isopropyl benzoates were prepared from benzaldehyde under irradiation of its alcoholic solutions with a mercury lamp in an oxygen 
atmosphere; esters were obtained in higher yields in the presence of catalytic amounts of $\mathrm{HCl}$ [172]. The formation of primary and secondary alcohol esters was observed after the ozonolysis of a mixture of aldehyde and alcohol in a basic medium [173]. The oxidative esterification of aldehydes was performed using peroxides in the presence of Lewis acids or in the absence of the latter; for example, using oxone in the presence of $\operatorname{In}(\mathrm{OTf})_{3}[174,175]$, oxone [174,176], Caro's acid [177], $\mathrm{H}_{2} \mathrm{O}_{2 \text { aq }}(30 \%)$ in the presence of $\mathrm{CaCl}_{2}$ or $\mathrm{MgCl}_{2}$ [178], $\mathrm{H}_{2} \mathrm{O}_{2 \text { aq }}$ $(50 \%)$ [179].

The oxidative coupling of structurally diverse aldehydes (aromatic, $\alpha, \beta$-unsaturated, etc.) with hexafluoroisopropanol was carried out in the presence of the oxoammonium salt (4-acetylamino-2,2,6,6-tetramethylpiperidine-1-oxoammonium tetrafluoroborate) and pyridine [180]. The drawback of this method is that it requires a rather complicated and expensive oxidant.

An efficient aerobic cross-dehydrogenative coupling of alcohols and $\alpha$-carbonyl aldehydes was achieved employing a $\mathrm{CuBr} /$ pyridine catalytic system in toluene, only 1.5 -fold excess of alcohols over aldehydes was used [181]. The reaction time is $18 \mathrm{~h}$ at $90{ }^{\circ} \mathrm{C}$, the yields of $\alpha$-ketoesters vary from 42 to $88 \%$.

The unusual $\mathrm{C}-\mathrm{O}$ cross-coupling of primary alcohols 184 with secondary alcohols $\mathbf{1 8 5}$ in the absence of oxidants was performed in the presence of ruthenium complex 186 as the catalyst; the reaction afforded molecular hydrogen and unsymmetrical ester 187 (Scheme 39) [182].

Cross-coupling products $\mathbf{1 8 7}$ were obtained in high yields; the expected homocoupling of primary alcohols giving symmetrical esters and the dehydrogenation of secondary alcohols yielding ketones were avoided.

\section{Ketones and 1,3-dicarbonyl compounds as $\mathrm{C}$-reagents in cross-dehydrogenative $\mathrm{C}-\mathrm{O}$ coupling}

Most of cross-dehydrogenative $\mathrm{C}-\mathrm{O}$ coupling reactions involving the $\alpha$-position of carbonyl compounds (acetoxylation, alkoxylation, sulfonyloxylation) are based on the use of iodinecontaining oxidizing agents. Transition metal salts, such as copper and manganese salts, were less often employed for this purpose.

\subsection{Oxidative systems based on iodine compounds}

Iodine(III) organic compounds, including those generated in situ from aryl iodides and peracids (for example, $m$-chloroperbenzoic acid (MCPBA) and peracetic acid) are most commonly employed in the oxidative coupling of $\mathrm{OH}-$ reagents with carbonyl compounds. Methods were developed for the sulfonyloxylation of ketones, in which iodoarene is generated in situ by the iodination of arene with molecular iodine [183] or $\mathrm{NH}_{4} \mathrm{I}$ [184] in the presence of $m$-chloroperbenzoic acid.

In the presence of $p$-(difluoroiodo)toluene (188), $\beta$-dicarbonyl compounds 189 undergo oxidative coupling with various $\mathrm{OH}$-reagents (Scheme 40), such as sulfonic acids (coupling products 190), acetic acid (products 191), diphenyl phosphate (products 192), and alcohols (products 193) [185]. The reactions with alcohols are most slow. It is suggested that the oxidative $\mathrm{C}-\mathrm{O}$ coupling at the $\alpha$-position of carbonyl (or $\beta$-dicarbonyl) compounds and various $\mathrm{OH}$-reagents in the presence of iodine(III) compounds proceeds through an ionic mechanism. Thus, the electrophilic iodine atom attacks the enol of carbonyl compound 194 followed by the replacement of the iodinecontaining moiety in intermediate $\mathbf{1 9 5}$ by the O-nucleophile to form $\mathrm{C}-\mathrm{O}$ coupling product 196 (Scheme 40).

Table 6 presents other examples of $\mathrm{C}-\mathrm{O}$ coupling reactions at the $\alpha$-position of carbonyl compounds based on the oxidation

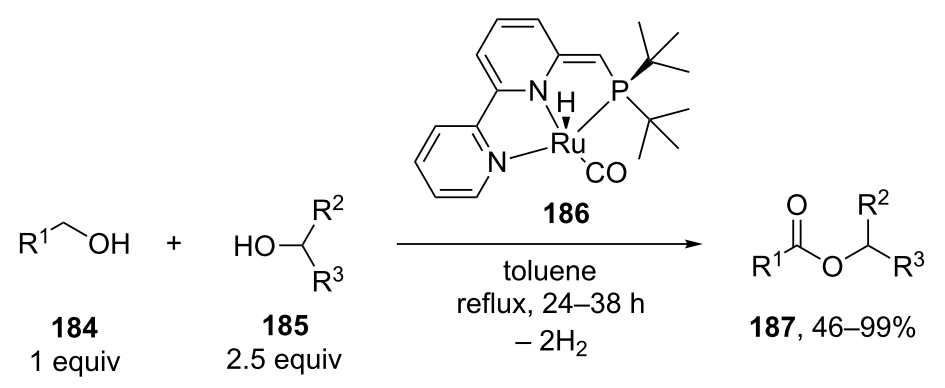




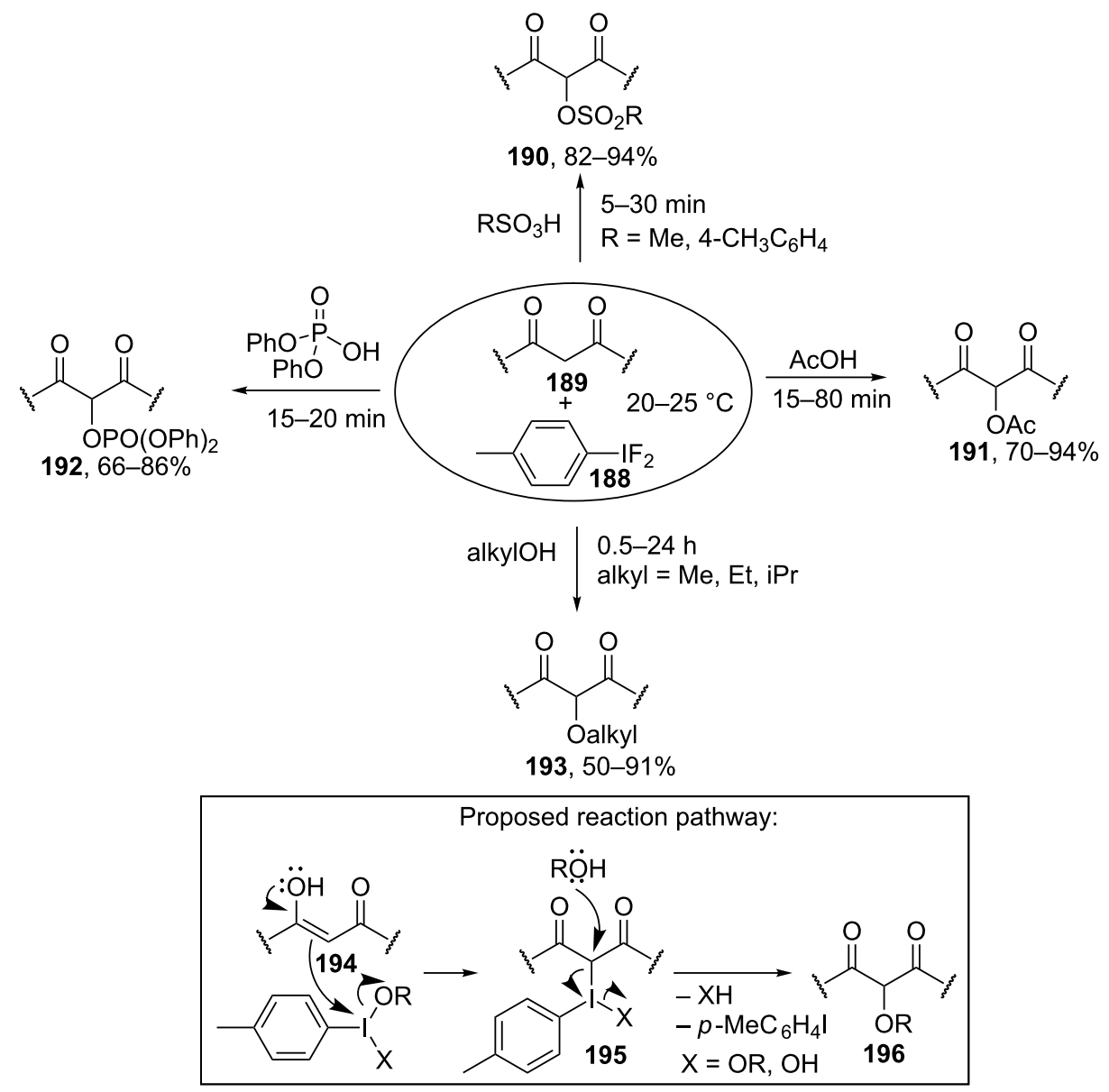

Scheme 40: Cross-dehydrogenative C-O coupling reactions of $\beta$-dicarbonyl compounds with sulfonic acids, acetic acid, diphenyl phosphate, and alcohols using $p$-(difluoroiodo)toluene.

Table 6: C-O coupling reactions at the a-position of carbonyl compounds mediated by iodine(III) compounds or iodoarenes in the presence of peroxides.

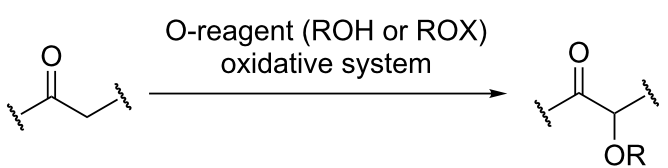

\begin{tabular}{|c|c|c|c|c|}
\hline C-reagent & O-reagent & Oxidative system & Conditions; yields & Ref. \\
\hline$\beta$-diketones, $\beta$-keto esters & $\mathrm{MeSO}_{3} \mathrm{H}$ (1 equiv) & PhlO & $\begin{array}{l}\mathrm{CHCl}_{3} \text {, reflux, } 2 \mathrm{~h} ; \\
37-83 \%\end{array}$ & [187] \\
\hline$\beta$-diketones, $\beta$-keto esters & $\begin{array}{l}\mathrm{MeOH} \text { or } \mathrm{EtOH} \text { (as the } \\
\text { solvents) }\end{array}$ & $\mathrm{PhIO}, \mathrm{BF}_{3} \cdot \mathrm{Et}_{2} \mathrm{O}$ & $\begin{array}{l}\text { room temperature, } 5 \mathrm{~h} \text {; } \\
59-67 \%\end{array}$ & {$[187]$} \\
\hline $\mathrm{O}$ & $\begin{array}{l}\mathrm{ROH}, \mathrm{R}=\mathrm{iBu}, \mathrm{CMe}_{2} \mathrm{Et} \text {, } \\
\left(\mathrm{CH}_{2}\right)_{2} \mathrm{CF}_{3} \text {, } \\
\left(\mathrm{CH}_{2}\right)_{3} \mathrm{OBn} \text {, etc. }\end{array}$ & $\mathrm{PhIO}, \mathrm{BF}_{3} \cdot \mathrm{Et}_{2} \mathrm{O}$ & $\begin{array}{l}\mathrm{CHCl}_{3} \text {, } \\
\text { room temperature, } 5 \mathrm{~h} \text {; } \\
\text { yields were not } \\
\text { reported }\end{array}$ & [188] \\
\hline 0 & $\begin{array}{l}\text { acetoxylation with } \\
\mathrm{Phl}(\mathrm{OAc})_{2} \text { ( } 1.2 \text { equiv) }\end{array}$ & $\mathrm{Phl}(\mathrm{OAc})_{2}, \mathrm{Bu}_{4} \mathrm{NBr}, \mathrm{KOH}$ & $\begin{array}{l}\text { dioxane, room } \\
\text { temperature, } 1 \mathrm{~h} \text {; } \\
74-87 \%\end{array}$ & [189] \\
\hline
\end{tabular}


Table 6: C-O coupling reactions at the $\alpha$-position of carbonyl compounds mediated by iodine(III) compounds or iodoarenes in the presence of peroxides. (continued)

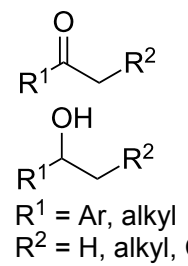<smiles>[R]CC([R])=O</smiles>

$\mathrm{R}^{1}=\mathrm{Ar}$, alkyl,

$\mathrm{R}^{2}=\mathrm{H}$, alkyl, $\mathrm{CO}_{2} \mathrm{Et}$

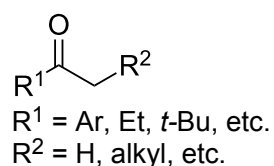

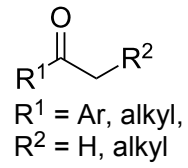

Phl or poly(4-iodostyrene) (cat), MCPBA; $\mathrm{KBr}_{\text {cat }}$ or TEMPO cat $^{\text {was }}$ added to oxidize alcohols

$\mathrm{MeCN}$ or $\mathrm{CHCl}_{3}, 50^{\circ} \mathrm{C}, \quad$ [190] 5 h; $25-81 \%$

polymer-immobilized iodobenzene,

$50{ }^{\circ} \mathrm{C}, 9-16 \mathrm{~h} ; 51-88 \%$

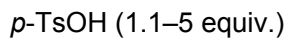
with $\mathrm{Ac}_{2} \mathrm{O}$

p-TsOH (3-5 equiv)

$p-\mathrm{MeC}_{6} \mathrm{H}_{4} \mathrm{I}$ (1 equiv), oxone (1.5 equiv),

$\mathrm{MeCN}, 60^{\circ} \mathrm{C}$ $32-100 \%$

$\mathrm{RSO}_{3} \mathrm{H}$ (1.5 equiv), $\mathrm{R}=$ Ar, alkyl, etc.

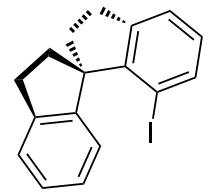

EtOAc, room temperature; [186] with iodine(III) compounds or iodoarenes in the presence of peroxides. Chiral iodoarenes, such as $\mathbf{1 9 7}$, served as the catalysts in the asymmetric $\mathrm{C}-\mathrm{O}$ coupling of sulfonic acids with ketones. The enantiomeric excess of the product was not higher than $58 \%$ due, in particular, to instability of the configuration of the products, $\alpha$-sulfonyloxy ketones, under the reaction conditions, resulting in the partial racemization [186].

Good results were achieved in the oxidative $\mathrm{C}-\mathrm{O}$ coupling of ketones, aldehydes and $\beta$-dicarbonyl compounds 198 with carboxylic acids 199 in the presence of the $\mathrm{Bu}_{4} \mathrm{NI} / t$ - $\mathrm{BuOOH}$ system [194] (Scheme 41). The coupling can be accomplished with a wide range of substrates and gives products $\mathbf{2 0 0}$ in high yields, the $\mathrm{C}$-component and the $\mathrm{O}$-component being taken in a ratio of $1: 1$. The reactions of aldehydes are similar to the reactions of ketones, the aldehyde moiety remaining unchanged. The authors hypothesized that the reaction proceeds through a radical mechanism [194].

The $\mathrm{Bu}_{4} \mathrm{NI} / t$ - $\mathrm{BuOOH}$ system was employed also in the oxidative coupling of carboxylic acids with $\beta$-keto esters [195].

The cross-dehydrogenative $\mathrm{C}-\mathrm{O}$ coupling of alcohols 201 and ketones $\mathbf{2 0 2}$ in the presence of the $\mathrm{Bu}_{4} \mathrm{NI} / t$ - $\mathrm{BuOOH}$ system was

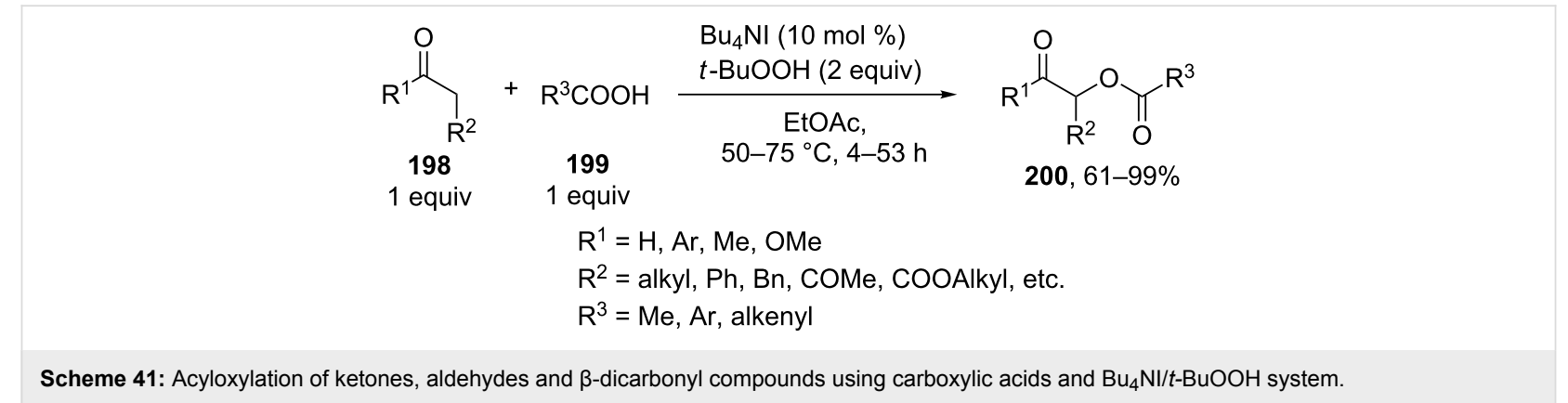


accomplished to prepare $\alpha$-acyloxy ketones 203 [196]. Coupling products $\mathbf{2 0 3}$ were synthesized mainly from benzyl alcohols and propiophenone (Scheme 42).

The authors proposed two radical reaction pathways, including the formation of C-radicals from ketones. One of these pathways involves the formation of tert-butyl peresters from alcohols. This pathway is confirmed by the fact that, in the presence of $\mathrm{Bu}_{4} \mathrm{NI}$, tert-butyl per(1-naphthylate) gives products $\mathbf{2 0 3}$ in the reaction with propiophenone.

\subsection{Oxidative systems based on transition metal compounds}

In addition to iodine compounds, transition metal salts, such as copper and manganese salts, were used for the oxidative functionalization at the $\alpha$-position of carbonyl compounds.

$\mathrm{N}$-Hydroxyimides and $\mathrm{N}$-hydroxyamides 204 are involved in the oxidative $\mathrm{C}-\mathrm{O}$ coupling with 1,3-dicarbonyl compounds and their hetero analogues, such as 2 -substituted malononitriles and cyanoacetic esters, $\mathbf{2 0 5}$ in the presence of oxidants based on manganese, cobalt, and cerium [197]. The best results were achieved with the use of $\mathrm{Mn}(\mathrm{OAc})_{3}$ and the $\mathrm{Co}(\mathrm{OAc})_{2 \text { (cat) }} /$ $\mathrm{KMnO}_{4}$ system (Scheme 43). The yields of products 206 were as high as $94 \%$. It is supposed that the oxidant serves two functions: the generation of $N$-oxyl radicals 207 from $N$-hydroxyimides or $N$-hydroxyamides 204 and the one-electron oxidation of 1,3-dicarbonyl compounds via the formation of complex 208 . Apparently, the oxidative coupling of 1,3-dicarbonyl compounds 209 with oximes 210 occurs via a similar mechanism
[198]. The reaction takes place in the presence of various oxidants, such as $\mathrm{KMnO}_{4}, \mathrm{Mn}(\mathrm{OAc})_{2} / \mathrm{KMnO}_{4}, \mathrm{Mn}(\mathrm{OAc})_{3}$, $\mathrm{MnO}_{2}, \mathrm{Mn}(\text { acac })_{3}, \mathrm{Fe}\left(\mathrm{ClO}_{4}\right)_{3}, \mathrm{Cu}\left(\mathrm{ClO}_{4}\right)_{2}, \mathrm{Cu}\left(\mathrm{NO}_{3}\right)_{2}$, and $\left(\mathrm{NH}_{4}\right)_{2} \mathrm{Ce}\left(\mathrm{NO}_{3}\right)_{6}$. Twenty coupling products 211 were prepared in yields of $27-92 \%$ using $\mathrm{KMnO}_{4}, \mathrm{Mn}(\mathrm{OAc})_{3} \cdot 2 \mathrm{H}_{2} \mathrm{O}$, or the $\mathrm{Mn}(\mathrm{OAc})_{2} / \mathrm{KMnO}_{4}$ system. The syntheses do not require excess amounts of reagents. The formation of $N$-oxyl radicals 212 and 207 from oximes and $N$-hydroxyimides was confirmed by ESR spectroscopy [197,198].

The oxidative coupling of 1,3-dicarbonyl compounds [199] and their hetero analogues [200] 213 with tert-butyl hydroperoxides catalyzed by transition metal salts $(\mathrm{Cu}, \mathrm{Fe}, \mathrm{Co}, \mathrm{Mn})$ was achieved. tert-Butyl hydroperoxide acts both as the oxidizing agent and the O-component in the coupling. The best results were obtained in the reaction catalyzed by $\mathrm{Cu}\left(\mathrm{ClO}_{4}\right)_{2} \cdot 6 \mathrm{H}_{2} \mathrm{O}$. It was hypothesized that copper serves for the formation of the reactive complex with 1,3-dicarbonyl compounds or their hetero analogues, as well as for the generation of tert-butyl peroxide radicals, which react with this complex to give coupling products 214 (Scheme 44).

The related peroxidation reactions with hydroperoxides $\left(t-\mathrm{BuOOH}, \mathrm{PhMe}_{2} \mathrm{COOH}\right)$ in the presence of transition metal salts (cobalt, manganese, or copper) were performed with cyclohexanone, 2-methylcyclohexanone, cyclohexene, 1-octene, cumene, xylene, dimethylaniline, and dioxane [201].

The enantioselective oxidative coupling of 2,6-dialkylphenyl- $\beta$ keto esters and thioesters 215 with tert-butyl hydroxycarbamate

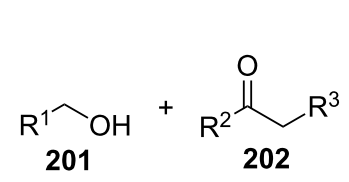

$\mathrm{R}^{1}=\mathrm{Ar}, \mathrm{CH}=\mathrm{CHPh}, \mathrm{iPr}$

$\mathrm{R}^{2}=\mathrm{Ph}, 4-\mathrm{BrC}_{6} \mathrm{H}_{4}$, 4-pyridyl, 2-thiophenyl, $\mathrm{CH}=\mathrm{CHPh}$, etc.

$\mathrm{R}^{3}=\mathrm{Me}$, Et, $n-\mathrm{Pr}$, etc.

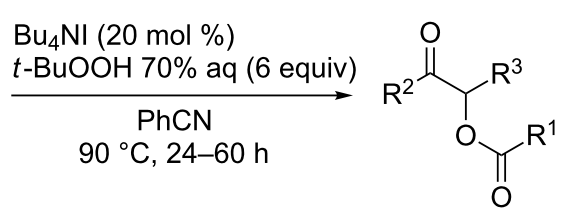

203, 33-90\%

Examples of synthesized products, yields

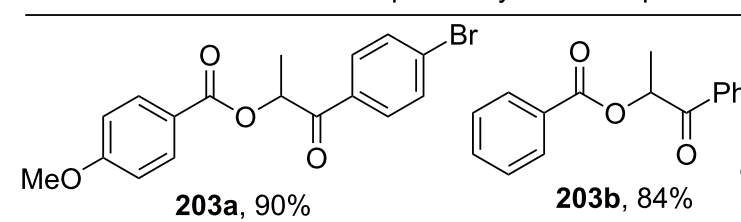<smiles>CC(C)(C)OC(=O)c1ccc([N+](=O)[O-])cc1</smiles><smiles>CC(C)C(=O)OC(C)C(=O)c1ccccc1</smiles>

203d, $48 \%$<smiles>CC(OC(=O)/C=C/c1ccccc1)C(=O)c1ccccc1</smiles>

203e, $51 \%$<smiles>COc1ccc(C(=O)OC2CCCCC2=O)cc1</smiles> 

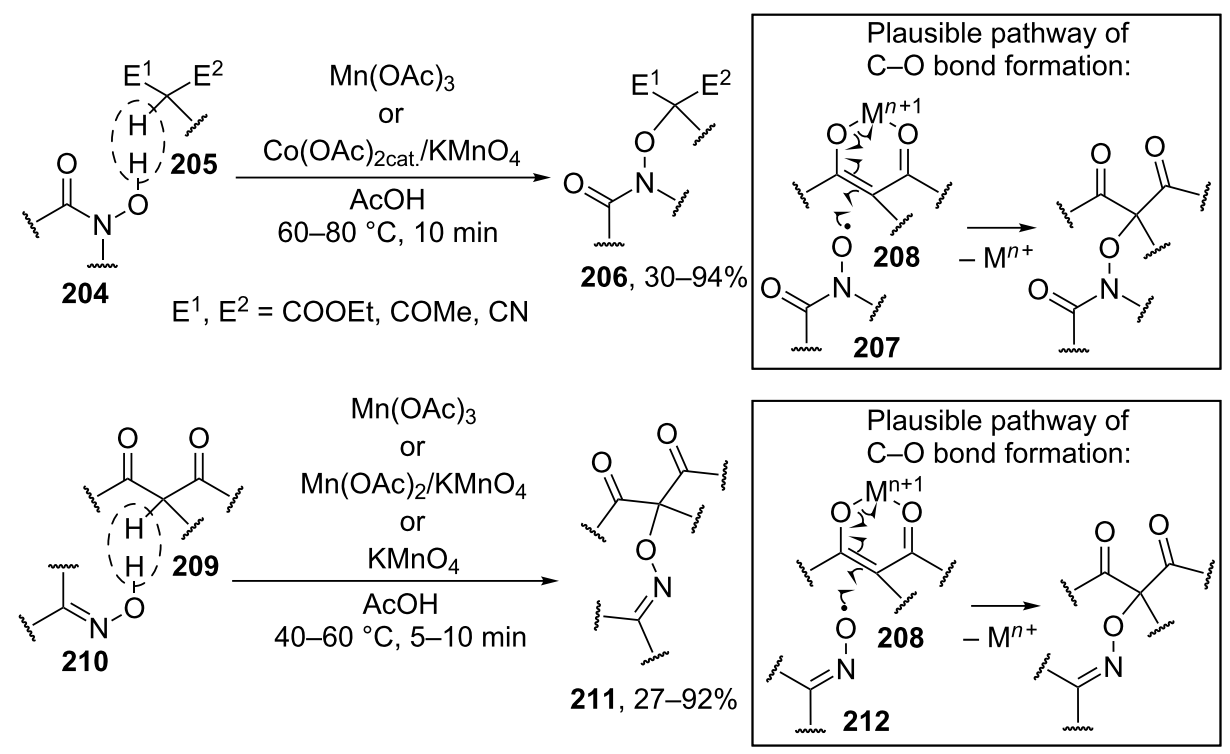

Scheme 43: Cross-dehydrogenative $\mathrm{C}-\mathrm{O}$ coupling of $\beta$-dicarbonyl compounds and their heteroanalogues with $\mathrm{N}$-hydroxyimides, $N$-hydroxyamides, and oximes.

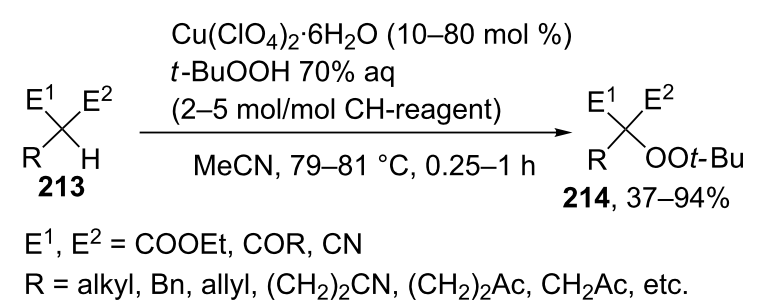

Scheme 44: Cross-dehydrogenative $C-O$ coupling of $\beta$-dicarbonyl compounds and their heteroanalogues with $t-\mathrm{BuOOH}$.

216 was performed using the $\mathrm{Cu}(\mathrm{OTf})_{2} /$ chiral ligand $217 / \mathrm{MnO}_{2}$ system (Scheme 45) [202]. Apparently, product 218 is generated via an ionic mechanism involving the generation of electrophilic nitrosocarbonyl intermediate 219 [202].
The improved version of that oxidative coupling method is based on $\mathrm{CuCl} / \mathrm{Cu}(\mathrm{OAc})_{2} /$ ligand/air catalytic system; different $\beta$-keto esters and hydroxamic acid derivatives can be used [203].

The acetoxylation at the $\alpha$-position of $\alpha, \beta$-unsaturated ketones with $\mathrm{Mn}(\mathrm{OAc})_{3}$ was studied in detail. It is suggested that manganese(III) acetate causes the generation of C-radicals from ketones followed by the acetoxylation of these radicals. In this reaction, $\mathrm{Mn}(\mathrm{OAc})_{3}$ [204-210] or acetic acid [209,210], which was used as the co-solvent, can serve as the source of the acetoxy group. The synthesis is usually performed in benzene. In some cases, the $\alpha$ '-phenylation- $\alpha$ '-acetoxylation was observed due, apparently, to the addition of the C-radical generated from ketone to benzene [204]. It was shown [209] that the
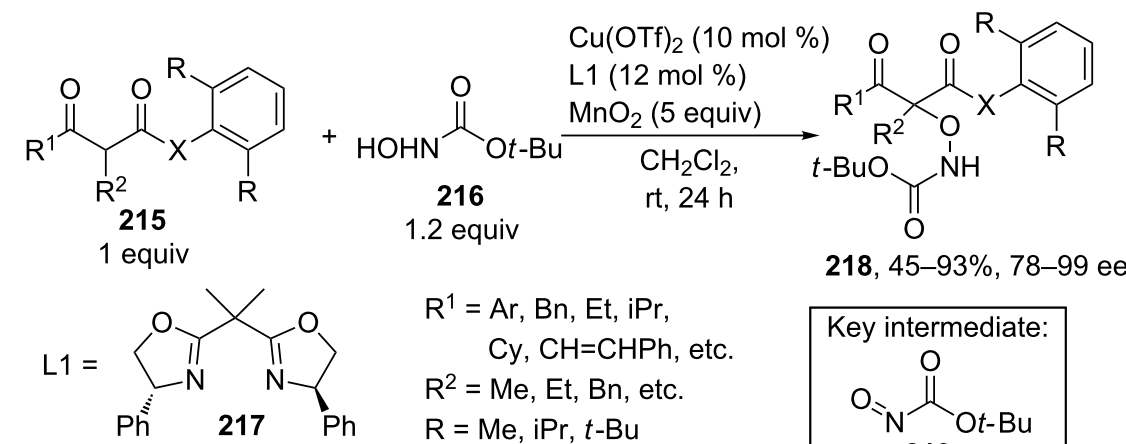

$\mathrm{R}^{1}=\mathrm{Ar}, \mathrm{Bn}, \mathrm{Et}, \mathrm{iPr}$, $\mathrm{Cy}, \mathrm{CH}=\mathrm{CHPh}$, etc. $\mathrm{R}^{2}=\mathrm{Me}, \mathrm{Et}, \mathrm{Bn}$, etc. $\mathrm{R}=\mathrm{Me}, \mathrm{iPr}, t-\mathrm{Bu}$ $\mathrm{X}=\mathrm{O}, \mathrm{S}$

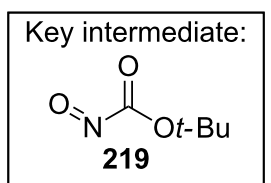


$\alpha$-acetoxylation of enones occurs with good selectivity in other solvents, such as cyclohexane and acetonitrile, as well.

The acyloxylation of enones and aryl ketones 220 with carboxylic acids occurs in benzene in the presence of $\mathrm{KMnO}_{4}$ to form coupling products 221 (Scheme 46) [211]. Acids were present in a large excess relative to ketones.

The synthesis was successfully accomplished, in particular, with readily oxidizable formic acid; the corresponding formates (for example, 221b) were obtained in $61-85 \%$ yield [211]. This method was modified by using not carboxylic acids but their mixtures with the corresponding anhydrides and was applied to the $\alpha^{\prime}$-acyloxylation of $\alpha, \beta$-unsaturated ketones with complex structures with the aim of preparing analogues of natural compounds [212].

\section{Compounds with an allyl, propargyl, or benzyl group as C-reagents in cross-dehy- drogenative $\mathrm{C}-\mathrm{O}$ coupling}

4.1 Palladium- and copper-based oxidative systems Studies on the acyloxylation at the allylic position of alkenes with palladium(II) complexes started in the 1960s [213]. This type of reactions was considered in more detail in reviews on the palladium complex-catalyzed functionalization of allylcontaining compounds [20,21].

It is suggested that the reaction proceeds through the cleavage of the allylic $\mathrm{C}-\mathrm{H}$ bond in $\mathbf{2 2 2}$ to form $\pi$-allyl-palladium complex 223 followed by the nucleophilic attack of acetate to give C-O coupling product 224a (Scheme 47) [214-217]. The alternative mechanism involves the acetoxypalladation of the double bond in $\mathbf{2 2 2}$ resulting in the formation of intermediate $\mathbf{2 2 5}$ fol-

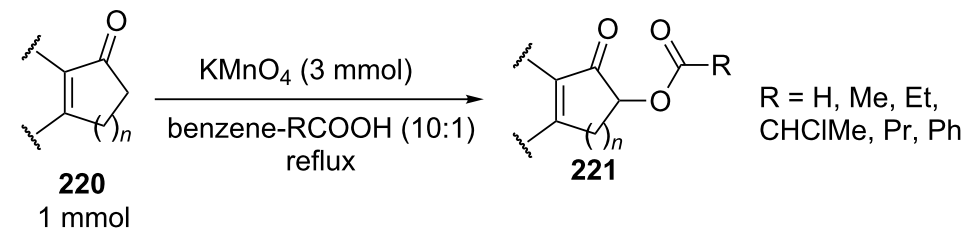

Examples of synthesized products, yields

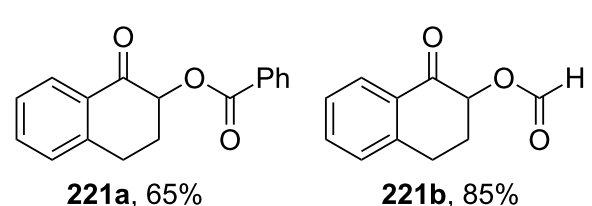<smiles>CC(=O)OC1CCc2ccccc2C1=O</smiles>

221d, $89 \%$<smiles>COC1=CC(=O)C(OC(C)=O)CC1</smiles>

221g, $97 \%$<smiles>CC(Cl)C(=O)OC1CCc2ccccc2C1=O</smiles>

221c, $91 \%$<smiles>CCCNC(=O)OC1C(=O)C=C(C)CC1(C)C</smiles>

221h, $82 \%$

Scheme 46: $\alpha^{\prime}$-Acyloxylation of $\alpha, \beta$-unsaturated ketones using $\mathrm{KMnO}_{4}$.

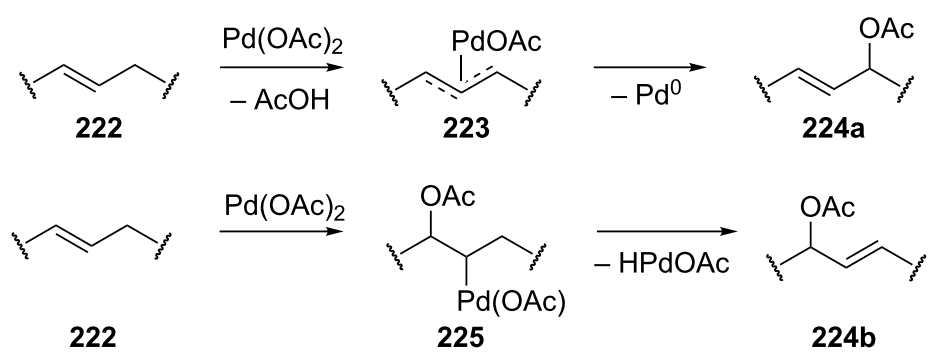


lowed by the elimination of HPdOAc to give product 224b [213]. The first mechanism of the acetoxylation was confirmed by the data on the acetoxylation of 1,2-dideuteriocyclohexene [215], as well as by the detection of the $\pi$-allyl-palladium intermediate [217]. However, it cannot be ruled out that the acetoxylation can occur via the second mechanism under certain conditions (Scheme 47) [21,213].

The palladium-complex-catalyzed acetoxylation of terminal alkenes $\mathbf{2 2 6}$ under non-optimized conditions can afford a large number of products: vinyl acetate $\mathbf{2 2 7}$ and methyl ketone $\mathbf{2 2 8}$ (Wacker reaction), $E$ and $Z$ isomers of linear allyl ethers 229 and 230, and branched allyl ether 231 (Scheme 48) [218].

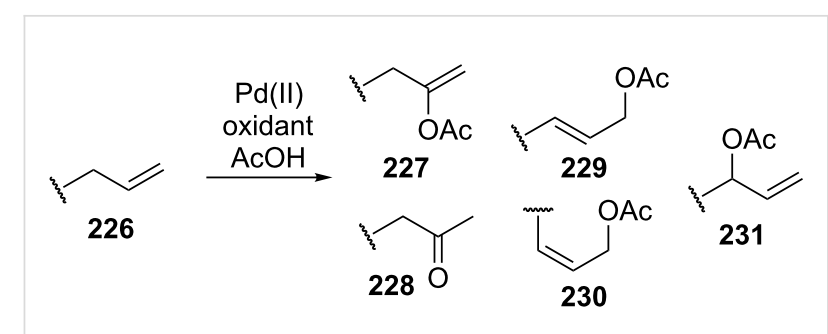

Scheme 48: Products of the oxidation of terminal alkenes by $\mathrm{Pd}(\mathrm{II}) /$ $\mathrm{AcOH} /$ oxidant system.

It was found that the selectivity of the reaction can be controlled by changing the polarity of the solvent. The reactions of terminal alkens with the $\mathrm{Pd}(\mathrm{OAc})_{2}$ /benzoquinone system in a mixture of DMSO and $\mathrm{AcOH}$ as the solvent selectively produced linear $E$-allyl acetates in $50-65 \%$ yield [218]. The reaction in acetic acid affords methyl ketone and vinyl acetate; branched allyl ether is formed as the major product in the $\mathrm{CH}_{2} \mathrm{Cl}_{2} / \mathrm{AcOH}$ system using the 1,2-bis (benzylsulfinyl)ethane ligand [218].

The acyloxylation of terminal alkenes $\mathbf{2 3 2}$ with carboxylic acids 233 in the presence of 1,4-benzoquinone (BQ) as the oxidant, vinyl phenyl sulfoxide ligand $\mathbf{2 3 4}$, and $\mathrm{Pd}(\mathrm{OAc})_{2}$ resulted in the selective formation of branched allyl esters 235 [217]. This reaction afforded linear esters $\mathbf{2 3 6}$ as byproducts. Apparently, ligand 234 serves for the formation of the $\pi$-allyl-palladium intermediate, and benzoquinone mediates the subsequent reductive elimination to give product $\mathbf{2 3 5}$ (Scheme 49) [217].

The $\mathrm{Pd}(\mathrm{OAc})_{2} \cdot[1,2$-bis(phenylsulfinyl)ethane]-catalyzed enantioselective acetoxylation of terminal alkenes was accomplished in the presence of a chiral Lewis acid; ee $=45-63 \%$; the reaction was performed with a small excess of $\mathrm{AcOH}$ (1.1 equiv) in ethyl acetate using benzoquinone as the oxidant [219].

The $\mathrm{Pd}(\mathrm{OAc})_{2}$-catalyzed acetoxylation of terminal alkenes employing 4,5-diazafluorenone as the ligand can be performed in the presence of oxygen as the oxidizing agent (1 atm). The reaction gave linear allyl esters. The authors reported that this ligand facilitates the reductive elimination of the allyl ester from the $\pi$-allyl-palladium intermediate [220]. Linear $E$-allyl acetates were synthesized also by the acetoxylation of terminal alkenes with the $\mathrm{PdCl} 2 / \mathrm{NaOAc} / \mathrm{AcOH} / \mathrm{O}_{2}$ system (5 atm) in $N, N$ dimethylacetamide [221]. The Wacker reaction giving methyl ketones occurs when using water instead of sodium acetate and acetic acid, all other conditions being the same [221].

The coupling of terminal alkenes 237 with carboxylic acids having complex structures $\mathbf{2 3 8}$ resulted in the selective formation of linear $E$-allyl esters 239 (Scheme 50) [222]. These reactions afford a $Z$ isomer of linear ester and branched allyl ester as byproducts.

Similar results were obtained in the coupling of terminal alkenes in the presence of lithium hydroxide as the base in carboxylic acid acting as the $\mathrm{OH}$-reagent or in a carboxylic acid/acetonitrile mixture; the coupling was performed with acetic, propionic, isobutyric, and pivalic acids [223].

$$
\begin{aligned}
& \mathrm{R}^{1}=n-\mathrm{C}_{8} \mathrm{H}_{17},\left(\mathrm{CH}_{2}\right)_{2} \mathrm{OBn}_{(}\left(\mathrm{CH}_{2}\right)_{3} \mathrm{CONEt}_{2},\left(\mathrm{CH}_{2}\right)_{2} \mathrm{CH}=\mathrm{CMe}_{2} \text {, etc. } \\
& \mathrm{R}^{2}=\mathrm{Me}, 4-\mathrm{BrC}_{6} \mathrm{H}_{4}, 4-\mathrm{NO}_{2}-\mathrm{C}_{6} \mathrm{H}_{4}, 4-\mathrm{MeOC}_{6} \mathrm{H}_{4}, \mathrm{iPr}^{232}
\end{aligned}
$$




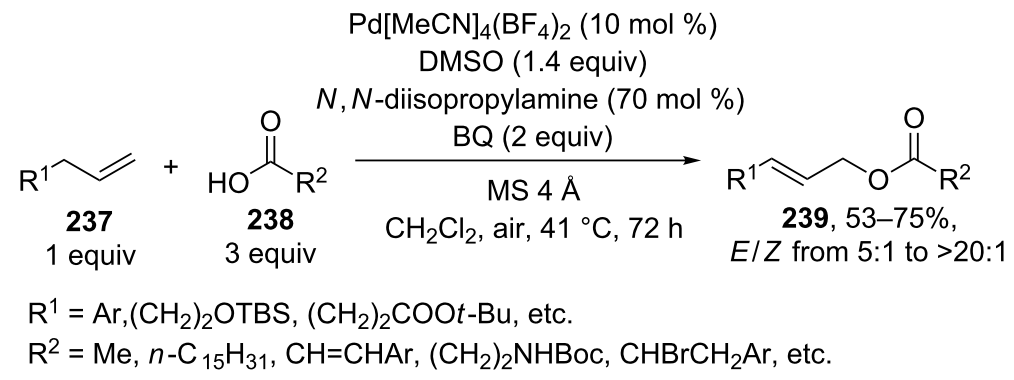

Scheme 50: Synthesis of linear E-allyl esters by cross-dehydrogenative coupling of terminal alkenes wih carboxylic acids.

It was shown that the stereoselectivity of the $\mathrm{Pd}(\mathrm{OAc})_{2}$ catalyzed acetoxylation of $Z$-vinyl(triethylsilanes) $\mathbf{2 4 0}$ can be controlled using benzoquinone or (diacetoxyiodo)benzene as the oxidant [224]. The reaction with benzoquinone affords the $E$ isomer of $\mathrm{C}-\mathrm{O}$ coupling product $\mathbf{2 4 1}$, whereas $Z$ isomer $\mathbf{2 4 2}$ is formed as the major product in the case of (diacetoxyiodo)benzene (Scheme 51).

The $\alpha$-acetoxylation of $\alpha$-acetoxyalkenes 243 with copper(II) chloride in acetic acid was reported [225] (Scheme 52). Alkenes free of the $\alpha$-acetoxy group undergo trans-chlorination of the double bond in the presence of $\mathrm{CuCl}_{2} \cdot \alpha, \alpha$-Diacetoxyalkenes 244 were synthesized from alkenes with the additional use of the $\mathrm{PdCl}_{2} / \mathrm{NaOAc} / \mathrm{DDQ}$ or $\mathrm{Pd}(\mathrm{OAc})_{2} /$ benzoquinone/ $\mathrm{MnO}_{2}$ reagents.

The oxidative acyloxylation at the allylic position of alkenes and at the benzylic position of some alkylarenes 245 with carboxylic acids $\mathbf{2 4 6}$ was accomplished in the presence of tertbutyl hydroperoxide and mixed copper aluminum oxide as the heterogeneous catalyst (Scheme 53) [226]. The catalyst was prepared from $\mathrm{CuCl}_{2}$ and $\mathrm{AlCl}_{3} \cdot 6 \mathrm{H}_{2} \mathrm{O}$ by the co-precipitation from an aqueous solution in the presence of $\mathrm{NaOH}$ and $\mathrm{Na}_{2} \mathrm{CO}_{3}$. Allyl esters 247 with various structures were synthesized. The reactions were carried out taking alkene and carboxylic acid in a ratio of $1: 1$ or in the presence of an excess of alkene.

The intermolecular alkoxylation of methylheterocyclic compounds 248, 249 using the $\mathrm{CuBr} / 5,6$-dimethyl-1,10-phenanthroline $\left(5,6-\mathrm{Me}_{2}\right.$ phen $) /(t-\mathrm{BuO})_{2}$ oxidative system was shown by a few examples [227]. The yields of coupling products 250, 251 were not higher than $37 \%$ (Scheme 54).

Methylarenes 252 were introduced into the oxidative $\mathrm{C}-\mathrm{O}$ coupling with $\beta$-dicarbonyl compounds 253 and phenols 254 [228]. The coupling afforded structures 255 and $\mathbf{2 5 6}$. The method is applicable to phenols containing an aldehyde group, which was not oxidized in the course of the reaction (Scheme 55).

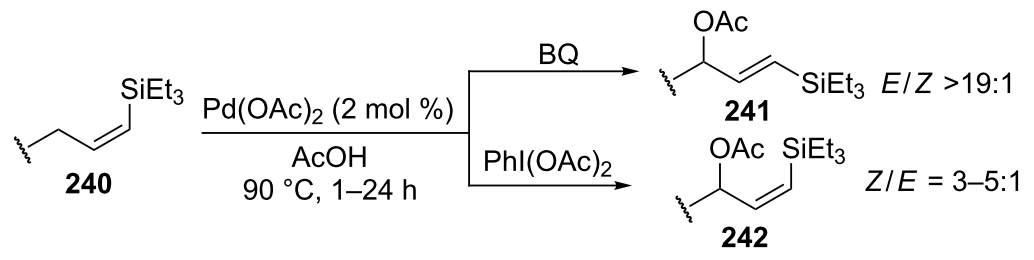

Scheme 51: $\mathrm{Pd}(\mathrm{OAc})_{2}$-catalyzed acetoxylation of Z-vinyl(triethylsilanes).

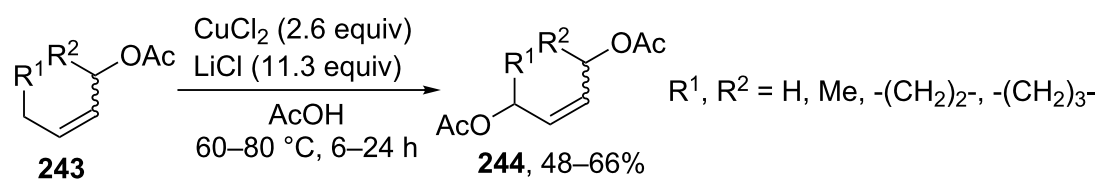



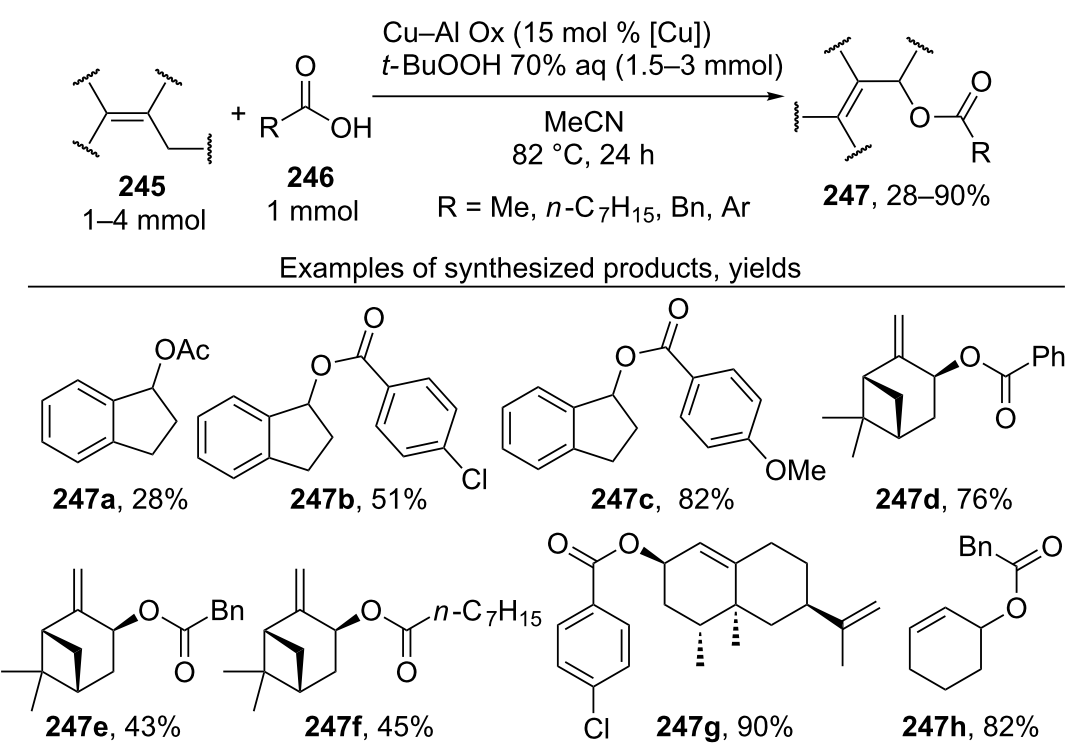

Scheme 53: Oxidative acyloxylation at the allylic position of alkenes and at the benzylic position of alkylarenes with carboxylic acids.

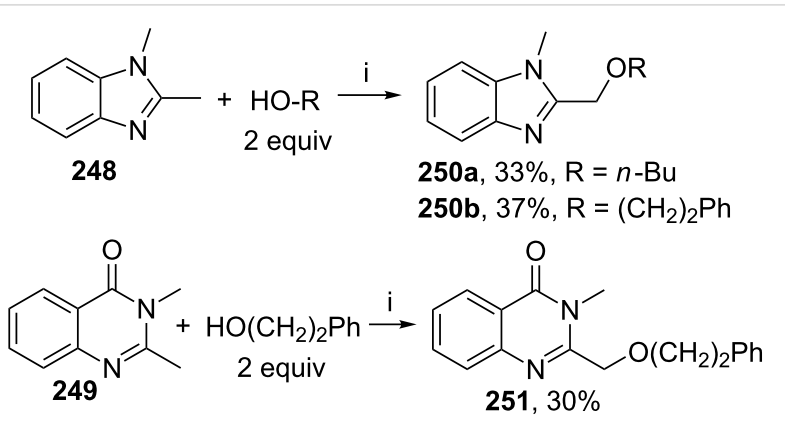

i: $\mathrm{CuBr}(20 \mathrm{~mol} \%), 5,6-\mathrm{Me}_{2}$ phen $(24 \mathrm{~mol} \%)$, $(t-B u O))_{2}$ (4 equiv), $\mathrm{PhCl}, 100^{\circ} \mathrm{C}, 3 \mathrm{~h}$

Scheme 54: Copper-catalyzed alkoxylation of methylheterocyclic compounds using di-tert-butylperoxide as oxidant.
Oxidative $\mathrm{C}-\mathrm{O}$ coupling of methylarenes 257 with cyclic ethers 258 and cycloalkanes 259 afforded $\alpha$-acyloxy ethers 260 and allyl esters 261, respectively. The reactions were accomplished using the $\mathrm{Cu}(\mathrm{OAc})_{2} / t$ - $\mathrm{BuOOH}$ oxidative system at low conversions of methylarenes in the corresponding ether or cycloalkane as solvent [229] (Scheme 56).

The proposed mechanism includes the copper-mediated generation of tert-butyl peresters from $t$-BuOOH and methylarenes and the formation of final products via intermolecular coupling of O-centered and C-centered radicals. Related oxidative $\mathrm{C}-\mathrm{O}$ coupling reactions of alkanes with aromatic aldehydes [169] and carboxylic acids are discussed in sections 2.5 and 6 , respectively.

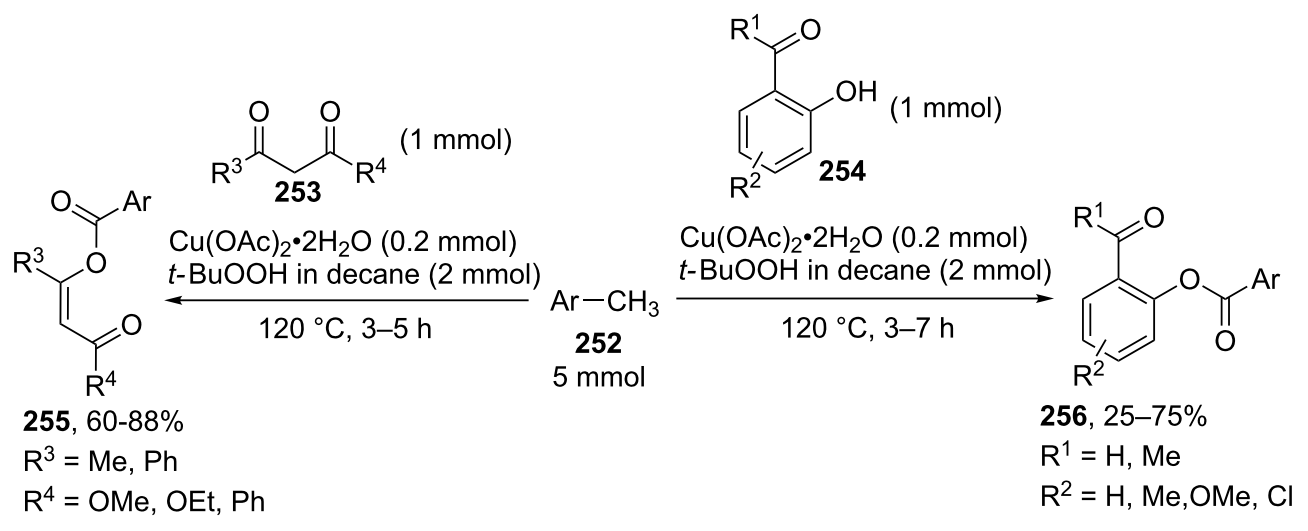




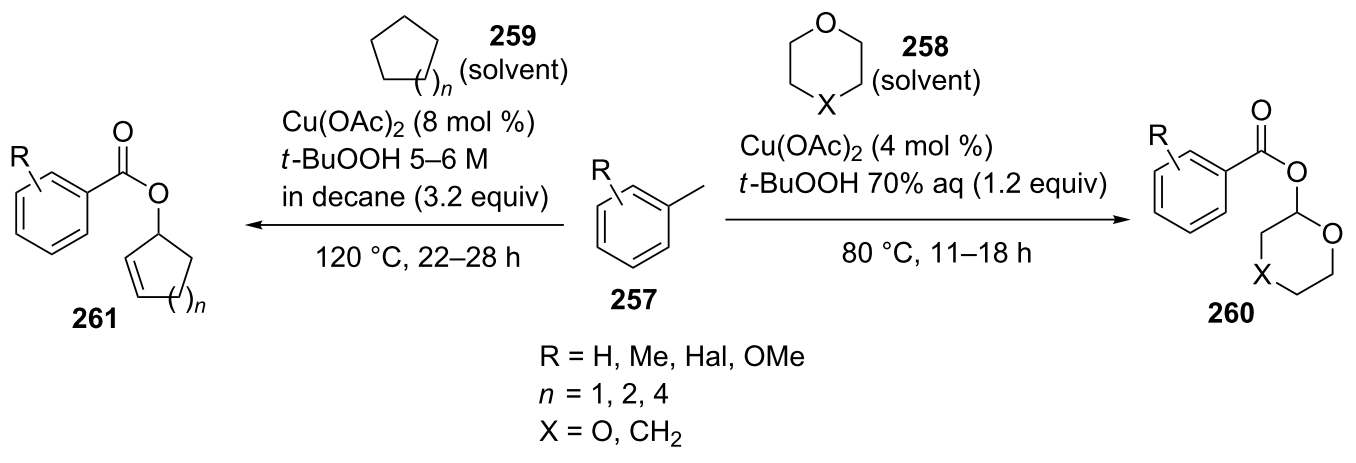

Scheme 56: Copper-catalyzed esterification of methylbenzenes with cyclic ethers and cycloalkanes.

The 4-methyl group of 2,4,6-trimethylphenol was selectively methoxylated in methanol in the presence of a copper(II) complex and hydrogen peroxide [230]; the similar alkoxylation reaction was performed with a stoichiometric amount of copper(II) chloride [231].

The benzylation of aryl-, alkyl-, and cycloalkylcarboxylic acids 262 in toluene was accomplished in the presence of the $\mathrm{Pd}(\mathrm{OAc})_{2} / \mathrm{CF}_{3} \mathrm{SO}_{3} \mathrm{H} /$ dimethylacetamide/O $\mathrm{O}_{2}$ system (Scheme 57) [232]. Apparently, the reaction proceeds through an ionic mechanism involving the cleavage of the $\mathrm{C}-\mathrm{H}$ bond of toluene with $\mathrm{Pd}(\mathrm{II})$. The product is formed either via the nucleophilic attack of carboxylic acid on Pd(II) complex 264 or as a result of the reductive elimination of product $\mathbf{2 6 3}$ from complex 265. It is supposed that dimethylacetamide promotes the reoxidation of $\mathrm{Pd}(0)$ to $\mathrm{Pd}(\mathrm{II})$ with oxygen and suppresses the aggregation of $\operatorname{Pd}(0)$, while trifluoromethanesulfonic acid facilitates the cleavage of the $\mathrm{C}-\mathrm{H}$ bond of toluene through the formation of cationic $\mathrm{Pd}(\mathrm{II})$ compounds [232].
The gas-phase aerobic acetoxylation of toluene with acetic acid catalyzed by $\mathrm{TiO}_{2-}, \gamma-\mathrm{Al}_{2} \mathrm{O}_{3}-, \mathrm{SiO}_{2-}$, and $\mathrm{ZrO}_{2}$-supported $\mathrm{Pd}-\mathrm{Sb}$ particles was also reported [233-236].

\subsection{Reactions catalyzed by tetrabutylammonium iodide}

The oxidative acyloxylation at the allylic position of alkenes 266 with carboxylic acids 267 was performed using the $\mathrm{Bu}_{4} \mathrm{NI} /$ $t$-BuOOH system to prepare esters 268 [237]. Apparently, the reaction proceeds through a radical mechanism, involving the hydrogen atom abstraction from the allylic position of alkene 266 with the tert-butyl peroxyl or tert-butoxyl radical; the authors suggested that the new $\mathrm{C}-\mathrm{O}$ bond is formed as a result of the cross-recombination of the allyl and carboxyl radicals (Scheme 58) [237].

The coupling of carboxylic acids $\mathbf{2 6 9}$ with alkylarenes $\mathbf{2 7 0}$ occurs analogously to the coupling with alkenes (Scheme 59) $[141,237]$. It is supposed that $\left[\mathrm{Bu}_{4} \mathrm{~N}\right]^{+} \mathrm{IO}^{-}$or $\left[\mathrm{Bu}_{4} \mathrm{~N}\right]^{+}\left[\mathrm{IO}_{2}\right]^{-}$

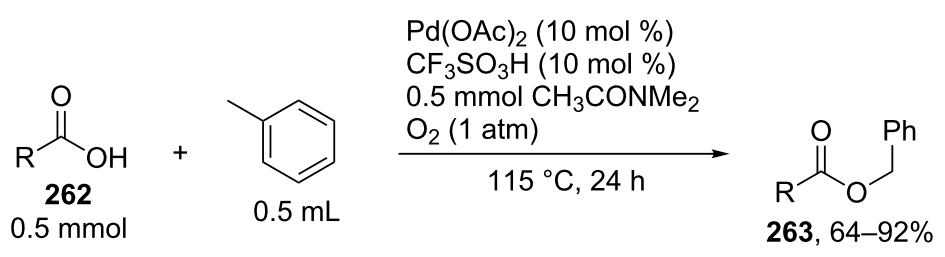

$\mathrm{R}=$ aryl, $\mathrm{PhCH}=\mathrm{CH}, 4-\mathrm{F}-\mathrm{C}_{6} \mathrm{H}_{4} \mathrm{CH}_{2}, n-\mathrm{C}_{7} \mathrm{H}_{15}$, cyclopropyl, $\mathrm{Cy}$

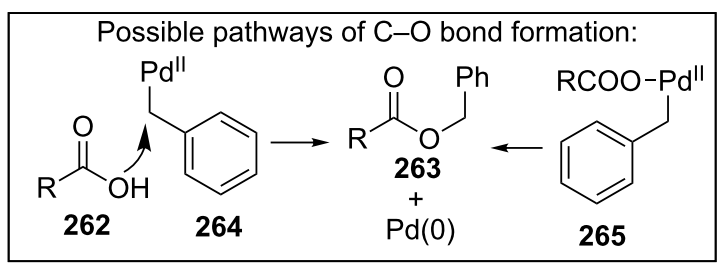




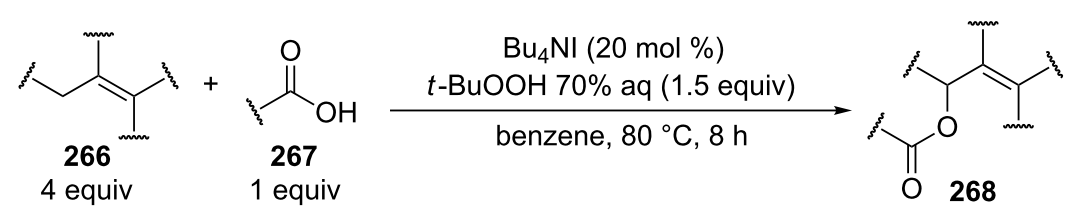

Examples of synthesized products, yields

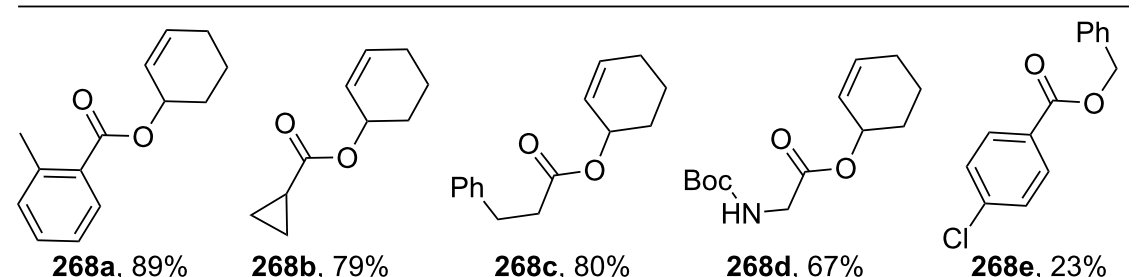<smiles>[R6]c1ccc(C(=C(C)COC(=O)c2ccc(C(=O)OCC=C3CCCCC3)cc2)c2ccc(Cl)cc2)cc1</smiles>

Scheme 58: Oxidative acyloxylation at the allylic position of alkenes with carboxylic acids using the $\mathrm{Bu}_{4} \mathrm{NI} / t-\mathrm{BuOOH}$ system.

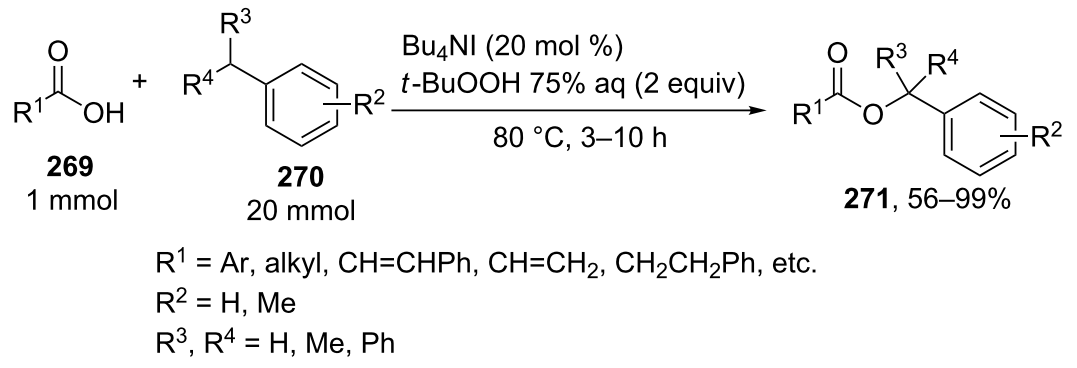

Scheme 59: Cross-dehydrogenative $\mathrm{C}-\mathrm{O}$ coupling of carboxylic acids with alkylarenes using the $\mathrm{Bu}_{4} \mathrm{NI} / t-\mathrm{BuOOH}$ system

generated in the $\mathrm{Bu}_{4} \mathrm{NI} / t-\mathrm{BuOOH}$ system act as active oxidizing agents; the fact that the reaction proceeds via the hydrogen atom abstraction from the benzylic position to form the benzyl radical is confirmed by a number of experiments, including the trapping of the benzyl radical by the TEMPO radical [141]. The authors hypothesized that the benzyl radical is oxidized to the benzyl cation, which undergoes nucleophilic attack by the carboxylate anion to give cross-dehydrogenative $\mathrm{C}-\mathrm{O}$ coupling product 271. It was shown that 1-iodo-1-phenylethane does not react with carboxylic acid under these reaction conditions [141].

The oxidative $\mathrm{C}-\mathrm{O}$ coupling of alkylarenes with aromatic benzyl alcohols [140] and aldehydes [142] in the presence of the $\mathrm{Bu}_{4} \mathrm{NI} / t$ - $\mathrm{BuOOH}$ system is considered in section 2.4 (Scheme 27 and Scheme 28).

The synthesis of symmetrical esters from methylarenes and of unsymmetrical esters 274 from methylarenes 272 and ethylarenes 273 in the presence of the $\mathrm{Bu}_{4} \mathrm{NI} / t-\mathrm{BuOOH}$ system was documented (Scheme 60). The reaction was accomplished at low conversions of alkylarenes [238]. It was suggested that methylarene is oxidized to carboxylic acid and reacts with the benzylic carbocation generated from the second methylarene molecule or from ethylarene through the hydrogen atom abstraction followed by the oxidation.

The achievement of the cited study is that the authors succeeded in performing the selective oxidative $\mathrm{C}-\mathrm{O}$ cross-coupling of methylarenes 272 with ethylarenes 273 and excluded side processes, in which symmetrical esters could be generated from methylarenes $\mathbf{2 7 2}$ (the formation of only small amounts of symmetrical esters was observed; $2-5 \%$ yield), as well as the oxidation of ethylarene $\mathbf{2 7 3}$ to aryl methyl ketone.

Phosphorylation of benzyl C-H bonds of alkylarenes 275 using the $\mathrm{Bu}_{4} \mathrm{NI} / t$ - $\mathrm{BuOOH}$ oxidative system was documented to afford products 277 (Scheme 61) [239]. In this process two 


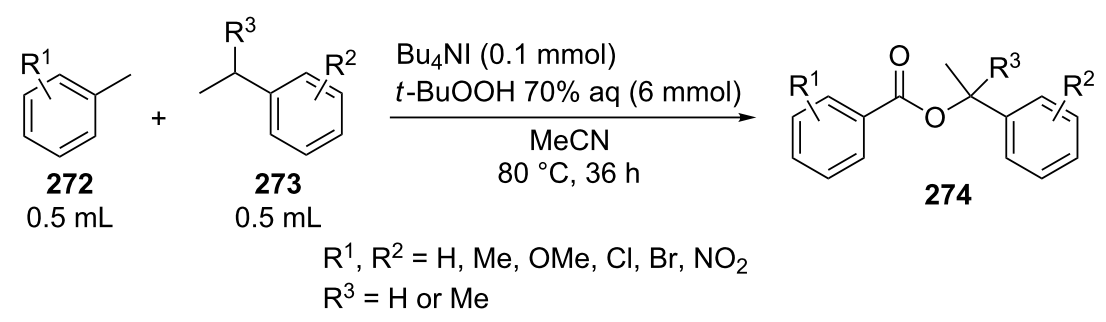

Scheme 60: Oxidative C-O cross-coupling of methylarenes with ethyl or isopropylarenes.

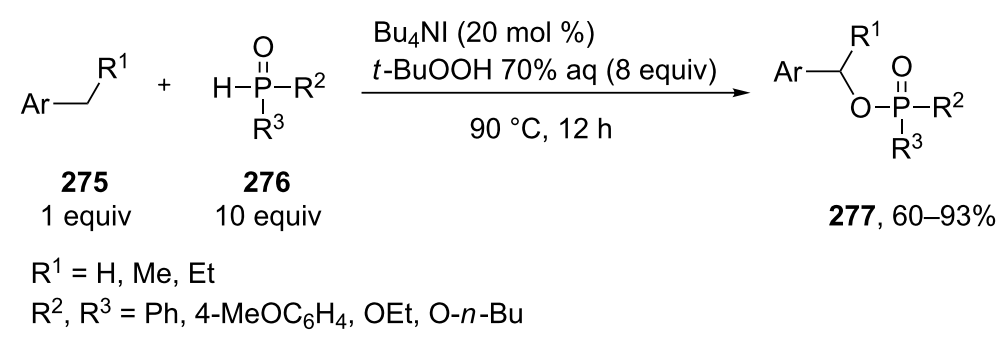

Scheme 61: Phosphorylation of benzyl C-H bonds using the $\mathrm{Bu}_{4} \mathrm{NI} / t-\mathrm{BuOOH}$ oxidative system.

bonds $(\mathrm{C}-\mathrm{H}$ and $\mathrm{P}-\mathrm{H})$ are cleaved and two new bonds $(\mathrm{C}-\mathrm{O}$ and $\mathrm{P}-\mathrm{O}$ ) are formed. The proposed mechanism includes benzyl radical formation, oxidation of the latter to the benzylic cation, and nucleophilic attack of phosphate which is formed by the oxidation of the $\mathrm{P}-\mathrm{H}$ bond in $\mathbf{2 7 6}$.

2,3-Disubstituted indoles $\mathbf{2 7 8}$ are acetoxylated in the presence of the $\mathrm{Bu}_{4} \mathrm{NI} / \mathrm{PhI}(\mathrm{OAc})_{2}$ system in a $\mathrm{CH}_{2} \mathrm{Cl}_{2} / \mathrm{AcOH}$ solvent mixture. In most cases, the reaction resulted in the regioselective introduction of the acetoxy group at one of the two possible positions resulting in the formation of product $\mathbf{2 7 9}$ or $\mathbf{2 8 0}$ (Scheme 62) [240].

The authors supposed that indoles undergo iodination (as exemplified by indoles 278a,b) with AcOI, which is generated from $\mathrm{PhI}(\mathrm{OAc})_{2}$ and the iodide anion, through the formation of intermediates 281a,b to give one of the two allyl iodides (282a or 282b); the nucleophilic attack of acetic acid or the acetate anion ( $\mathrm{S}_{\mathrm{N}}$ ' nucleophilic substitution) affords products $280 \mathrm{a}$ or $279 \mathbf{a}$.

\subsection{Reactions using 2,3-dichloro-5,6-dicyano-1,4- benzoquinone (DDQ)}

The common feature of the cross-dehydrogenative $\mathrm{C}-\mathrm{O}$ coupling reactions that take place in the presence of DDQ is that C-reagents should contain conjugated systems without strong electron-withdrawing groups.
For example, the acetoxylation of alkylarenes $\mathbf{2 8 3}$ with DDQ in acetic acid under ultrasound irradiation produced acetates 284 (Scheme 63) [241].

The ultrasound irradiation results in a considerable increase in the selectivity of the reaction. The proposed mechanism involves the generation of acetoxyl radicals and DDQ-H radicals in the reaction of DDQ with acetic acid, and the latter radicals abstract a hydrogen atom from the benzylic position of alkylarene. The target product is formed as a result of the recombination of benzyl and acetoxyl radicals. The reactions with methylarenes were not performed; alkylarenes containing electron-withdrawing substituents $\left(\mathrm{Br}, \mathrm{NO}_{2}\right)$ were not involved in the oxidative coupling.

The oxidative coupling of diarylmethanes 285 with carboxylic acids 286 takes place in the presence of the $D^{2} Q_{\text {cat }} / \mathrm{MnO}_{2}$ system (Scheme 64) [242]. It is suggested that DDQ oxidizes diarylmethanes to diarylmethyl cations, which react with carboxylic acids to form esters 287. Manganese dioxide serves for the oxidation of the reduced form of the catalyst $\mathrm{DDQH}_{2}$ to DDQ. The drawback of this method is that the reaction center of the C-component should contain two aryl groups and that a fourfold excess of carboxylic acids (O-components) is required. In the cited study, it was also reported that the coupling of carboxylic acids $\mathbf{2 8 9}$ with 3-phenyl-2-propen-1-yl acetate (288) 
<smiles>Cn1c2c(c3ccccc31)CC[IH]C2</smiles>

278
$\mathrm{Bu}_{4} \mathrm{NI}(0.2$ equiv)

$\mathrm{Phl}(\mathrm{OAc})_{2}$ (1.5 equiv)

$\mathrm{CH}_{2} \mathrm{Cl}_{2} / \mathrm{AcOH} 1: 1$

$0{ }^{\circ} \mathrm{C}, 2 \mathrm{~h}$

Examples of synthesized products, yields

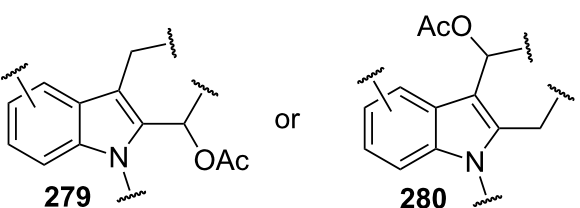

280 in<smiles></smiles>

Ts

279a, $79 \%$<smiles>CC(=O)OC1CCCc2c1[nH]c1ccc(Cl)cc21</smiles>

279b, $85 \%$<smiles>COc1ccc2[nH]c3c(c2c1)CCCC3OC(C)=O</smiles>

279c, $78 \%$<smiles></smiles>

280a, $61 \%$<smiles>CC(=O)OC1CCCc2c1[nH]c1ccccc21</smiles>

279d, $49 \%$<smiles>CC(=O)OC1CCCCc2c1[nH]c1ccccc21</smiles>

279f, $68 \%$<smiles>CC(=O)OC1CCC(=O)n2c1c(Cc1ccccc1)c1ccccc12</smiles>

$279 e, 80 \%$

Proposed mechanism of the coupling

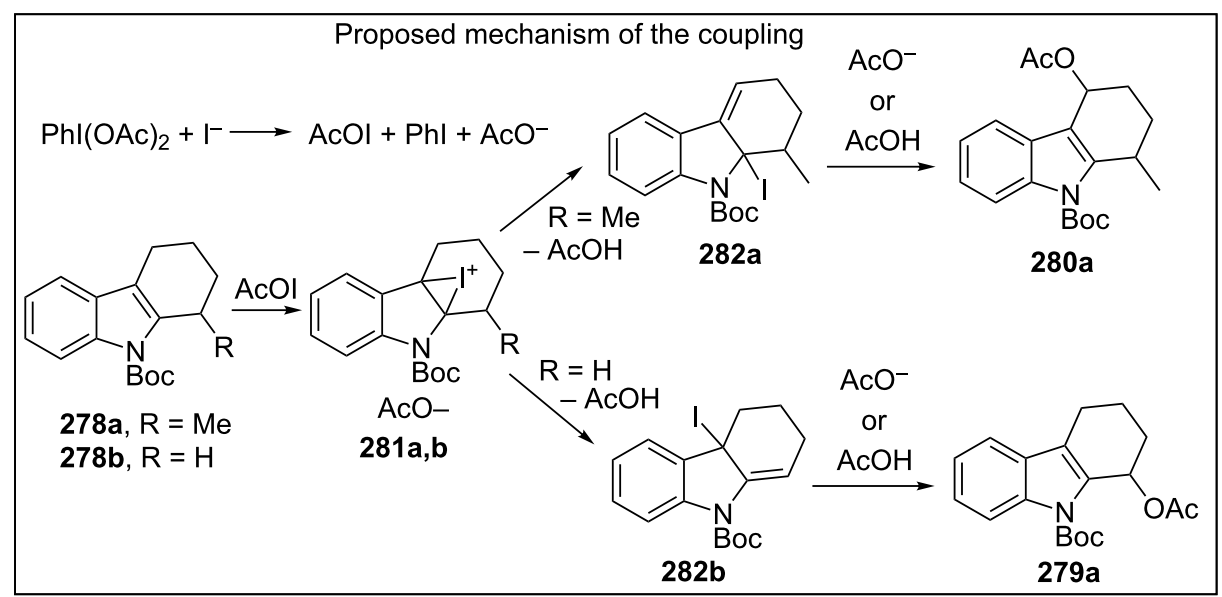

Scheme 62: Selective C-H acetoxylation of 2,3-disubstituted indoles.

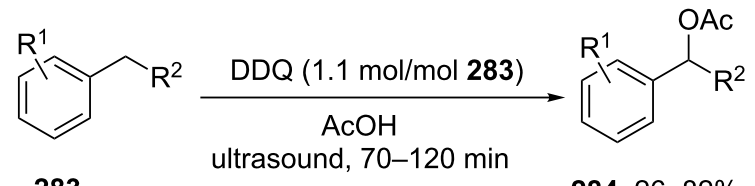

283

284, 26-82\%

$\mathrm{R}^{1}=-\mathrm{H},-\mathrm{OMe},-\mathrm{OCH}_{2} \mathrm{O}-, \mathrm{OH}$

$\mathrm{R}^{2}=\mathrm{Me}, \mathrm{Et}, \mathrm{Bu}, \mathrm{Bn}, \mathrm{CH}=\mathrm{CH}_{2}$

Scheme 63: Acetoxylation of benzylic position of alkylarenes using $\mathrm{DDQ}$ as oxidant.

in the presence of DDQ gives allyl esters 290. DDQ was used also for the acyloxylation at the benzylic position of dimethoxyarene $\mathbf{2 9 1}$ with carboxylic acids $\mathbf{2 9 2}$ to prepare esters $\mathbf{2 9 3}$ (Scheme 64) [243].

The benzylic position of $\beta$-phenylethylbenzamides was acetoxylated with DDQ in acetic acid at $80{ }^{\circ} \mathrm{C}$; the reaction readily proceeds if the phenyl ring contains activating methoxy groups; in the case of unsubstituted $\beta$-phenylethylbenzamide, the conversion was incomplete [244]. ( $p$-Isopropoxyphenyl)acetic acid esters were stereoselectively acetoxylated with DDQ despite the presence of an electron-withdrawing ester group in the vicinity of the reaction center [245].

The oxidative $\mathrm{C}-\mathrm{O}$ coupling of 1,3-diarylpropylenes 294 with alcohols 295 was accomplished in the presence of DDQ [246]; the reaction was completed at room temperature in a period of time shorter than one hour; a mixture of two isomeric coupling products 296 was obtained in the case of different substituents $\mathrm{R}^{1}$ and $\mathrm{R}^{2}$. Under similar conditions, the oxidative coupling of 1,3-diarylpropynes 297 with alcohols, phenols, and carboxylic acids 298 afforded coupling products 299 (Scheme 65) [247]. 


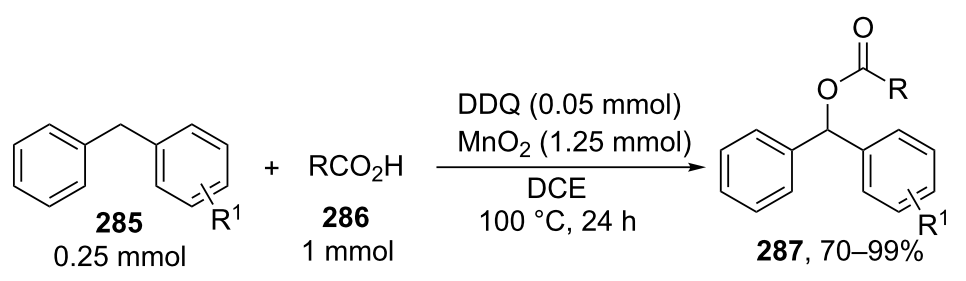

$\mathrm{R}=$ alkyl, $\mathrm{Ar}, \mathrm{CH}=\mathrm{CH}_{2}, \mathrm{Bn}, 1$-bromopropyl

$\mathrm{R}^{1}=\mathrm{H}, \mathrm{OMe}, \mathrm{Me}, \mathrm{Cl}, \mathrm{F}$; if $\mathrm{NO}_{2}$ - no reaction

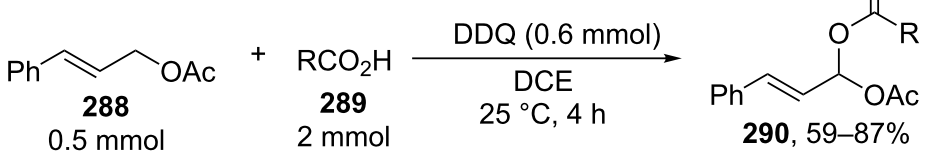

$\mathrm{R}=\mathrm{Me}, \mathrm{Bn}, \mathrm{Ph}, \mathrm{CH}=\mathrm{CH}_{2}$

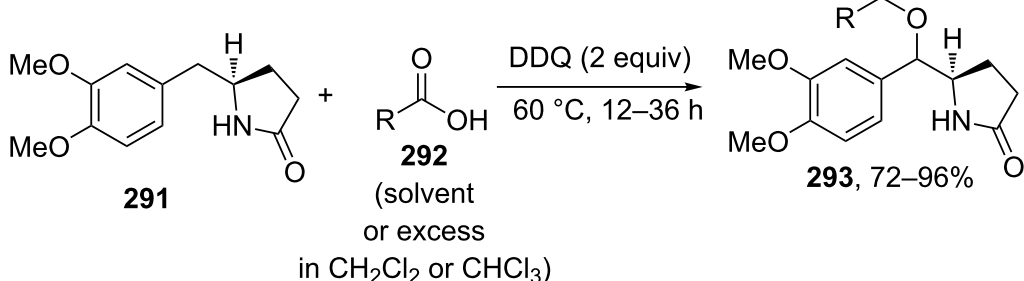

$\mathrm{R}=\mathrm{Me}, \mathrm{CH}=\mathrm{CH}_{2}$, allyl, $\mathrm{CH}=\mathrm{CHPh}, \mathrm{C}(\mathrm{O}) \mathrm{Ph}$, etc.

Scheme 64: C-H acyloxylation of diarylmethanes, 3-phenyl-2-propen-1-yl acetate and dimethoxyarene using DDQ.

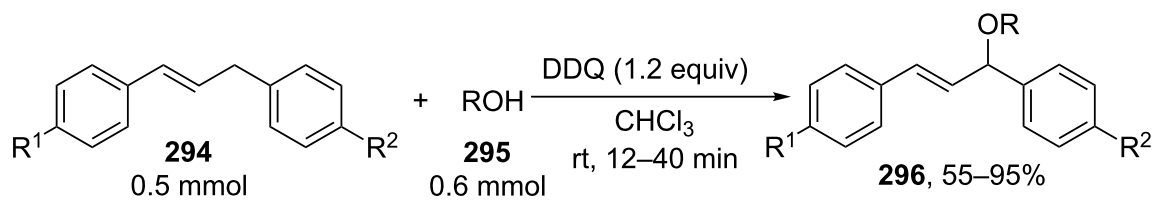

$\mathrm{R}=\mathrm{Me}$, Et, $t$-Bu, Cy, Allyl, $\mathrm{CH}_{2} \mathrm{Ar}$, etc.

$\mathrm{R}^{1}, \mathrm{R}^{2}=\mathrm{H}, \mathrm{CH}_{3}, \mathrm{Cl}$

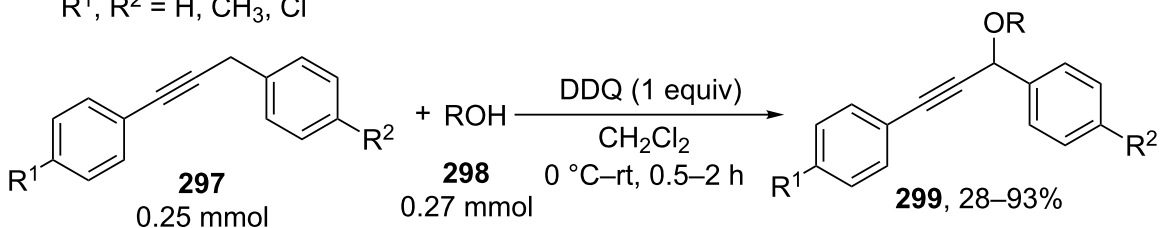

$\mathrm{R}=$ alkyl, Ar, allyl, propargyl, $\mathrm{MeC}=\mathrm{O}, \mathrm{PhC}=\mathrm{O}$, etc.

$\mathrm{R}^{1}, \mathrm{R}^{2}=\mathrm{H}, \mathrm{Me}, \mathrm{Et}, \mathrm{OMe}, \mathrm{Cl}$

Scheme 65: Cross-dehydrogenative C-O coupling of 1,3-diarylpropylenes and 1,3-diarylpropynes with alcohols.

A method was developed for the one-pot synthesis of 3-acyloxy-3-azido-1-aryl-1-propynes $\mathbf{3 0 2}$ from 3-chloro-1-arylpropynes $\mathbf{3 0 0}$ involving the acyloxylation of the methylene group with carboxylic acids $\mathbf{3 0 1}$ under the action of the $\mathrm{FeCl}_{2}$ / DDQ system (Scheme 66) [248]. In the absence of iron salts, the reaction is less efficient.

The cross-dehydrogenative $\mathrm{C}-\mathrm{O}$ coupling reactions with the use of oximes as O-reagents in the presence of DDQ were docu- mented. 1,3-Diarylpropylenes 303, as well as (E)-1-phenyl-2isopropylethylene (306) are involved in the oxidative coupling with oximes 304 and 307 in the presence of DDQ [249]. Under similar conditions, oximes $\mathbf{3 1 0}$ are involved in the coupling with isochromanes 309 [250] (Scheme 67).

It was suggested that carbocations are generated from $\mathrm{C}$-reagents under the action of DDQ, and these carbocations undergo nucleophilic attack by oxime anions to form coupling 


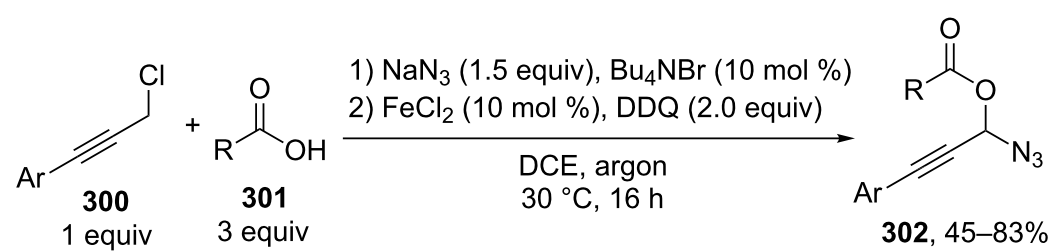

$\mathrm{R}=\mathrm{Me}, n$-alkyl, iPr, $t$-Bu, $\mathrm{Ad}, \mathrm{Ar}$, propene-2-yl, $\left(\mathrm{CH}_{2}\right)_{2} \mathrm{Ph},\left(\mathrm{CH}_{2}\right)_{2} \mathrm{CH}=\mathrm{CH}_{2}$, etc.

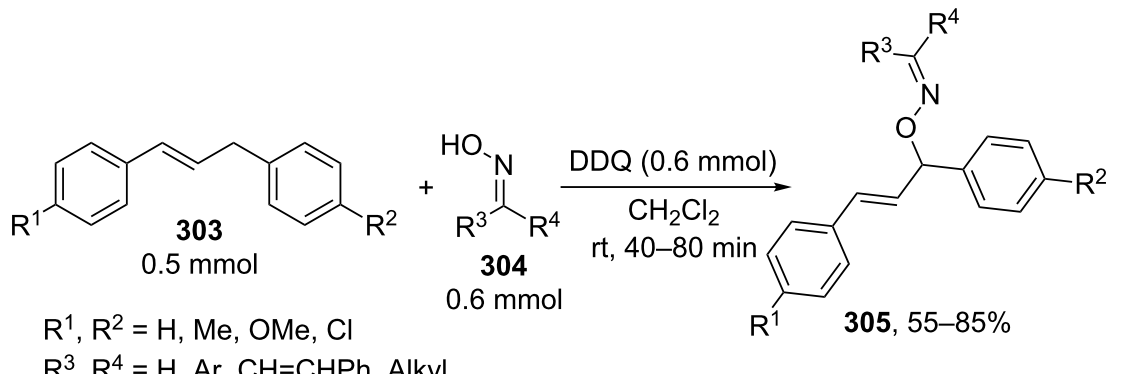

$\mathrm{R}^{3}, \mathrm{R}^{4}=\mathrm{H}, \mathrm{Ar}, \mathrm{CH}=\mathrm{CHPh}, \mathrm{Alkyl}$<smiles>CC(C)/C=C/c1ccccc1</smiles>

306 $0.5 \mathrm{mmol}$ $R^{3}, R^{4}=H, A r$, alkyl $0.6 \mathrm{mmol}$<smiles>[R]C([R16])=NO</smiles>
rt, $50-140 \mathrm{~min}$<smiles>[R]C([R])=NOC(C)(C)/C=C/c1ccccc1</smiles>

$308,55-80 \%$<smiles>c1ccc2c(c1)COc1nccc3cccc-2c13</smiles>

309

$0.5 \mathrm{mmol}$ $\mathrm{R}^{3}, \mathrm{R}^{4}=\mathrm{H}, \mathrm{Ar}, \mathrm{Me}$<smiles>[R]C([R3])=NOC1Oc2ccccc2-c2c1ccc1ccccc21</smiles>

311, 29-93\%

Scheme 67: Cross-dehydrogenative C-O coupling of 1,3-diarylpropylenes, (E)-1-phenyl-2-isopropylethylene and isochromanes with oximes.

products $\mathbf{3 0 5}, \mathbf{3 0 8}$, and $311[249,250]$. $N$-Hydroxyphthalimide was also employed as the O-reagent, the yield of the coupling product with isochromane was $62 \%$ [250]. DDQ was also used in the acetoxylation at the benzylic position of $p$-alkoxyalkylarenes and $p$-alkylphenols in acetic acid [251].

\subsection{Reactions with $N$-hydroxyphthalimide}

The oxidative $\mathrm{C}-\mathrm{O}$ coupling of alkylarenes and related compounds 312 with $N$-hydroxyphthalimide (154b) was performed using $\mathrm{CuCl} / \mathrm{PhI}(\mathrm{OAc})_{2}$ [252] or $\left(\mathrm{NH}_{4}\right)_{2} \mathrm{Ce}\left(\mathrm{NO}_{3}\right)_{6}$ [253] as the oxidizing agent (Scheme 68). The reaction in the presence of the $\mathrm{CuCl} / \mathrm{PhI}(\mathrm{OAc})_{2}$ system gives somewhat higher yields of coupling products 313 compared with $\left(\mathrm{NH}_{4}\right)_{2} \mathrm{Ce}\left(\mathrm{NO}_{3}\right)_{6}$, but it requires higher temperature, a longer reaction time, and relatively larger excesses of alkylarene. Apparently, the $\mathrm{C}-\mathrm{O}$ bond is formed as a result of the recombination of benzyl and phthalimide- $N$-oxyl radicals. Alkylarenes should be taken in an excess amount to achieve high yields. The coupling of $N$-hydroxyphthalimide with ethers and alkenes proceeds in a similar fashion [252].

It was reported that such oxidative coupling reactions with NHPI and alkylarenes can proceed through the generation of phthalimide- $N$-oxyl radicals from NHPI in the presence of $\mathrm{Pb}(\mathrm{OAc})_{4}$; however, the yields of the products were not published [254]. Later on, it was shown that cross-dehydrogena- 


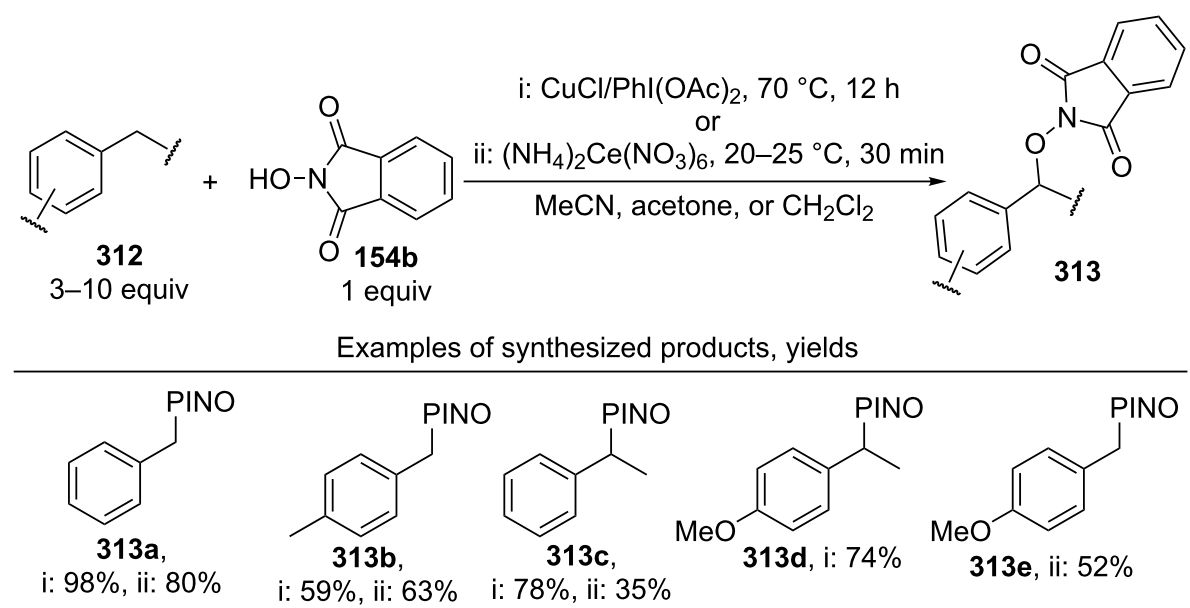

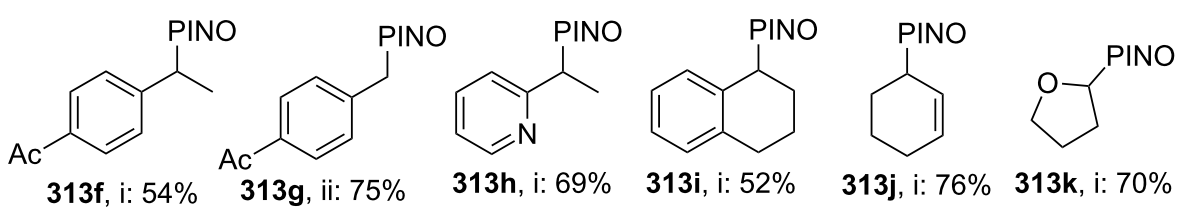<smiles>CCON1C(=O)c2ccccc2C1=O</smiles>

Scheme 68: Cross-dehydrogenative C-O coupling of alkylarenes and related compounds with $\mathrm{N}$-hydroxyphthalimide

tive coupling of NHPI with toluene proceeds in the presence of a variety of oxidants, $\left(\mathrm{NH}_{4}\right)_{2} \mathrm{Ce}\left(\mathrm{NO}_{3}\right)_{6}, \mathrm{PhI}(\mathrm{OAc})_{2}, \mathrm{KMnO}_{4}$, $\mathrm{Mn}(\mathrm{OAc})_{3} \cdot 2 \mathrm{H}_{2} \mathrm{O}, \mathrm{Pb}(\mathrm{OAc})_{4}$, or $\mathrm{Co}(\mathrm{OAc})_{2} / \mathrm{O}_{2}$ to afford $\mathrm{N}$-benzyloxyphthalimide in yields of $11-75 \%$ [255]. The oxidative coupling of NHPI with cyclohexene and cyclooctene using $\mathrm{NaIO}_{4}$ in the $\mathrm{CH}_{2} \mathrm{Cl}_{2} / \mathrm{H}_{2} \mathrm{O}$ mixture in the presence of silica gel was documented [256]; the coupling products were only partially characterized (the NMR spectra of the crude compounds were reported). In another study, the oxidative coupling of NHPI with cyclic and acyclic alkenes was performed in the presence of $\left(\mathrm{NH}_{4}\right)_{2} \mathrm{Ce}\left(\mathrm{NO}_{3}\right)_{6}, \mathrm{~Pb}(\mathrm{OAc})_{4}$, or anthraquinone; in the case of metal-containing oxidizing agents, the radical reaction mechanism is suggested along with the competitive ionic mechanism; the reaction products and procedures for their synthesis were not completely characterized [257].

The acetoxylation at the benzylic position of alkylarenes $\mathbf{3 1 4}$ in acetic acid was performed using the $N$-hydroxyphthalimide/ iodine/nitric acid system; in some experiments, $\mathrm{Co}(\mathrm{OAc})_{2}$ was employed as the cocatalyst (Scheme 69) [258]. Oxygen or nitric acid acts as the oxidant.

In the presence of oxidizing agents, phthalimide- $N$-oxyl radicals are generated from NHPI, and these radicals abstract a hydrogen atom from the benzylic position of alkylarene 314; the resulting benzyl radical is trapped by iodine to form iodide

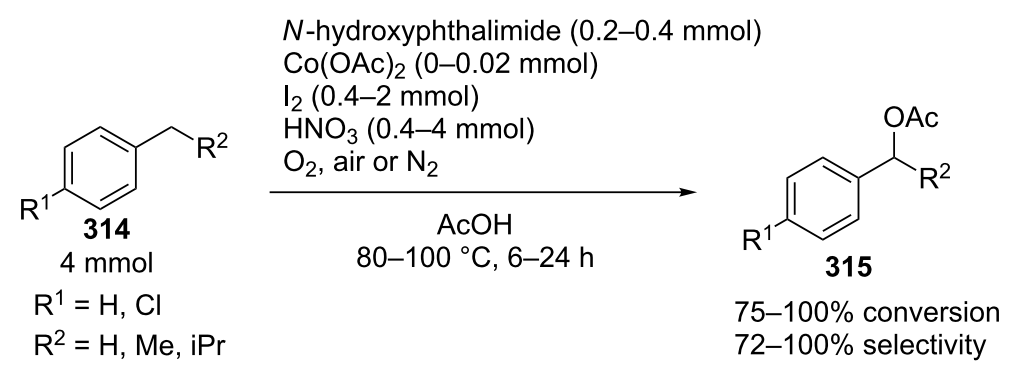

Scheme 69: Acetoxylation at the benzylic position of alkylarenes mediated by $N$-hydroxyphthalimide. 
followed by the replacement of iodine by acetic acid to give product 315. The proposed mechanism is confirmed by the fact that the reactions of alkylarenes containing electron-withdrawing substituents in the benzene ring afford benzyl iodides rather than the corresponding acetates.

\subsection{Other reactions}

The $\mathrm{C}-\mathrm{O}$ coupling of methylarenes $\mathbf{3 1 6}$ with aromatic carboxylic acids $\mathbf{3 1 7}$ in the presence of the $\mathrm{NaBrO}_{3} / \mathrm{NaHSO}_{3}$ system was described [259]. The synthesis was performed at room temperature with aromatic carboxylic acids $\mathbf{3 1 7}$ containing both electron-donating and -withdrawing groups; methylarene 316 (toluene or 3-ethoxytoluene), and carboxylic acid 317 were taken in a ratio of 1:1. It was suggested that benzyl bromides are formed in situ followed by the generation of products 318 through the nucleophilic attack by carboxylic acid (Scheme 70).

The tert-butyl peroxide group was introduced into allyl, propargyl and benzyl ethers 319 in the presence of the $\mathrm{Fe}(\mathrm{acac})_{3} / t$-BuOOH system [260]. It was suggested that a hydrogen atom is abstracted from the $\mathrm{CH}$-reagent by tert- butylperoxyl and tert-butoxyl radicals generated from tert-butyl hydroperoxide in the presence of $\mathrm{Fe}(\mathrm{acac})_{3}$; the resulting C-radical is oxidized with $\mathrm{Fe}$ (III) to the carbocation, and the latter is subjected to nucleophilic attack by tert-butyl hydroperoxide to give product $\mathbf{3 2 0}$ (Scheme 71).

The tert-butyl peroxidation at the allylic and benzylic positions of cyclohexene and ethylbenzene with tert-butyl hydroperoxide catalyzed by nanosized $\mathrm{CeO}_{2}$ proceeds with low yields [261].

The acetoxylation of alkylarenes in acetic acid was performed using the $\mathrm{CeO}_{2} / \mathrm{NaBrO}_{3}$ [262], $\mathrm{LiBr} / \mathrm{NaIO}_{4}$ [263], and $\mathrm{H}_{5} \mathrm{PV}_{2} \mathrm{Mo}_{10} \mathrm{O}_{40} / \mathrm{NaNO}_{3}$ systems [264]. The methyl group of 1,2,3-trimethoxy-5-methylbenzene in acetic acid was acetoxylated with $65 \%$ nitric acid [265]. $N$-Benzylphthalimides were acetoxylated at the benzylic position with the $N$-bromosuccinimide/NaOAc/HOAc system by heating under reflux in chlorobenzene for $12 \mathrm{~h}$ [266].

The alkoxylation [267,268] or acyloxylation [267,269] at the allylic position of alkenes occurs in the presence of seleniumbased oxidizing agents, such as $\mathrm{ArSeSeAr}_{\text {cat. }} / \mathrm{S}_{2} \mathrm{O}_{8}{ }^{2-}[267,268]$

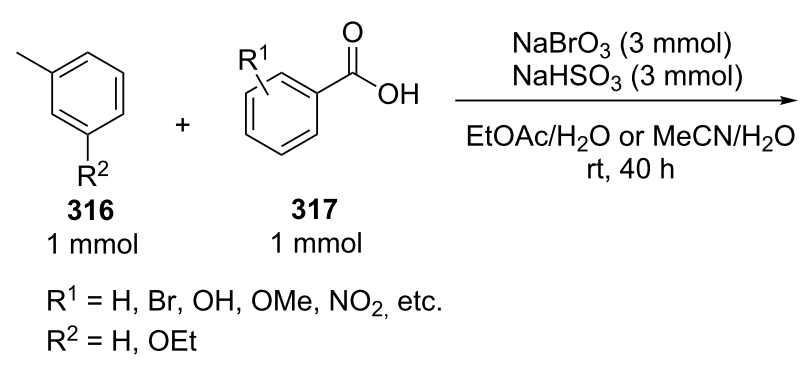<smiles></smiles>

$318,61-95 \%$

Scheme 70: C-O coupling of methylarenes with aromatic carboxylic acids employing the $\mathrm{NaBrO}_{3} / \mathrm{NaHSO}_{3}$ system.

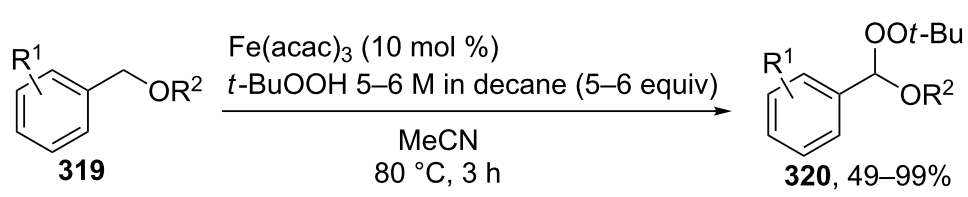

$\mathrm{R}^{1}=\mathrm{H}, \mathrm{Me}, \mathrm{OMe}, \mathrm{Cl}, \mathrm{NO}_{2}$, etc.

$\mathrm{R}^{2}=\mathrm{Bu}, t-\mathrm{Bu}, \mathrm{Cy}$, etc.

Examples of synthesized products, yields

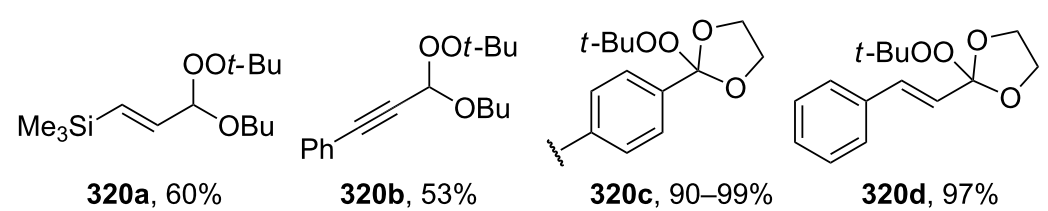


or $\mathrm{SeO}_{2}$ [269]. It is suggested that the reactions proceed through electrophilic attack of selenium on the $\mathrm{C}=\mathrm{C}$ double bond [268,269].

\section{Ethers, amines, and amides as C-reagents in cross-dehydrogenative $\mathrm{C}-\mathrm{O}$ coupling} 5.1 Reactions catalyzed by tetrabutylammonium iodide

The $\mathrm{Bu}_{4} \mathrm{NI} / t$ - $\mathrm{BuOOH}$ system proved to be efficient in the oxidative $\mathrm{C}-\mathrm{O}$ coupling of ethers $\mathbf{3 2 2}$ with carboxylic acids $\mathbf{3 2 1}$ (Scheme 72) [270]. The coupling was performed with ethers taken in a 20 -fold excess relative to carboxylic acids. It is supposed that the tert-butoxyl radical, which is generated in the $\mathrm{Bu}_{4} \mathrm{NI} / t$-BuOOH system, abstracts a hydrogen atom from the $\alpha$-position of the ether, and the resulting $\mathrm{C}$-radical is oxidized to the carbocation, which reacts with the carboxylate anion to form coupling product $\mathbf{3 2 3}$.
The $\mathrm{Bu}_{4} \mathrm{NI} / t$-BuOOH system was applied to perform the oxidative acyloxylation of dimethylamides $\mathbf{3 2 5}$ and dioxane with 2-aryl-2-oxoacetic acids $\mathbf{3 2 4}$ accompanied by the decarboxylation [271]. It was shown that, in the presence of the $\mathrm{Bu}_{4} \mathrm{NI} / t$-BuOOH system, 2-oxo-2-phenylacetic acid (324a) is transformed into benzoic acid (328) followed by the coupling of the latter with dimethylformamide to give product 326a. Hence, it is supposed that arylcarboxylic acids are intermediates in the synthesis of compounds $\mathbf{3 2 6}$ and $\mathbf{3 2 7}$ (Scheme 73).

The peroxidation of $N$-benzylamides and $N$-allylbenzamide 329 with the $\mathrm{Bu}_{4} \mathrm{NI} / t$-BuOOH system (Scheme 74) was documented [272]. The tert-butyl peroxide group in products 330 can be replaced with an aryl, benzyl, or alkyl group by the reaction with the corresponding Grignard reagent to afford products 331.

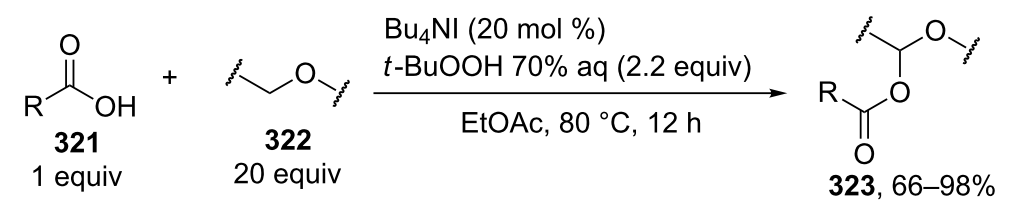

$\mathrm{R}=\mathrm{Ar}, \mathrm{PhCH}=\mathrm{CH}, \mathrm{PhCH}_{2} \mathrm{CH}_{2}, n-\mathrm{C}_{15} \mathrm{H}_{31}$

Scheme 72: Cross-dehydrogenative $\mathrm{C}-\mathrm{O}$ coupling of ethers with carboxylic acids mediated by $\mathrm{Bu}_{4} \mathrm{NI} / t-\mathrm{BuOOH}$ system.

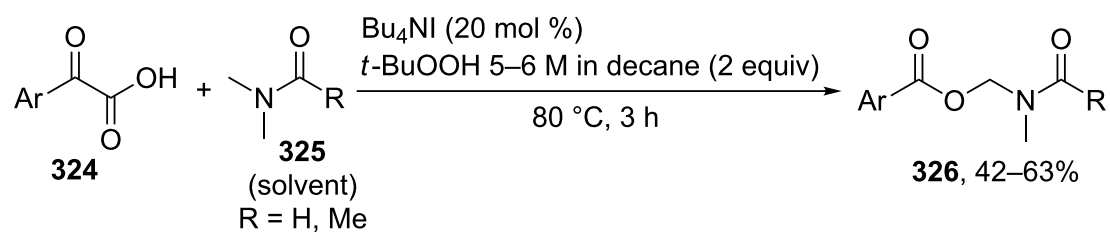

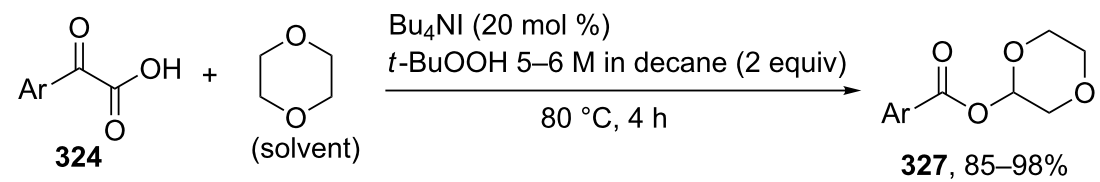

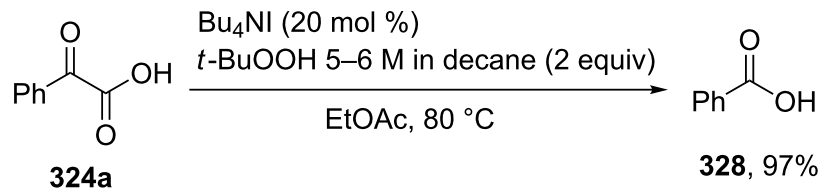

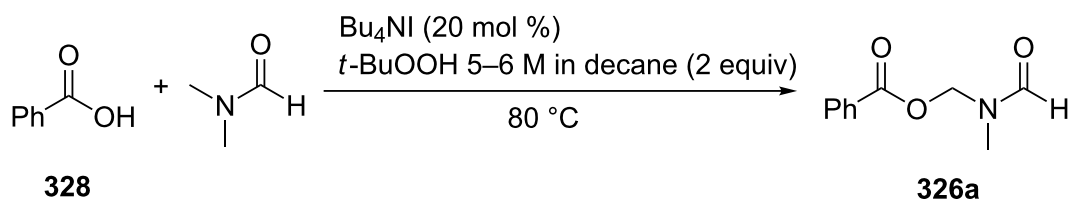




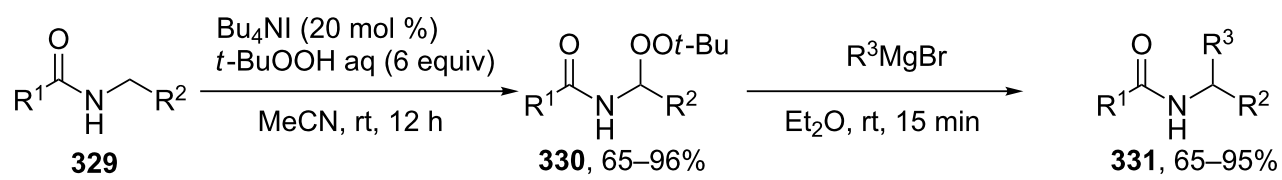

$\mathrm{R}^{1}=\mathrm{Ar}, \mathrm{CH}=\mathrm{CHPh}, \mathrm{iPr}, \mathrm{OBn}, \mathrm{O} t-\mathrm{Bu}$

$\mathrm{R}^{2}=\mathrm{Ar}, \mathrm{CH}=\mathrm{CH}_{2}$

$\mathrm{R}^{3}=\mathrm{Ar}, n-\mathrm{Bu}, \mathrm{Bn}$

Scheme 74: tert-Butyl peroxidation of $\mathrm{N}$-benzylamides and $\mathrm{N}$-allylbenzamide using the $\mathrm{Bu} 4 \mathrm{NI} / \mathrm{t}$-BuOOH system.

\subsection{Reactions catalyzed by transition metal salts}

The oxidative coupling of aromatic carboxylic acids $\mathbf{3 3 2}$ with ethers 333, which served as the solvents, was accomplished using the $\mathrm{Fe}(\mathrm{acac})_{3}$ /di-tert-butyl peroxide system to prepare $\alpha$-acyloxy ethers 334 (Scheme 75) [273].

In addition to aromatic carboxylic acids $\mathbf{3 3 2}$, the coupling was performed with phenylacetic acid. The reaction takes place both with ethers and cyclohexene. In almost all syntheses, one of the following two C-reagents was used: 1,4-dioxane or 1,3-dioxo- lane. It is interesting that the oxidative coupling of carboxylic acids with 1,3-dioxolane occurs at the 4-poisition of dioxolane (with one adjacent oxygen atom) rather than at the 2-position (with two adjacent oxygen atoms), which is usually considered to be more activated for the hydrogen atom abstraction.

The oxidative coupling of 2-hydroxybenzaldehydes 335 with cyclic ethers 336 (1,4-dioxane, tetrahydrofuran) was performed in the presence of the iron carbonyl/t-BuOOH system; in these reactions, the ethers served as the solvents (Scheme 76) [274].

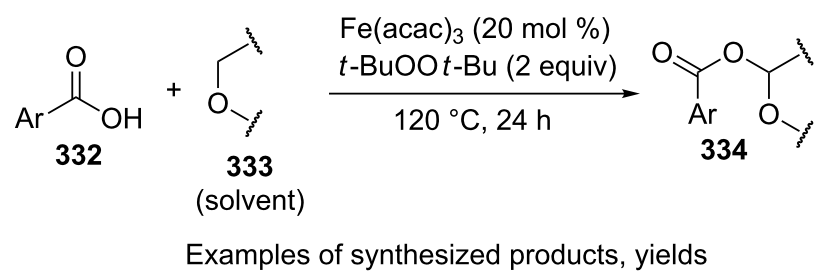<smiles>O=C(OC1COCCO1)c1cccs1</smiles>

334a, $97 \%$<smiles>O=C(OC1C=CCCC1)c1cccs1</smiles>

$334 \mathrm{e}, 42 \%$<smiles>Cn1cccc1C(=O)OC1COCCO1</smiles>

334b, $89 \%$<smiles>COCCOC(=O)c1cn(C)c2ccccc12</smiles>

$334 c, 88 \%$<smiles>O=C(CBr)OC1COCCO1</smiles>

$334 f, 62 \%$<smiles>CCOC(=O)OC1COCO1</smiles>

334g, $90 \%$<smiles>O=C(OCOCc1ccccc1)c1ccccc1</smiles>

334d, $82 \%$

$334 \mathrm{~h}, 82 \%$

Scheme 75: Cross-dehydrogenative $\mathrm{C}-\mathrm{O}$ coupling of aromatic carboxylic acids with ethers using $\mathrm{Fe}(\mathrm{acac})_{3}$ as catalyst and di-tert-butyl peroxide as oxidant.<smiles>[R]c1cccc(O)c1C=O</smiles>

335

(solvent)

$\mathrm{R}=\mathrm{Me}, t-\mathrm{Bu}, \mathrm{OMe}, \mathrm{OCF}_{3}, \mathrm{Br}$, etc.
$\mathrm{Fe}_{2}(\mathrm{CO})_{9}(10 \mathrm{~mol} \%)$ $t$-BuOOH 5-6 $\mathrm{M}$ in decane (6 equiv) $110^{\circ} \mathrm{C}, 15-90 \mathrm{~min}$

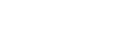

Scheme 76: Cross-dehydrogenative $\mathrm{C}-\mathrm{O}$ coupling of cyclic ethers with 2-hydroxybenzaldehydes using iron carbonyl as catalyst and tert-butyl hydroperoxide as oxidant. 
The reactions afforded products $\mathbf{3 3 7}$, leaving the aldehyde group unchanged.

Ethers 338 were subjected to oxidative coupling with 1,3dicarbonyl compounds 339 and $o$-acylphenols 340 using the copper salt $/ t$-BuOOH system to prepare esters 341 and $\mathbf{3 4 2}$ (Scheme 77) [275].

In the proposed mechanism (Scheme 77) the reactive benzoyl radical 344 derived from ether 343 by TBHP and a catalytic amount of copper catalyst reacts with complex 345 by single electron transfer to produce $\mathrm{Cu}(\mathrm{III})$ complex 346. Finally, reductive elimination of intermediate 346 affords the desired product 347 and the $\mathrm{Cu}(\mathrm{I})$ complex, which can be reoxidized to $\mathrm{Cu}(\mathrm{II})$ by TBHP.
Dioxane undergoes $\mathrm{C}-\mathrm{O}$ oxidative coupling with 2-hydroxybenzaldehyde 348 in the presence of tert-butyl hydroperoxide and the metal-organic framework (MOF) $\mathrm{Cu}_{2}$ (BPDC) $)_{2}$ (BPY) (BPY $=4,4$ '-bipyridine, $\mathrm{BPDC}=4,4$ '-biphenyldicarboxylate) as the heterogeneous catalyst [276] (Scheme 78). The yield of

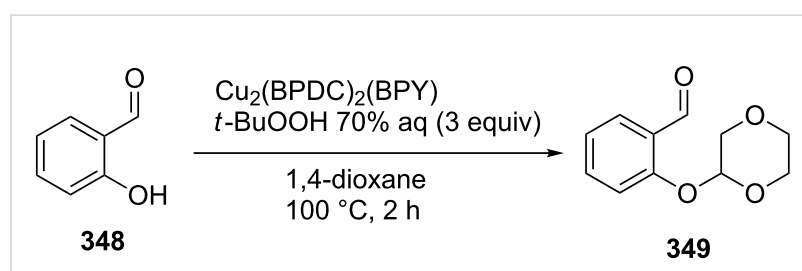

Scheme 78: Cross-dehydrogenative C-O coupling of 2-hydroxybenzaldehyde with dioxane catalyzed by $\mathrm{Cu}_{2}(\mathrm{BPDC})_{2}(\mathrm{BPY})$.

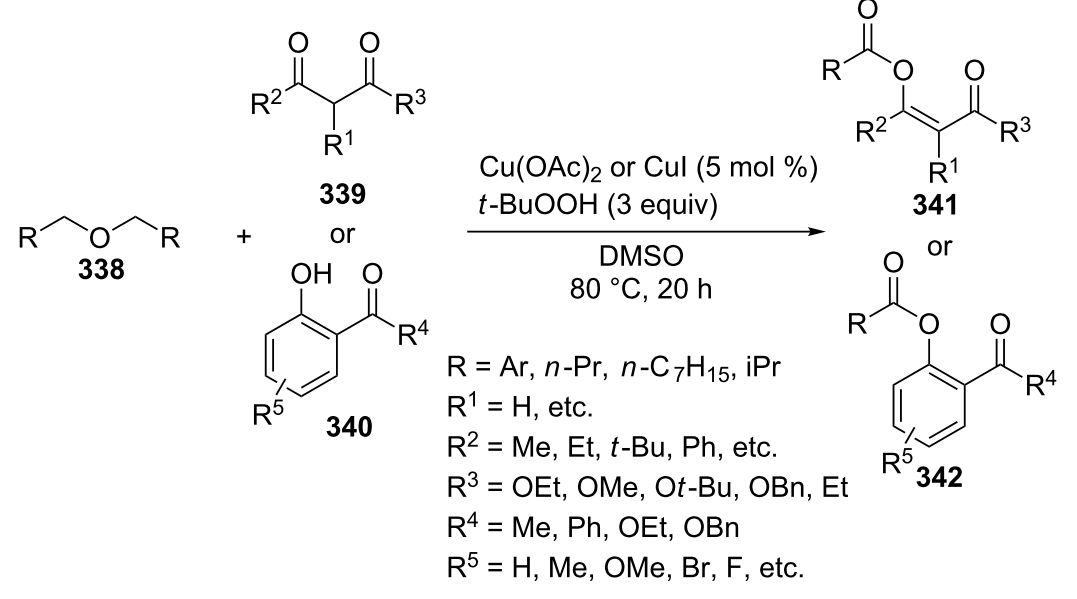

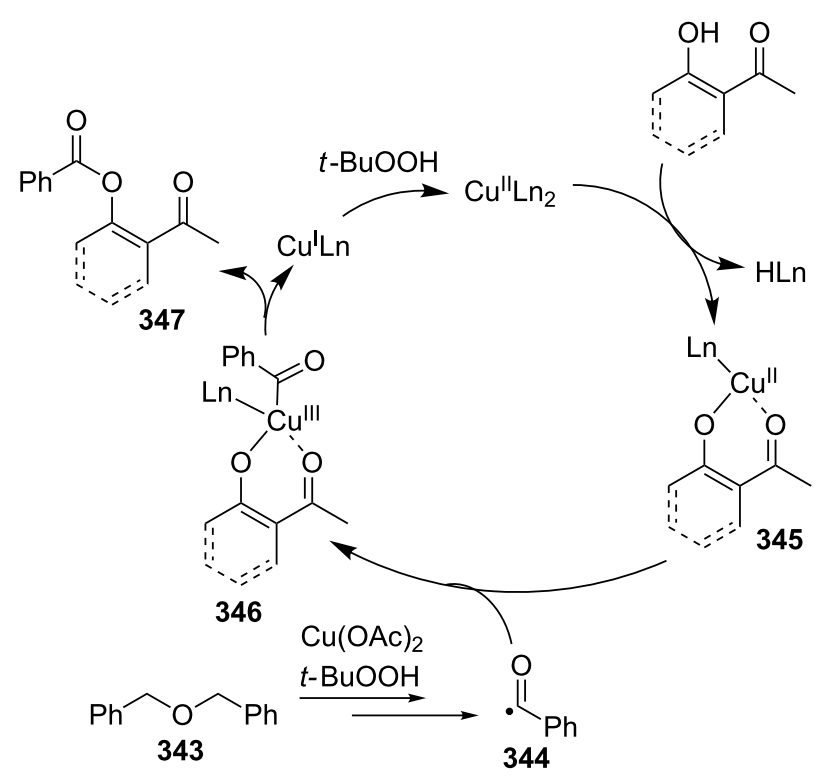

Scheme 77: Cross-dehydrogenative $\mathrm{C}-\mathrm{O}$ coupling of ethers with $\beta$-dicarbonyl compounds and phenols using copper catalysts and tert-butyl hydroperoxide as oxidant. 


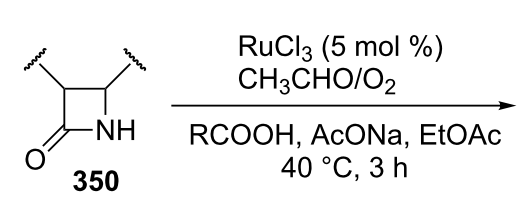

350

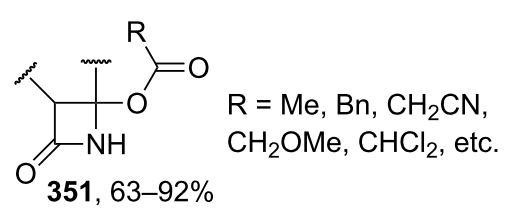

$351,63-92 \%$

Scheme 79: Ruthenium chloride-catalyzed acyloxylation of $\beta$-lactams.

product 349 and the reactivity of related $\mathrm{CH}$ - and $\mathrm{OH}-$ reagents under these reaction conditions were not discussed.

The ruthenium chloride-catalyzed acyloxylation of $\beta$-lactams 350 with an excess of acids as O-reagents was accomplished using oxygen in the presence of acetaldehyde (Scheme 79). It was hypothesized that the reaction proceeds through the generation of the $\mathrm{Ru}(\mathrm{V})$ oxo intermediate, which oxidizes the $\beta$-lactam to the carbocation, and the latter is subjected to nucleophilic attack by carboxylic acid to form substituted $\beta$-lactam $\mathbf{3 5 1}$ [277].

The tert-butyl peroxidation (product 354) or acetoxylation (product 355) of the methylene groups of amides $\mathbf{3 5 2}$ and $\mathbf{3 5 3}$ adjacent to the nitrogen atom was performed in the presence of a ruthenium-based catalyst using tert-butyl hydroperoxide or peracetic acid, respectively [278] (Scheme 80).

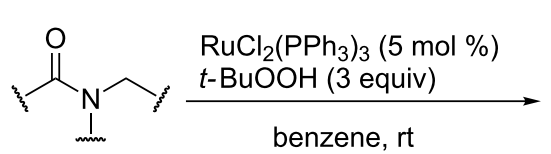

352<smiles>[R]C1NC(=O)C([R])C1=O</smiles>

Ru-C

$\mathrm{AcOOH}$ (2.2 equiv) $\mathrm{R}^{1} \quad \mathrm{R}^{2}$ AcONa (1 equiv) AcOEt / $\mathrm{AcOH}$ $\mathrm{rt}, 2.5 \mathrm{~h}$

$$
\begin{aligned}
& \mathrm{R}^{1}=\mathrm{H}, \mathrm{CH}(\mathrm{Me}) \mathrm{OSiMe}_{2}-t-\mathrm{Bu} \\
& \mathrm{R}^{2}=\mathrm{H}, \mathrm{Me}
\end{aligned}
$$

Scheme 80: Ruthenium-catalyzed tert-butyl peroxydation amides and acetoxylation of $\beta$-lactams.

The $\alpha, \beta$-diacetoxylation of $N$-arylpiperidines 356 with $\mathrm{PhI}(\mathrm{OAc})_{2}$ affords products 357 in $20-46 \%$ yield. Apparently, the reaction proceeds through the oxidation of amine to enamine [279] (Scheme 81).

Examples of the alkoxylation of tertiary amines $\mathbf{3 5 8}$ and $\mathbf{3 5 9}$ by their electrooxidation in alcohols were reported in the literature, examples are given in Scheme 82 [280] (the ratio of products 360-363 was determined by gas chromatography).

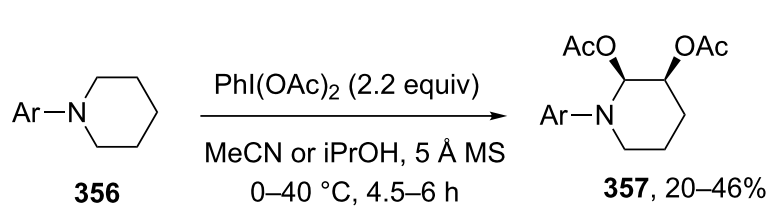

Scheme 81: $\mathrm{Phl}(\mathrm{OAc})_{2}$-mediated $\alpha, \beta$-diacetoxylation of tertiary amines.

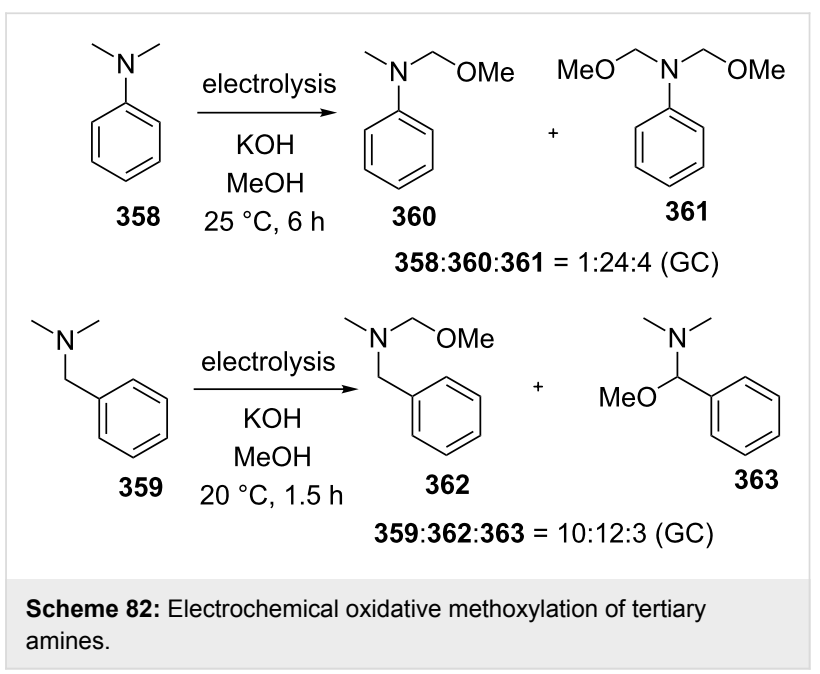

The coupling of $N$-hydroxyphthalimide with tetrahydrofuran (70\% yield) and isochromane (71\% yield) takes place in the presence of the $\mathrm{CuCl} / \mathrm{PhI}(\mathrm{OAc})_{2}$ system; $\mathrm{CH}$-reagents are taken in a 10-fold excess (see section 4.4, Scheme 68) [252].

\section{Other cross-dehydrogenative $\mathrm{C}-\mathrm{O}$ coupling reactions}

Ketene dithioacetals 364 were subjected to acyloxylation in the presence of the $\mathrm{Pd}(\mathrm{OAc})_{2} / \mathrm{PhI}(\mathrm{OAc})_{2}$ system and an excess of carboxylic acids that served as the co-solvents to prepare products 365 (Scheme 83) [281]. The range of carboxylic acids used in this reaction is limited to lower members of the series.

The oxidative coupling of enamines containing an electronwithdrawing substituent 366 with carboxylic acids 367 occurs efficiently in the presence of iodosobenzene (Scheme 84); oxidative coupling products 368 were employed in the synthesis of oxazoles [282]. 


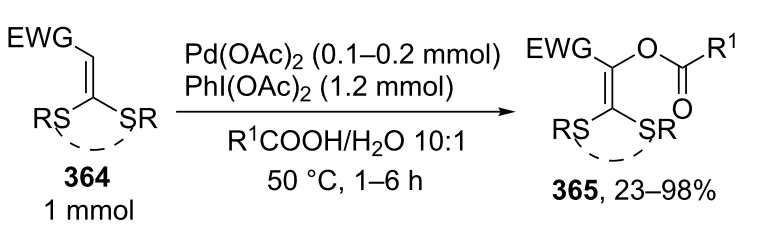

$$
\begin{aligned}
& \mathrm{R}=-\left(\mathrm{CH}_{2}\right)_{2^{-}}, \mathrm{Et} \\
& \mathrm{R}^{1}=\mathrm{Me}, \mathrm{Et}, \mathrm{CHCl}_{2} \\
& \mathrm{EWG}=\mathrm{COMe}, \mathrm{CO} t-\mathrm{Bu}, \mathrm{COPh}, \mathrm{COOMe}, \mathrm{COCH}=\mathrm{CHPh} \text {, etc } \text {. }
\end{aligned}
$$

Scheme 83: Cross-dehydrogenative $\mathrm{C}-\mathrm{O}$ coupling of ketene dithioacetals with carboxylic acids in the presence of the $\mathrm{Pd}(\mathrm{OAc})_{2} / \mathrm{Phl}(\mathrm{OAc})_{2}$ system.

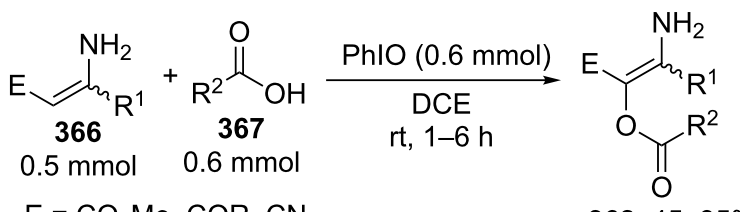

$$
\begin{aligned}
& \mathrm{E}=\mathrm{CO}_{2} \mathrm{Me}, \mathrm{COR}, \mathrm{CN} \\
& \mathrm{R}^{1}=\mathrm{Me}, \mathrm{Ph} \\
& 368,45-85 \% \\
& \mathrm{R}^{2}=\text { alkyl, Ar, alkenyl, etc. }
\end{aligned}
$$

Scheme 84: Cross-dehydrogenative C-O coupling of enamides with carboxylic acids using iodosobenzene as oxidant.

The oxidative alkoxylation [283], acetoxylation [283], and tosyloxylation [284] of anilides $\mathbf{3 6 9}$ at the para-position were accomplished using $\mathrm{PhI}\left(\mathrm{OOCCF}_{3}\right)_{2}$ in the presence of boron trifluoride to prepare products 370-372, respectively (Scheme 85); OH-reagents were taken in an excess.

The following mechanism was proposed. Anilide $\mathbf{3 7 3}$ is subjected to electrophilic attack by (di(trifluoroacetoxy)iodo)benzene to form intermediate $\mathbf{3 7 4}$ followed by the elimination of phenyl iodide from $\mathbf{3 7 4}$ to give cation $\mathbf{3 7 5}$, which is subjected to nucleophilic attack ( $\mathrm{ROH}, \mathrm{AcOH}$, or TsOH) affording coupling product 376 (Scheme 86).

In the presence of $\mathrm{PhI}(\mathrm{OAc})_{2}$, aldehydes $\mathbf{3 7 7}$, anilines 378 and alcohols undergo three-component coupling to produce alkoxyl-

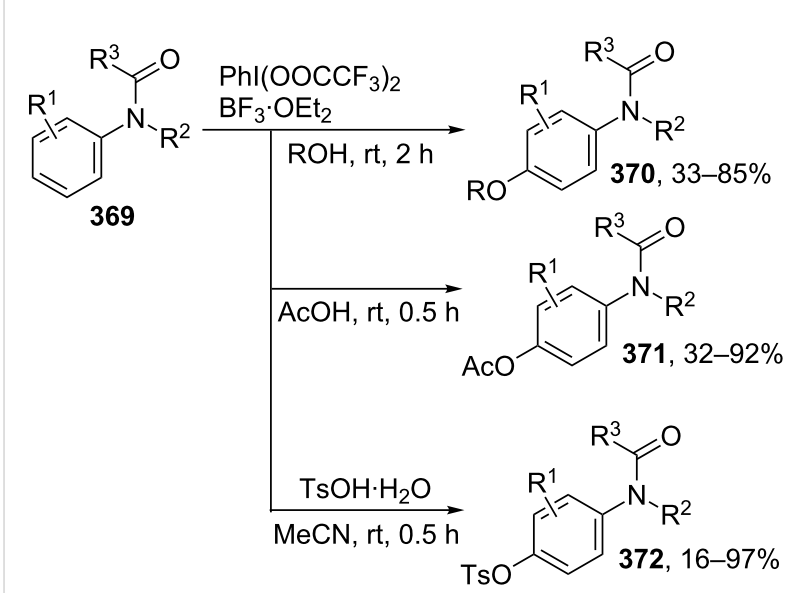

Scheme 85: Oxidative alkoxylation, acetoxylation, and tosyloxylation of acylanilides using $\mathrm{Phl}\left(\mathrm{O}(\mathrm{O}) \mathrm{CCF}_{3}\right)_{2}$ in the presence of boron trifluoride.

substituted $N$-arylimines 379 (Scheme 87 ). The preliminary mechanism investigations revealed that the transformation proceeds via imines as intermediates. Reactions were performed in the medium of alcohol (OH-reagent) at room temperature [285].

Various oxidants, such as (diacetoxyiodo)benzene [286-288], $\mathrm{PbCl}_{2} / \mathrm{HClO}_{4}, \mathrm{NaIO}_{3} / \mathrm{HClO}_{4}, \mathrm{Br}_{2} / N$-iodosuccinimide, or $\mathrm{I}_{2} / 30 \%$ aq $\mathrm{H}_{2} \mathrm{O}_{2}$ [289], were employed in the oxidative coupling of phenols $\mathbf{3 8 0}$ with alcohols serving as the solvents (Scheme 88 ) to prepare non-aromatic products $\mathbf{3 8 1}$ or $\mathbf{3 8 2}$.

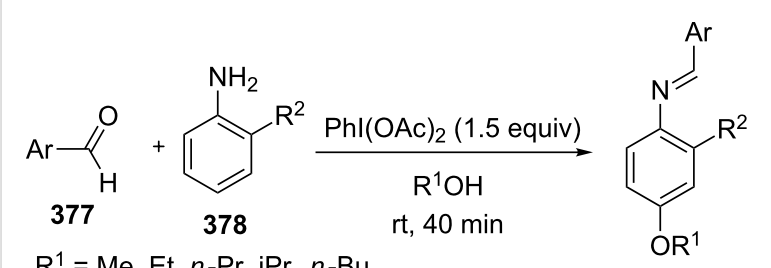

$\mathrm{R}^{1}=\mathrm{Me}, \mathrm{Et}, n-\mathrm{Pr}, \mathrm{iPr}, n-\mathrm{Bu}$ $379,13-74 \%$

Scheme 87: Three-component coupling of aldehydes, anilines and alcohols involving oxidative intermolecular $\mathrm{C}-\mathrm{O}$ bond formation.

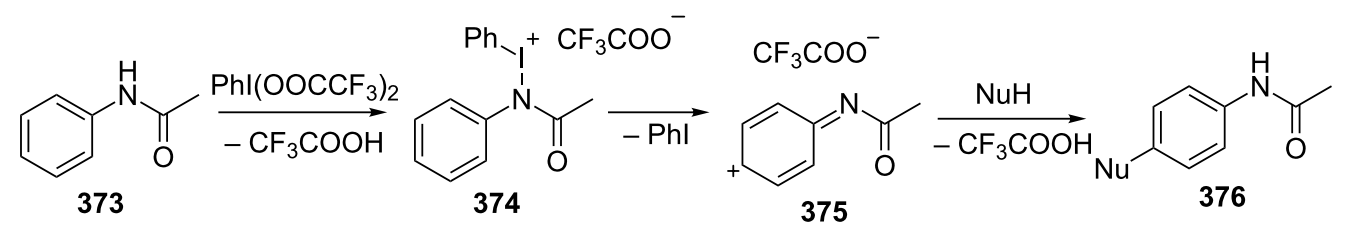

Scheme 86: Proposed mechanism of the oxidative $\mathrm{C}-\mathrm{O}$ coupling of actetanilide with O-nucleophiles in the presence of (di(trifluoroacetoxy)iodo)benzene. 
<smiles>[R]c1cc([R])c(O)c(I)c1C</smiles>

380<smiles>[R]C1=CC([R])(O[AlH2])C(CI)=C(I)C1=O</smiles>

381

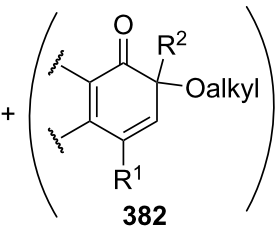

382
Scheme 88: Oxidative coupling of phenols with alcohols.

The 2-acyloxylation of quinoline $N$-oxides 383 with arylaldehydes 384 in the presence of the $\mathrm{CuOTf} / t-\mathrm{BuOOH}$ system afforded products 385 (Scheme 89) [290]. Benzaldehyde and aromatic aldehydes containing electron-donating groups were employed in the coupling. In addition to aromatic aldehydes, the coupling was performed with cyclohexanecarbaldehyde. It is suggested that the reaction proceeds through a radical mechanism.

The oxidative coupling of primary alcohols 387 with azoles 386 was performed in the presence of the $\mathrm{CuCl} /(t-\mathrm{BuO})_{2}$ system (Scheme 90) to prepare products $\mathbf{3 8 8}$ in $16-57 \%$ yield [291]. It was hypothesized that the $\mathrm{C}-\mathrm{O}$ bond is formed as a result of the reductive elimination of coupling product $\mathbf{3 8 8}$ from the copper(III) complex.

Alkoxylated heterocycles 391 were obtained in an excess of alcohol in the presence of $\mathrm{Na}_{3} \mathrm{Co}\left(\mathrm{NO}_{2}\right)_{6}$ from dipyrrins 390, which were generated from dipyrroles 389 (Scheme 91) [292].<smiles>[R19]c1ccc[n+]([O-])c1</smiles>

1 equiv<smiles>[R16][R4]1ccc(C=O)cc1</smiles>

3 equiv

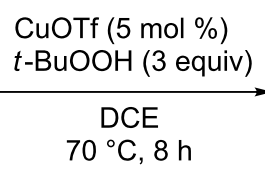

$\mathrm{R}^{2}=\mathrm{H}$, OMe, etc.<smiles>[R][R]c1cccc2c(C(=O)Oc3ccc4cc([R16])ccc4[n+]3[O-])cccc12</smiles>

$385,36-94 \%$

Scheme 89: 2-Acyloxylation of quinoline $\mathrm{N}$-oxides with arylaldehydes in the presence of the CuOTf/t-BuOOH system.

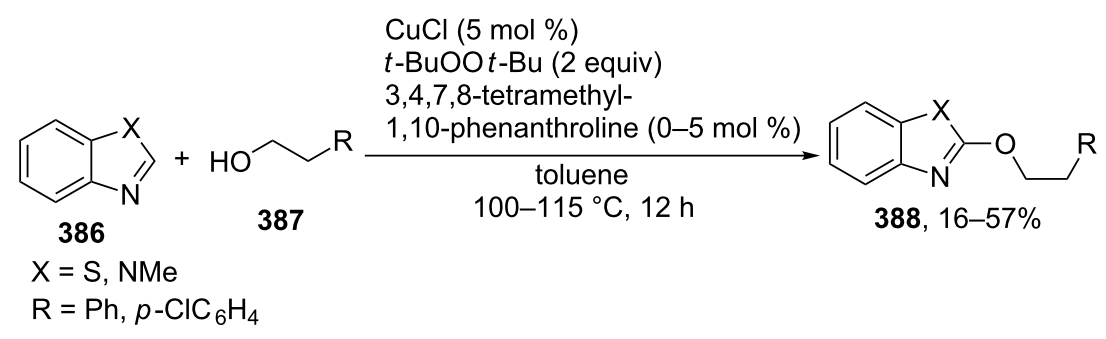

Scheme 90: Cross-dehydrogenative C-O coupling of azoles with primary alcohols.

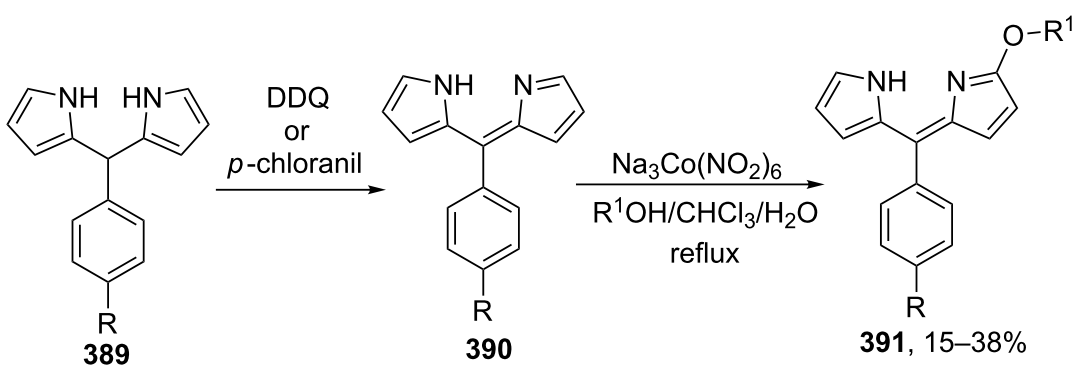

$\mathrm{R}=\mathrm{CN}, \mathrm{CO}_{2} \mathrm{Me}$

$\mathrm{R}^{1}=\mathrm{Me}, \mathrm{Et}, \mathrm{Pr}$ 
1,2- and 1,4-naphthoquinones undergo alkoxylation in an alcoholic medium in the presence of transition metal salts [293], $\mathrm{I}_{2} / \mathrm{CeCl}_{3}$ [294], and $\mathrm{HgO}$ [295].

Alkanes are rarely used in the cross-dehydrogenative $\mathrm{C}-\mathrm{O}$ coupling because of low reactivity of $\mathrm{C}-\mathrm{H}$ bonds. An example is the trifluoroacetoxylation of cyclohexane, cycloheptane, cyclooctane, and adamantane in trifluoroacetic acid in the presence of peracetic acid [296] or hydrogen peroxide [297-299] with the addition of transition metal salts ( $\mathrm{Rh}, \mathrm{Ru}, \mathrm{Pd}, \mathrm{Pt}, \mathrm{Fe}$ ) [296,297] or in the absence of metal compounds [298,299]; the reactions were usually accomplished at room temperature for a few hours.

Copper-catalyzed oxidative dehydrogenative carboxylation of unactivated alkanes 393 with various aromatic acids 392 to produce the corresponding allylic esters 394 was reported recently [300] (Scheme 92). Mechanistic studies allowed proposing a mechanism involving the generation of an allyl radical via the formation of alkene from the starting alkane. Related oxidative $\mathrm{C}-\mathrm{O}$ coupling of aromatic aldehydes [169] and methylarenes [229] with cycloalkanes using a $\mathrm{Cu}(\mathrm{OAc})_{2} / t$ $\mathrm{BuOOH}$ system were considered in sections 2.5 (Scheme 38) and 4.1 (Scheme 56), respectively.

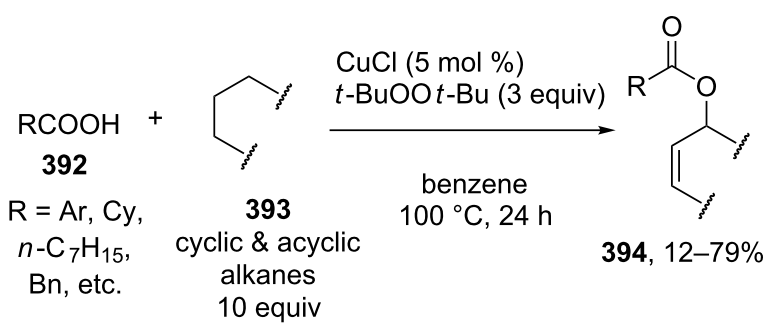

Scheme 92: Oxidative dehydrogenative carboxylation of alkanes and cycloalkanes to allylic esters.

Acetoxylation of benzene was achieved employing $\mathrm{Pd}(\mathrm{OAc})_{2} /$ $\mathrm{K}_{2} \mathrm{~S}_{2} \mathrm{O}_{8}$ oxidative system in $\mathrm{AcOH} / \mathrm{Ac}_{2} \mathrm{O}$ mixture in the presence of a pyridinium-substituted pyridine ligand [301] (Scheme 93). It was proposed that a key role for this cationic ligand is to serve as a phase transfer catalyst to bring poorly soluble $\mathrm{S}_{2} \mathrm{O}_{8}{ }^{2-}$ into contact with the Pd catalyst.

The electrochemical cross-dehydrogenative $\mathrm{C}-\mathrm{O}$ coupling, in which the O-reagent serves as the solvent, was described in the literature. For example, the methoxylation of methylarenes, amides, phenols, and other compounds was performed in methanol using bases immobilized on a solid support [302].

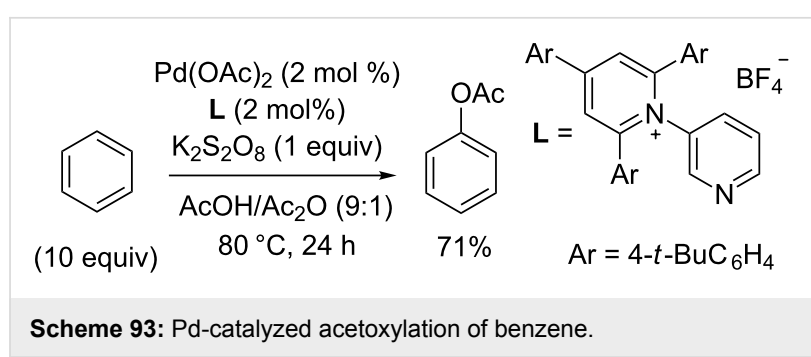

\section{Conclusion}

The analysis of the published data shows that oxidative $\mathrm{C}-\mathrm{O}$ coupling reactions attract an increasing interest of organic chemists in recent years. In the past two decades, a considerable body of experimental data has been accumulated. Compared with other types of coupling, the oxidative $\mathrm{C}-\mathrm{O}$ coupling is less well-studied despite the fact that the $\mathrm{C}-\mathrm{O}-\mathrm{R}$ group is rather commonly present in various classes of organic compounds, and a large number of diverse O-reagents are available for the coupling.

The drawback of the majority of the available methods for the cross-dehydrogenative $\mathrm{C}-\mathrm{O}$ coupling, which limits their application to the coupling of two expensive complex compounds, is the use of an excess of one of the starting components, the C- or O-reagent. Besides, the synthesis often requires high temperature and long time to be completed.

The main goals in the development of the cross-dehydrogenative $\mathrm{C}-\mathrm{O}$ coupling are as follows: (1) a search for new reactions involving various oxidative systems, C- and O-reagents; (2) the development of methods, which do not require an excess of the C- or O-reagent; (3) the development of methods based on available, convenient, and safe oxidants; (4) a decrease in the reaction temperature and time; (5) investigations of the mechanisms of the oxidative coupling with the aim of predicting conditions necessary for the efficient synthesis.

\section{Acknowledgements}

This work was supported by the Russian Science Foundation (Grant 14-23-00150).

\section{References}

1. Li, C.-J.; Li, Z. Pure Appl. Chem. 2006, 78, 935-945. doi:10.1351/pac200678050935

2. Li, Z.; Bohle, D. S.; Li, C.-J. Proc. Natl. Acad. Sci. U. S. A. 2006, 103, 8928-8933. doi:10.1073/pnas.0601687103

3. Beccalli, E. M.; Broggini, G.; Martinelli, M.; Sottocornola, S. Chem. Rev. 2007, 107, 5318-5365. doi:10.1021/cr068006f

4. Li, C.-J. Acc. Chem. Res. 2009, 42, 335-344. doi:10.1021/ar800164n

5. Scheuermann, C. J. Chem. - Asian J. 2010, 5, 436-451. doi:10.1002/asia.200900487 
6. Yoo, W.-J.; Li, C.-J. Top. Curr. Chem. 2010, 292, 281-302. doi:10.1007/128_2009_17

7. Yeung, C. S.; Dong, V. M. Chem. Rev. 2011, 111, 1215-1292. doi:10.1021/cr100280d

8. Cho, S. H.; Kim, J. Y.; Kwak, J.; Chang, S. Chem. Soc. Rev. 2011, 40, 5068-5083. doi:10.1039/c1cs15082k

9. Sun, C.-L.; Li, B.-J.; Shi, Z.-J. Chem. Rev. 2011, 111, 1293-1314. doi:10.1021/cr100198w

10. Zhang, C.; Tang, C.; Jiao, N. Chem. Soc. Rev. 2012, 41, 3464-3484. doi:10.1039/C2CS15323H

11. Song, G.; Wang, F.; Li, X. Chem. Soc. Rev. 2012, 41, 3651-3678. doi:10.1039/c2cs15281a

12. Hirano, K.; Miura, M. Chem. Commun. 2012, 48, 10704-10714. doi:10.1039/C2CC34659A

13. Liu, C.; Liu, D.; Lei, A. Acc. Chem. Res. 2014, 47, 3459-3470. doi:10.1021/ar5002044

14. Girard, S. A.; Knauber, T.; Li, C.-J. Angew. Chem., Int. Ed. 2014, 53, 74-100. doi:10.1002/anie.201304268

15. Samanta, R.; Matcha, K.; Antonchick, A. P. Eur. J. Org. Chem. 2013, 5769-5804. doi:10.1002/ejoc.201300286

16. Hoffman, R. V.; Wilson, A. L.; Kim, H. O. J. Org. Chem. 1990, 55, 1267-1270. doi:10.1021/jo00291a030

17. Lifchits, O.; Demoulin, N.; List, B. Angew. Chem., Int. Ed. 2011, 50, 9680-9683. doi:10.1002/anie.201104244

18. Jones, K. M.; Tomkinson, N. C. O. J. Org. Chem. 2012, 77, 921-928. doi:10.1021/j0202084w

19. Liu, B.; Shi, B.-F. Tetrahedron Lett. 2015, 56, 15-22. doi:10.1016/j.tetlet.2014.11.039

20. Liu, G.; Wu, Y. Top. Curr. Chem. 2010, 292, 195-209. doi:10.1007/128_2009_16

21. Liron, F.; Oble, J.; Lorion, M. M.; Poli, G. Eur. J. Org. Chem. 2014, 5863-5883. doi:10.1002/ejoc.201402049

22. Wu, X.-F.; Gong, J.-L.; Qi, X. Org. Biomol. Chem. 2014, 12, 5807-5817. doi:10.1039/C4OB00276H

23. Ananikov, V. P.; Khemchyan, L. L.; Ivanova, Yu. V.; Bukhtiyarov, V. I.; Sorokin, A. M.; Prosvirin, I. P.; Vatsadze, S. Z.; Medved'ko, A. V.; Nuriev, V. N.; Dilman, A. D.; Levin, V. V.; Koptyug, I. V.; Kovtunov, K. V.; Zhivonitko, V. V.; Likholobov, V. A.; Romanenko, A. V.; Simonov, P. A.; Nenajdenko, V. G.; Shmatova, O. I.; Muzalevskiy, V. M.; Nechaev, M. S.; Asachenko, A. F.; Morozov, O. S.; Dzhevakov, P. B.; Osipov, S. N.; Vorobyeva, D. V.; Topchiy, M. A.; Zotova, M. A.; Ponomarenko, S. A.; Borshchev, O. V.; Luponosov, Y. N.; Rempel, A. A.; Valeeva, A. A.; Stakheev, A. Yu.; Turova, O. V.; Mashkovsky, I. S.; Sysolyatin, S. V.; Malykhin, V. V.; Bukhtiyarova, G. A.; Terent'ev, A. O.; Krylov, I. B. Russ. Chem. Rev. 2014, 83, 885-985. doi:10.1070/RC2014v083n10ABEH004471

24. Ekoue-Kovi, K.; Wolf, C. Chem. - Eur. J. 2008, 14, 6302-6315. doi:10.1002/chem.200800353

25. Stowers, K. J.; Sanford, M. S. Org. Lett. 2009, 11, 4584-4587. doi:10.1021/ol901820w

26. Anand, M.; Sunoj, R. B. Org. Lett. 2011, 13, 4802-4805. doi:10.1021/ol201830r

27. Zhu, W.; Wang, H.; Peng, H.; Liu, G.; Guo, Y. Chin. J. Chem. 2013, 31, 371-376. doi:10.1002/cjoc.201201167

28. Desai, L. V.; Stowers, K. J.; Sanford, M. S. J. Am. Chem. Soc. 2008, 130, 13285-13293. doi:10.1021/ja8045519

29. Racowski, J. M.; Dick, A. R.; Sanford, M. S. J. Am. Chem. Soc. 2009, 131, 10974-10983. doi:10.1021/ja9014474
30. Powers, D. C.; Ritter, T. Acc. Chem. Res. 2012, 45, 840-850. doi:10.1021/ar2001974

31. Camasso, N. M.; Pérez-Temprano, M. H.; Sanford, M. S. J. Am. Chem. Soc. 2014, 136, 12771-12775. doi:10.1021/ja507056u

32. Dick, A. R.; Kampf, J. W.; Sanford, M. S. J. Am. Chem. Soc. 2005, 127, 12790-12791. doi:10.1021/ja0541940

33. Dick, A. R.; Hull, K. L.; Sanford, M. S. J. Am. Chem. Soc. 2004, 126, 2300-2301. doi:10.1021/ja031543m

34. Kalyani, D.; Sanford, M. S. Org. Lett. 2005, 7, 4149-4152. doi:10.1021/ol051486x

35. Ye, Z.; Wang, W.; Luo, F.; Zhang, S.; Cheng, J. Org. Lett. 2009, 11, 3974-3977. doi:10.1021/ol901609t

36. Hu, C.-J.; Zhang, X.-H.; Ding, Q.-P.; Lv, T.; Ge, S.-P.; Zhong, P. Tetrahedron Lett. 2012, 53, 2465-2468. doi:10.1016/j.tetlet.2012.03.022

37. Li, L.; Yu, P.; Cheng, J.; Chen, F.; Pan, C. Chem. Lett. 2012, 41, 600-602. doi:10.1246/cl.2012.600

38. Bian, Y.-J.; Xiang, C.-B.; Chen, Z.-M.; Huang, Z.-Z. Synlett 2011, 2407-2409. doi:10.1055/s-0030-1261224

39. Rout, S. K.; Guin, S.; Gogoi, A.; Majji, G.; Patel, B. K. Org. Lett. 2014, 16, 1614-1617. doi:10.1021/ol500224e

40. Chen, X.; Hao, X.-S.; Goodhue, C. E.; Yu, J.-Q. J. Am. Chem. Soc. 2006, 128, 6790-6791. doi:10.1021/ja061715q

41. Dudkina, Y. B.; Mikhaylov, D. Y.; Gryaznova, T. V.; Tufatullin, A. I.; Kataeva, O. N.; Vicic, D. A.; Budnikova, Y. H. Organometallics 2013, 32, 4785-4792. doi:10.1021/om400492g

42. Zheng, X.; Song, B.; Xu, B. Eur. J. Org. Chem. 2010, 4376-4380. doi:10.1002/ejoc.201000631

43. Leng, Y.; Yang, F.; Zhu, W.; Wu, Y.; Li, X. Org. Biomol. Chem. 2011, 9, 5288-5296. doi:10.1039/C1OB05223C

44. Kamal, A.; Srinivasulu, V.; Sathish, M.; Tangella, Y.; Nayak, V. L.; Rao, M. P. N.; Shankaraiah, N.; Nagesh, N. Asian J. Org. Chem. 2014, 3, 68-76. doi:10.1002/ajoc.201300214

45. Wang, Z.; Kuang, C. Adv. Synth. Catal. 2014, 356, 1549-1554. doi:10.1002/adsc. 201400096

46. Shi, S.; Kuang, C. J. Org. Chem. 2014, 79, 6105-6112. doi:10.1021/j05008306

47. Bhadra, S.; Matheis, C.; Katayev, D.; Gooßen, L. J. Angew. Chem., Int. Ed. 2013, 52, 9279-9283. doi:10.1002/anie.201303702

48. Li, W.; Sun, P. J. Org. Chem. 2012, 77, 8362-8366. doi:10.1021/jo301384r

49. Wang, G.-W.; Yuan, T.-T. J. Org. Chem. 2010, 75, 476-479. doi:10.1021/jo902139b

50. Jiang, T.-S.; Wang, G.-W. J. Org. Chem. 2012, 77, 9504-9509. doi:10.1021/jo301964m

51. Wang, G.-W.; Yuan, T.-T.; Wu, X.-L. J. Org. Chem. 2008, 73, 4717-4720. doi:10.1021/j08003088

52. Yadav, M. R.; Rit, R. K.; Sahoo, A. K. Chem. - Eur. J. 2012, 18, 5541-5545. doi:10.1002/chem.201200092

53. Rit, R. K.; Yadav, M. R.; Sahoo, A. K. Org. Lett. 2014, 16, 968-971. doi:10.1021/ol403699d

54. Desai, L. V.; Malik, H. A.; Sanford, M. S. Org. Lett. 2006, 8 , 1141-1144. doi:10.1021/ol0530272

55. Wang, L.; Xia, X.-D.; Guo, W.; Chen, J.-R.; Xiao, W.-J. Org. Biomol. Chem. 2011, 9, 6895-6898. doi:10.1039/C1OB05887H

56. Neufeldt, S. R.; Sanford, M. S. Org. Lett. 2010, 12, 532-535. doi:10.1021/ol902720d

57. Padala, K.; Jeganmohan, M. Chem. Commun. 2013, 49, 9651-9653. doi:10.1039/C3CC45350B 
58. Reddy, B. V. S.; Revathi, G.; Reddy, A. S.; Yadav, J. S. Tetrahedron Lett. 2011, 52, 5926-5929. doi:10.1016/j.tetlet.2011.08.098

59. Péron, F.; Fossey, C.; Sopkova-de Oliveira Santos, J.; Cailly, T.; Fabis, F. Chem. - Eur. J. 2014, 20, 7507-7513. doi:10.1002/chem.201303923

60. Yin, Z.; Jiang, X.; Sun, P. J. Org. Chem. 2013, 78, 10002-10007. doi:10.1021/jo401623j

61. Zhang, C.; Sun, P. J. Org. Chem. 2014, 79, 8457-8461. doi:10.1021/jo5014146

62. Zhang, S.-Y.; He, G.; Zhao, Y.; Wright, K.; Nack, W. A.; Chen, G. J. Am. Chem. Soc. 2012, 134, 7313-7316. doi:10.1021/ja3023972

63. Chen, F.-J.; Zhao, S.; Hu, F.; Chen, K.; Zhang, Q.; Zhang, S.-Q.; Shi, B.-F. Chem. Sci. 2013, 4, 4187-4192. doi:10.1039/C3SC51993G

64. Gou, F.-R.; Wang, X.-C.; Huo, P.-F.; Bi, H.-P.; Guan, Z.-H.; Liang, Y.-M. Org. Lett. 2009, 11, 5726-5729. doi:10.1021/ol902497k

65. Chan, L. Y.; Meng, X.; Kim, S. J. Org. Chem. 2013, 78, 8826-8832. doi:10.1021/j04011188

66. Roane, J.; Daugulis, O. Org. Lett. 2013, 15, 5842-5845. doi:10.1021/ol402904d

67. Hao, X.-Q.; Chen, L.-J.; Ren, B.; Li, L.-Y.; Yang, X.-Y.; Gong, J.-F.; Niu, J.-L.; Song, M.-P. Org. Lett. 2014, 16, 1104-1107. doi:10.1021/ol500166d

68. Zhang, L.-B.; Hao, X.-Q.; Zhang, S.-K.; Liu, K.; Ren, B.; Gong, J.-F.; Niu, J.-L.; Song, M.-P. J. Org. Chem. 2014, 79, 10399-10409. doi:10.1021/jo502005j

69. Zhang, L.-B.; Hao, X.-Q.; Zhang, S.-K.; Liu, Z.-J.; Zheng, X.-X.; Gong, J.-F.; Niu, J.-L.; Song, M.-P. Angew. Chem., Int. Ed. 2015, 54, 272-275. doi:10.1002/anie.201409751

70. Chernyak, N.; Dudnik, A. S.; Huang, C.; Gevorgyan, V. J. Am. Chem. Soc. 2010, 132, 8270-8272. doi:10.1021/ja1033167

71. Huang, C.; Chernyak, N.; Dudnik, A. S.; Gevorgyan, V. Adv. Synth. Catal. 2011, 353, 1285-1305. doi:10.1002/adsc. 201000975

72. Gulevich, A. V.; Melkonyan, F. S.; Sarkar, D.; Gevorgyan, V. J. Am. Chem. Soc. 2012, 134, 5528-5531. doi:10.1021/ja3010545

73. Sarkar, D.; Melkonyan, F. S.; Gulevich, A. V.; Gevorgyan, V. Angew. Chem., Int. Ed. 2013, 52, 10800-10804. doi:10.1002/anie.201304884

74. Gao, T.; Sun, P. J. Org. Chem. 2014, 79, 9888-9893. doi:10.1021/j0501902d

75. Nakano, Y.; Lupton, D. W. Chem. Commun. 2014, 50, 1757-1760. doi:10.1039/C3CC48545E

76. Ju, L.; Yao, J.; Wu, Z.; Liu, Z.; Zhang, Y. J. Org. Chem. 2013, 78, 10821-10831. doi:10.1021/jo401830k

77. Cheng, T.; Yin, W.; Zhang, Y.; Zhang, Y.; Huang, Y. Org. Biomol. Chem. 2014, 12, 1405-1411. doi:10.1039/С3ОB42196A

78. Jiang, H.; Chen, H.; Wang, A.; Liu, X. Chem. Commun. 2010, 46, 7259-7261. doi:10.1039/C0CC00841A

79. Zhang, S.; Luo, F.; Wang, W.; Jia, X.; Hu, M.; Cheng, J. Tetrahedron Lett. 2010, 51, 3317-3319. doi:10.1016/j.tetlet.2010.04.075

80. Wang, D.; Zavalij, P. Y.; Vedernikov, A. N. Organometallics 2013, 32, 4882-4891. doi:10.1021/om400618n

81. Shan, G.; Yang, X.; Zong, Y.; Rao, Y. Angew. Chem., Int. Ed. 2013, 52, 13606-13610. doi:10.1002/anie.201307090

82. Zhou, L.; Lu, W. Org. Lett. 2014, 16, 508-511. doi:10.1021/ol403393w

83. Rit, R. K.; Yadav, M. R.; Sahoo, A. K. Org. Lett. 2012, 14, 3724-3727. doi:10.1021/ol301579q
84. Zong, Y.; Rao, Y. Org. Lett. 2014, 16, 5278-5281. doi:10.1021/ol502377x

85. Wu, X.; Zhao, Y.; Ge, H. Chem. - Asian J. 2014, 9, 2736-2739. doi:10.1002/asia.201402510

86. Desai, L. V.; Hull, K. L.; Sanford, M. S. J. Am. Chem. Soc. 2004, 126, 9542-9543. doi:10.1021/ja046831c

87. Stowers, K. J.; Kubota, A.; Sanford, M. S. Chem. Sci. 2012, 3, 3192-3195. doi:10.1039/C2SC20800H

88. Giri, R.; Liang, J.; Lei, J.-G.; Li, J.-J.; Wang, D.-H.; Chen, X.; Naggar, I. C.; Guo, C.; Foxman, B. M.; Yu, J.-Q. Angew. Chem., Int. Ed. 2005, 44, 7420-7424. doi:10.1002/anie.200502767

89. Wang, Z.; Kuninobu, Y.; Kanai, M. Org. Lett. 2014, 16, 4790-4793. doi:10.1021/ol5022542

90. Owston, N. A.; Parker, A. J.; Williams, J. M. J. Chem. Commun. 2008, 624-625. doi:10.1039/B717073D

91. Owston, N. A.; Nixon, T. D.; Parker, A. J.; Whittlesey, M. K.; Williams, J. M. J. Synthesis 2009, 1578-1581. doi:10.1055/s-0028-1088026

92. Yamamoto, N.; Obora, Y.; Ishii, Y. J. Org. Chem. 2011, 76, 2937-2941. doi:10.1021/jo2003264

93. Tschaen, B. A.; Schmink, J. R.; Molander, G. A. Org. Lett. 2013, 15, 500-503. doi:10.1021/ol303298g

94. Heropoulos, G. A.; Villalonga-Barber, C. Tetrahedron Lett. 2011, 52, 5319-5322. doi:10.1016/j.tetlet.2011.08.021

95. Liu, C.; Tang, S.; Zheng, L.; Liu, D.; Zhang, H.; Lei, A. Angew. Chem., Int. Ed. 2012, 51, 5662-5666. doi:10.1002/anie.201201960

96. Liu, C.; Wang, J.; Meng, L.; Deng, Y.; Li, Y.; Lei, A. Angew. Chem., Int. Ed. 2011, 50, 5144-5148. doi:10.1002/anie.201008073

97. Gowrisankar, S.; Neumann, H.; Beller, M. Angew. Chem., Int. Ed. 2011, 50, 5139-5143. doi:10.1002/anie.201008035

98. Nielsen, I. S.; Taarning, E.; Egeblad, K.; Madsen, R.; Christensen, C. H. Catal. Lett. 2007, 116, 35-40. doi:10.1007/s10562-007-9086-9

99. Marsden, C.; Taarning, E.; Hansen, D.; Johansen, L.; Klitgaard, S. K.; Egeblad, K.; Christensen, C. H. Green Chem. 2008, 10, 168-170. doi:10.1039/B712171G

100. Fristrup, P.; Johansen, L. B.; Christensen, C. H. Chem. Commun. 2008, 2750-2752. doi:10.1039/B803270J

101.Su, F.-Z.; Ni, J.; Sun, H.; Cao, Y.; He, H.-Y.; Fa, K.-N. Chem. - Eur. J. 2008, 14, 7131-7135. doi:10.1002/chem.200800982

102. Yasukawa, T.; Miyamura, H.; Kobayashi, S. Chem. - Asian J. 2011, 6, 621-627. doi:10.1002/asia.201000624

103.Suzuki, K.; Yamaguchi, T.; Matsushita, K.; litsuka, C.; Miura, J.; Akaogi, T.; Ishida, H. ACS Catal. 2013, 3, 1845-1849. doi:10.1021/cs4004084

104.Noonan, C.; Baragwanath, L.; Connon, S. J. Tetrahedron Lett. 2008, 49, 4003-4006. doi:10.1016/j.tetlet.2008.04.097

105. Maki, B. E.; Scheidt, K. A. Org. Lett. 2008, 10, 4331-4334. doi:10.1021/ol8018488

106. Maki, B. E.; Chan, A.; Phillips, E. M.; Scheidt, K. A. Tetrahedron 2009, 65, 3102-3109. doi:10.1016/j.tet.2008.10.033

107.Reddy, R. S.; Rosa, J. N.; Veiros, L. F.; Caddick, S.; Gois, P. M. P. Org. Biomol. Chem. 2011, 9, 3126-3129. doi:10.1039/C1OB05151B

108. Finney, E. E.; Ogawa, K. A.; Boydston, A. J. J. Am. Chem. Soc. 2012, 134, 12374-12377. doi:10.1021/ja304716r

109. Kiran, I. N. C.; Lalwani, K.; Sudalai, A. RSC Adv. 2013, 3, 1695-1698. doi:10.1039/C2RA22718E 
110.Zhao, J.; Mück-Lichtenfeld, C.; Studer, A. Adv. Synth. Catal. 2013, 355, 1098-1106. doi:10.1002/adsc.201300034

111. Chiarotto, I.; Feroci, M.; Sotgiu, G.; Inesi, A. Tetrahedron 2013, 69, 8088-8095. doi:10.1016/j.tet.2013.06.014

112.Ji, M.; Wang, X.; Lim, Y. N.; Kang, Y.-W.; Jang, H.-Y. Eur. J. Org. Chem. 2013, 7881-7885. doi:10.1002/ejoc.201301337

113.Maki, B. E.; Chan, A.; Phillips, E. M.; Scheidt, K. A. Org. Lett. 2007, 9 , 371-374. doi:10.1021/ol062940f

114.Delany, E. G.; Fagan, C.-L.; Gundala, S.; Zeitler, K.; Connon, S. J. Chem. Commun. 2013, 49, 6513-6515. doi:10.1039/C3CC42597E

115.De Sarkar, S.; Grimme, S.; Studer, A. J. Am. Chem. Soc. 2010, 132, 1190-1191. doi:10.1021/ja910540j

116.Samanta, R. C.; De Sarkar, S.; Fröhlich, R.; Grimme, S.; Studer, A. Chem. Sci. 2013, 4, 2177-2184. doi:10.1039/C3SC00099K

117.Schmidt, A.; Habeck, T.; Snovydovych, B.; Eisfeld, W. Org. Lett. 2007, 9, 3515-3518. doi:10.1021/ol0713739

118. Cheng, S.; Chen, J.; Gao, W.; Jin, H.; Ding, J.; Wu, H. J. Chem. Res. 2010, 34, 130-132. doi:10.3184/030823410X12670951969185

119.Zhang, M.; Zhang, S.; Zhang, G.; Chen, F.; Cheng, J. Tetrahedron Lett. 2011, 52, 2480-2483.

doi:10.1016/j.tetlet.2011.03.017

120.Valizadeh, H.; Ahmadi, M. C. R. Chim. 2012, 15, 1077-1080. doi:10.1016/j.crci.2012.08.004

121. Kuwano, S.; Harada, S.; Oriez, R.; Yamada, K. Chem. Commun. 2012, 48, 145-147. doi:10.1039/C1CC15539C

122.Delany, E. G.; Fagan, C.-L.; Gundala, S.; Mari, A.; Broja, T.; Zeitler, K.; Connon, S. J. Chem. Commun. 2013, 49, 6510-6512. doi:10.1039/C3CC42596G

123.Luo, F.; Pan, C.; Cheng, J.; Chen, F. Tetrahedron 2011, 67, 5878-5882. doi:10.1016/j.tet.2011.06.060

124.Zhang, D.; Pan, C. Catal. Commun. 2012, 20, 41-45. doi:10.1016/j.catcom.2011.12.041

125.Iwahana, S.; lida, H.; Yashima, E. Chem. - Eur. J. 2011, 17, 8009-8013. doi:10.1002/chem.201100737

126. De Sarkar, S.; Biswas, A.; Song, C. H.; Studer, A. Synthesis 2011, 1974-1983. doi:10.1055/s-0030-1260030

127. Mori, N.; Togo, H. Tetrahedron 2005, 61, 5915-5925. doi:10.1016/j.tet.2005.03.097

128. Yamada, S.; Morizono, D.; Yamamoto, K. Tetrahedron Lett. 1992, 33, 4329-4332. doi:10.1016/S0040-4039(00)74252-3

129.Reddy, K. R.; Venkateshwar, M.; Maheswari, C. U.; Prashanthi, S. Synth. Commun. 2009, 40, 186-195. doi:10.1080/00397910902838920

130. Karade, N. N.; Budhewar, V. H.; Katkar, A. N.; Tiwari, G. B. ARKIVOC 2006, No. xi, 162-167.

131. Kiran, Y. B.; Ikeda, R.; Sakai, N.; Konakahara, T. Synthesis 2010, 276-282. doi:10.1055/s-0029-1217121

132. Karade, N. N.; Shirodkar, S. G.; Dhoot, B. M.; Waghmare, P. B. J. Chem. Res. 2005, 274-276. doi:10.3184/0308234054213357

133.Shaikh, T. M. A.; Emmanuvel, L.; Sudalai, A. Synth. Commun. 2007, 37, 2641-2646. doi:10.1080/00397910701465032

134.Leduc, A. B.; Jamison, T. F. Org. Process Res. Dev. 2012, 16 , 1082-1089. doi:10.1021/op200118h

135.Stevens, R. V.; Chapman, K. T.; Stubbs, C. A.; Tam, W. W.; Albizati, K. F. Tetrahedron Lett. 1982, 23, 4647-4650. doi:10.1016/S0040-4039(00)85677-4

136. Sayama, S. Synlett 2004, 2739-2745. doi:10.1055/s-2004-835630

137.Agrawal, M. K.; Adimurthy, S.; Ghosh, P. K. Synth. Commun. 2012, 42, 2931-2936. doi:10.1080/00397911.2011.572219
138. McDonald, C.; Holcomb, H.; Kennedy, K.; Kirkpatrick, E.; Leathers, T.; Vanemon, P. J. Org. Chem. 1989, 54, 1213-1215. doi:10.1021/jo00266a046

139. Ghorbani-Vaghei, R.; Shahbazee, E.; Veisi, H. Mendeleev Commun. 2005, 15, 207-208. doi:10.1070/MC2005v015n05ABEH002091

140.Liu, L.; Yun, L.; Wang, Z.; Fu, X.; Yan, C. Tetrahedron Lett. 2013, 54, 5383-5386. doi:10.1016/j.tetlet.2013.07.114

141.Feng, J.; Liang, S.; Chen, S.-Y.; Zhang, J.; Fu, S.-S.; Yu, X.-Q. Adv. Synth. Catal. 2012, 354, 1287-1292. doi:10.1002/adsc. 201100920

142.Huang, J.; Li, L.-T.; Li, H.-Y.; Husan, E.; Wang, P.; Wang, B. Chem. Commun. 2012, 48, 10204-10206. doi:10.1039/C2CC35450K

143.Wei, W.; Zhang, C.; Xu, Y.; Wan, X. Chem. Commun. 2011, 47, 10827-10829. doi:10.1039/C1CC14602E

144.Zhu, F.; Wang, Z.-X. Tetrahedron 2014, 70, 9819-9827. doi:10.1016/j.tet.2014.11.002

145. Tan, B.; Toda, N.; Barbas, C. F., III. Angew. Chem., Int. Ed. 2012, 51, 12538-12541. doi:10.1002/anie.201205921

146.Wang, G.; Yu, Q.-Y.; Wang, J.; Wang, S.; Chen, S.-Y.; Yu, X.-Q. RSC Adv. 2013, 3, 21306-21310. doi:10.1039/C3RA43799J

147.Wang, N.; Liu, R.; Xu, Q.; Liang, X. Chem. Lett. 2006, 35, 566-567. doi:10.1246/cl.2006.566

148. Schulze, A.; Giannis, A. Adv. Synth. Catal. 2004, 346, 252-256. doi:10.1002/adsc.200303195

149. Yao, H.; Tang, Y.; Yamamoto, K. Tetrahedron Lett. 2012, 53, 5094-5098. doi:10.1016/j.tetlet.2012.07.024

150.Toledo, H.; Pisarevsky, E.; Abramovich, A.; Szpilman, A. M. Chem. Commun. 2013, 49, 4367-4369. doi:10.1039/C2CC35220F

151.Rout, S. K.; Guin, S.; Ghara, K. K.; Banerjee, A.; Patel, B. K. Org. Lett. 2012, 14, 3982-3985. doi:10.1021/ol301756y

152. Raju, K. B.; Kumar, B. N.; Nagaiah, K. RSC Adv. 2014, 4, 50795-50800. doi:10.1039/C4RA06233G

153.Sharma, S.; Park, J.; Kim, M.; Kwak, J. H.; Jung, Y. H.; Kim, I. S. Tetrahedron 2013, 69, 9391-9397. doi:10.1016/j.tet.2013.08.079

154.Yoo, W.-J.; Li, C.-J. J. Org. Chem. 2006, 71, 6266-6268. doi:10.1021/jo0606103

155.Kumar, G. S.; Maheswari, C. U.; Kumar, R. A.; Kantam, M. L.; Reddy, K. R. Angew. Chem., Int. Ed. 2011, 50, 11748-11751. doi:10.1002/anie.201105020

156.Barve, B. D.; Wu, Y.-C.; El-Shazly, M.; Chuang, D.-W.; Chung, Y.-M.; Tsai, Y.-H.; Wu, S.-F.; Korinek, M.; Du, Y.-C.; Hsieh, C.-T.; Wang, J.-J.; Chang, F.-R. Eur. J. Org. Chem. 2012, 6760-6766. doi:10.1002/ejoc.201201160

157.Barve, B. D.; Wu, Y.-C.; El-Shazly, M.; Chuang, D.-W.; Cheng, Y.-B.; Wang, J.-J.; Chang, F.-R. J. Org. Chem. 2014, 79, 3206-3214. doi:10.1021/j0402798k

158.Saberi, D.; Heydari, A. Tetrahedron Lett. 2013, 54, 4178-4180. doi:10.1016/j.tetlet.2013.05.113

159.Phan, N. T. S.; Nguyen, T. T.; Vu, P. H. L. ChemCatChem 2013, 5 , 3068-3077. doi: $10.1002 /$ cctc. 201300400

160.Gopinath, R.; Patel, B. K. Org. Lett. 2000, 2, 577-579. doi:10.1021/ol990383+

161. Gopinath, R.; Barkakaty, B.; Talukdar, B.; Patel, B. K. J. Org. Chem. 2003, 68, 2944-2947. doi:10.1021/jo0266902

162. Talukdar, D.; Sharma, K.; Bharadwaj, S. K.; Thakur, A. J. Synlett 2013, 24, 963-966. doi:10.1055/s-0032-1316914

163. Yoo, W.-J.; Li, C.-J. Tetrahedron Lett. 2007, 48, 1033-1035. doi:10.1016/j.tetlet.2006.11.169

164.Wu, X.-F.; Darcel, C. Eur. J. Org. Chem. 2009, 1144-1147. doi:10.1002/ejoc.200801176 
165.Rafiee, E.; Eavani, S. J. Mol. Catal. A: Chem. 2013, 373, 30-37. doi:10.1016/j.molcata.2013.02.024

166. Sharma, R. K.; Gulati, S. J. Mol. Catal. A: Chem. 2012, 363-364, 291-303. doi:10.1016/j.molcata.2012.07.004

167.Esfandiari, H.; Jameh-bozorghi, S.; Esmaielzadeh, S.; Shafiee, M. R. M.; Ghashang, M. Res. Chem. Intermed. 2013, 39 , 3319-3325. doi:10.1007/s11164-012-0844-y

168.Wu, X.-F. Tetrahedron Lett. 2012, 53, 3397-3399. doi:10.1016/j.tetlet.2012.04.111

169.Zhao, J.; Fang, H.; Han, J.; Pan, Y. Org. Lett. 2014, 16, 2530-2533. doi:10.1021/ol5009119

170.O'Connor, B.; Just, G. Tetrahedron Lett. 1987, 28, 3235-3236. doi:10.1016/S0040-4039(00)95480-7

171.Sinha, A. K.; Sharma, A.; Swaroop, A.; Kumar, V. Tetrahedron 2007, 63, 1000-1007. doi:10.1016/j.tet.2006.11.011

172.Sakuragi, H.; Tokumaru, K. Chem. Lett. 1974, 3, 475-476. doi:10.1246/cl.1974.475

173.Sundararaman, P.; Walker, E. C.; Djerassi, C. Tetrahedron Lett. 1978, 19, 1627-1628. doi:10.1016/S0040-4039(01)94623-4

174.Mineno, T.; Sakai, M.; Ubukata, A.; Nakahara, K.; Yoshimitsu, H.; Kansui, H. Chem. Pharm. Bull. 2013, 61, 870-872. doi:10.1248/cpb.c13-00072

175. Mineno, T.; Yoshino, S.; Ubukata, A. Green Sustainable Chem. 2014 4, 20-23. doi:10.4236/gsc.2014.41004

176. Travis, B. R.; Sivakumar, M.; Hollist, G. O.; Borhan, B. Org. Lett. 2003, 5, 1031-1034. doi:10.1021/ol0340078

177. Nishihara, A.; Kubota, I. J. Org. Chem. 1968, 33, 2525-2526. doi:10.1021/jo01270a082

178.Feng, J.-B.; Gong, J.-L.; Li, Q.; Wu, X.-F. Tetrahedron Lett. 2014, 55, 1657-1659. doi:10.1016/j.tetlet.2014.01.111

179.Tank, R.; Pathak, U.; Vimal, M.; Bhattacharyya, S.; Pandey, L. K. Green Chem. 2011, 13, 3350-3354. doi:10.1039/C1GC16041A

180. Kelly, C. B.; Mercadante, M. A.; Wiles, R. J.; Leadbeater, N. E. Org. Lett. 2013, 15, 2222-2225. doi:10.1021/ol400785d

181.Zhang, C.; Jiao, N. Org. Chem. Front. 2014, 1, 109-112. doi:10.1039/C3Q000041A

182.Srimani, D.; Balaraman, E.; Gnanaprakasam, B.; Ben-David, Y.; Milstein, D. Adv. Synth. Catal. 2012, 354, 2403-2406. doi:10.1002/adsc.201200438

183. Tanaka, A.; Moriyama, K.; Togo, H. Synlett 2011, 1853-1858. doi:10.1055/s-0030-1260948

184.Hu, J.; Zhu, M.; Xu, Y.; Yan, J. Synthesis 2012, 1226-1232. doi:10.1055/s-0031-1289750

185. Yu, J.; Tian, J.; Zhang, C. Adv. Synth. Catal. 2010, 352, 531-546. doi:10.1002/adsc.200900737

186.Yu, J.; Cui, J.; Hou, X.-S.; Liu, S.-S.; Gao, W.-C.; Jiang, S.; Tian, J.; Zhang, C. Tetrahedron: Asymmetry 2011, 22, 2039-2055. doi:10.1016/j.tetasy.2011.12.003

187.Moriarty, R. M.; Vaid, R. K.; Ravikumar, V. T.; Vaid, B. K.; Hopkins, T. E. Tetrahedron 1988, 44, 1603-1607. doi:10.1016/S0040-4020(01)86720-X

188.Price, D. A.; Gayton, S.; Stupple, P. A. Synlett 2002, 1170-1172. doi:10.1055/s-2002-32577

189.Liu, W.-B.; Chen, C.; Zhang, Q.; Zhu, Z.-B. Bull. Korean Chem. Soc. 2012, 33, 1823-1824. doi:10.5012/bkcs.2012.33.6.1823

190. Yamamoto, Y.; Kawano, Y.; Toy, P. H.; Togo, H. Tetrahedron 2007, 63, 4680-4687. doi:10.1016/j.tet.2007.03.091

191.Suzuki, Y.; Togo, H. Synthesis 2010, 2355-2360 doi:10.1055/s-0029-1218795
192.Sheng, J.; Li, X.; Tang, M.; Gao, B.; Huang, G. Synthesis 2007, 1165-1168. doi:10.1055/s-2007-965984

193. Tanaka, A.; Togo, H. Synlett 2009, 3360-3364. doi:10.1055/s-0029-1218370

194. Uyanik, M.; Suzuki, D.; Yasui, T.; Ishihara, K. Angew. Chem., Int. Ed. 2011, 50, 5331-5334. doi:10.1002/anie.201101522

195.Li, X.; Zhou, C.; Xu, X. ARKIVOC 2012, No. ix, 150-158.

196.Guo, S.; Yu, J.-T.; Dai, Q.; Yang, H.; Cheng, J. Chem. Commun. 2014, 50, 6240-6242. doi:10.1039/C4CC01652A

197.Terent'ev, A. O.; Krylov, I. B.; Timofeev, V. P.; Starikova, Z. A.; Merkulova, V. M.; llovaisky, A. I.; Nikishin, G. I. Adv. Synth. Catal. 2013, 355, 2375-2390. doi:10.1002/adsc.201300341

198. Krylov, I. B.; Terent'ev, A. O.; Timofeev, V. P.; Shelimov, B. N.; Novikov, R. A.; Merkulova, V. M.; Nikishin, G. I. Adv. Synth. Catal. 2014, 356, 2266-2280. doi:10.1002/adsc.201400143

199. Terent'ev, A. O.; Borisov, D. A.; Yaremenko, I. A.; Chernyshev, V. V.; Nikishin, G. I. J. Org. Chem. 2010, 75, 5065-5071. doi:10.1021/jo100793j

200. Terent'ev, A. O.; Borisov, D. A.; Semenov, V. V.; Chernyshev, V. V.; Dembitsky, V. M.; Nikishin, G. I. Synthesis 2011, 2091-2100. doi:10.1055/s-0030-1260027

201. Kharasch, M. S.; Fono, A. J. Org. Chem. 1959, 24, 72-78. doi:10.1021/jo01083a022

202.Baidya, M.; Griffin, K. A.; Yamamoto, H. J. Am. Chem. Soc. 2012, 134, 18566-18569. doi:10.1021/ja309311z

203. Frazier, C. P.; Sandoval, D.; Palmer, L. I.; de Alaniz, J. R. Chem. Sci. 2013, 4, 3857-3862. doi:10.1039/C3SC51658J

204. Tanyeli, C.; Sezen, B. Tetrahedron Lett. 2000, 41, 7973-7976. doi:10.1016/S0040-4039(00)01374-5

205.Tanyeli, C.; Sezen, B.; Iyigün, Ç.; Elmalı, O. Tetrahedron Lett. 2001, 42, 6397-6399. doi:10.1016/S0040-4039(01)01262-X

206. Tanyeli, C.; Özdemirhan, D.; Sezen, B. Tetrahedron 2002, 58, 9983-9988. doi:10.1016/S0040-4020(02)01350-9

207. Tanyeli, C.; Tosun, A.; Turkut, E.; Sezen, B. Tetrahedron 2003, 59, 1055-1058. doi:10.1016/S0040-4020(02)01634-4

208. Tanyeli, C.; Iyigün, Ç. Tetrahedron 2003, 59, 7135-7139. doi:10.1016/S0040-4020(03)01094-9

209.Demir, A. S.; Reis, Ö.; Igdir, A. C. Tetrahedron 2004, 60, 3427-3432. doi:10.1016/j.tet.2004.02.039

210.Demir, A. S.; Caliskan, Z.; Aydin, A. E.; Bicer, I. Tetrahedron: Asymmetry 2006, 17, 786-791. doi:10.1016/j.tetasy.2006.01.025

211.Demir, A. S.; Findik, H. Tetrahedron 2008, 64, 6196-6201. doi:10.1016/j.tet.2008.05.004

212. Marín-Barrios, R.; García-Cabeza, A. L.; Moreno-Dorado, F. J.; Guerra, F. M.; Massanet, G. M. J. Org. Chem. 2014, 79, 6501-6509. doi:10.1021/j0500915r

213. Kitching, W.; Rappoport, Z.; Winstein, S.; Young, W. G. J. Am. Chem. Soc. 1966, 88, 2054-2055. doi:10.1021/ja00961a043

214. Engelin, C.; Jensen, T.; Rodriguez-Rodriguez, S.; Fristrup, $P$. ACS Catal. 2013, 3, 294-302. doi:10.1021/cs3007878

215.Grennberg, H.; Bäckvall, J.-E. Chem. - Eur. J. 1998, 4, 1083-1089. doi:10.1002/(SICI)1521-3765(19980615)4:6<1083::AID-CHEM1083>3 .0.CO;2-F

216.Diao, T.; Stahl, S. S. Polyhedron 2014, 84, 96-102. doi:10.1016/j.poly.2014.06.038

217. Chen, M. S.; Prabagaran, N.; Labenz, N. A.; White, M. C. J. Am. Chem. Soc. 2005, 127, 6970-6971. doi:10.1021/ja0500198

218. Chen, M. S.; White, M. C. J. Am. Chem. Soc. 2004, 126, 1346-1347. doi:10.1021/ja039107n 
219. Covell, D. J.; White, M. C. Angew. Chem., Int. Ed. 2008, 47, 6448-6451. doi:10.1002/anie.200802106

220.Campbell, A. N.; White, P. B.; Guzei, I. A.; Stahl, S. S. J. Am. Chem. Soc. 2010, 132, 15116-15119. doi:10.1021/ja105829t

221. Mitsudome, T.; Umetani, T.; Nosaka, N.; Mori, K.; Mizugaki, T.; Ebitani, K.; Kaneda, K. Angew. Chem., Int. Ed. 2006, 45, 481-485. doi:10.1002/anie.200502886

222.Vermeulen, N. A.; Delcamp, J. H.; White, M. C. J. Am. Chem. Soc 2010, 132, 11323-11328. doi:10.1021/ja104826g

223. Thiery, E.; Aouf, C.; Belloy, J.; Harakat, D.; Le Bras, J.; Muzart, J. J. Org. Chem. 2010, 75, 1771-1774. doi:10.1021/jo902587u

224.Check, C. T.; Henderson, W. H.; Wray, B. C.; Vanden Eynden, M. J.; Stambuli, J. P. J. Am. Chem. Soc. 2011, 133, 18503-18505. doi:10.1021/ja2089102

225. Macsári, I.; Szabó, K. J. Tetrahedron Lett. 1998, 39, 6345-6348. doi:10.1016/S0040-4039(98)01304-5

226. García-Cabeza, A. L.; Marín-Barrios, R.; Moreno-Dorado, F. J.; Ortega, M. J.; Massanet, G. M.; Guerra, F. M. Org. Lett. 2014, 16, 1598-1601. doi:10.1021/ol500198c

227. Takemura, N.; Kuninobu, Y.; Kanai, M. Org. Biomol. Chem. 2014, 12, 2528-2532. doi:10.1039/C4OB00215F

228.Rout, S. K.; Guin, S.; Banerjee, A.; Khatun, N.; Gogoi, A.; Patel, B. K. Org. Lett. 2013, 15, 4106-4109. doi:10.1021/ol401682a

229.Rout, S. K.; Guin, S.; Ali, W.; Gogoi, A.; Patel, B. K. Org. Lett. 2014, 16, 3086-3089. doi:10.1021/ol5011906

230.Boldron, C.; Gamez, P.; Tooke, D. M.; Spek, A. L.; Reedijk, J. Angew. Chem., Int. Ed. 2005, 44, 3585-3587. doi:10.1002/anie.200462946

231.Boldron, C.; Özalp-Yaman, Ş.; Gamez, P.; Tooke, D. M.; Spek, A. L.; Reedijk, J. Dalton Trans. 2005, 3535-3541. doi:10.1039/B507199B

232.Liu, H.; Shi, G.; Pan, S.; Jiang, Y.; Zhang, Y. Org. Lett. 2013, 15, 4098-4101. doi:10.1021/ol401687f

233.Benhmid, A.; Narayana, K. V.; Martin, A.; Lücke, B. Chem. Commun. 2004, 2118-2119. doi:10.1039/B406396A

234.Kalevaru, V. N.; Benhmid, A.; Radnik, J.; Pohl, M.-M.; Lücke, B.; Martin, A. Catal. Today 2009, 141, 317-324. doi:10.1016/j.cattod.2008.06.004

235. Gatla, S.; Madaan, N.; Radnik, J.; Kalevaru, V. N.; Pohl, M.-M.; Lücke, B.; Martin, A.; Brückner, A. Appl. Catal., A 2011, 398, 104-112. doi:10.1016/j.apcata.2011.03.025

236. Madaan, N.; Gatla, S.; Kalevaru, V. N.; Radnik, J.; Pohl, M.-M.; Lücke, B.; Brückner, A.; Martin, A. ChemCatChem 2013, 5, 185-191. doi:10.1002/cctc.201200522

237.Shi, E.; Shao, Y.; Chen, S.; Hu, H.; Liu, Z.; Zhang, J.; Wan, X. Org. Lett. 2012, 14, 3384-3387. doi:10.1021/ol3013606

238.Majji, G.; Guin, S.; Gogoi, A.; Rout, S. K.; Patel, B. K. Chem. Commun. 2013, 49, 3031-3033. doi:10.1039/C3CC40832A

239.Xu, J.; Zhang, P.; Li, X.; Gao, Y.; Wu, J.; Tang, G.; Zhao, Y. Adv. Synth. Catal. 2014, 356, 3331-3335. doi:10.1002/adsc.201400436

240.Zaimoku, H.; Hatta, T.; Taniguchi, T.; Ishibashi, H. Org. Lett. 2012, 14, 6088-6091. doi:10.1021/ol302983t

241.Kumar, V.; Sharma, A.; Sharma, M.; Sharma, U. K.; Sinha, A. K. Tetrahedron 2007, 63, 9718-9723. doi:10.1016/j.tet.2007.07.018

242. Yi, H.; Liu, Q.; Liu, J.; Zeng, Z.; Yang, Y.; Lei, A. ChemSusChem 2012, 5, 2143-2146. doi:10.1002/cssc.201200458

243.Aubry, S.; Pellet-Rostaing, S.; Lemaire, M. Eur. J. Org. Chem. 2007, 5212-5225. doi:10.1002/ejoc.200700366
244. Estévez, J. C.; Villaverde, M. C.; Estévez, R. J.; Seijas, J. A.; Castedo, L. Synth. Commun. 1990, 20, 503-507. doi:10.1080/00397919008244897

245.Guy, A.; Lemor, A.; Imbert, D.; Lemair, M. Tetrahedron Lett. 1989, 30, 327-330. doi:10.1016/S0040-4039(00)95192-X

246.Li, Y.; Bao, W. Adv. Synth. Catal. 2009, 351, 865-868. doi:10.1002/adsc. 200800810

247. Mo, H.; Bao, W. Tetrahedron 2011, 67, 4793-4799. doi:10.1016/j.tet.2011.05.030

248.Wang, T.; Zhou, W.; Yin, H.; Ma, J.-A.; Jiao, N. Angew. Chem., Int. Ed. 2012, 51, 10823-10826. doi:10.1002/anie.201205779

249.Jin, J.; Li, Y.; Wang, Z.-j.; Qian, W.-X.; Bao, W.-I. Eur. J. Org. Chem. 2010, 1235-1238. doi:10.1002/ejoc.200901321

250.He, H.-F.; Wang, K.; Xing, B.; Sheng, G.; Ma, T.; Bao, W. Synlett 2013, 24, 211-214. doi:10.1055/s-0032-1317960

251.Bouquet, M.; Guy, A.; Lemaire, M.; Guetté, J. P. Synth. Commun. 1985, 15, 1153-1157. doi:10.1080/00397918508077258

252.Lee, J. M.; Park, E. J.; Cho, S. H.; Chang, S. J. Am. Chem. Soc. 2008, 130, 7824-7825. doi:10.1021/ja8031218

253.Terent'ev, A. O.; Krylov, I. B.; Sharipov, M. Y.; Kazanskaya, Z. M.; Nikishin, G. I. Tetrahedron 2012, 68, 10263-10271. doi:10.1016/j.tet.2012.10.018

254.Koshino, N.; Saha, B.; Espenson, J. H. J. Org. Chem. 2003, 68, 9364-9370. doi:10.1021/jo0348017

255. Terent'ev, A. O.; Krylov, I. B.; Lipatnikov, A. D. Russ. J. Gen. Chem. 2014, 84, 2084-2087. doi:10.1134/S1070363214110061 Zhurnal Obschei Khimii 2014, 84, 1786-1789.

256. Coseri, S. Eur. J. Org. Chem. 2007, 1725-1729. doi:10.1002/ejoc. 200601072

257. Coseri, S. J. Phys. Org. Chem. 2009, 22, 397-402. doi:10.1002/poc.1466

258. Minisci, F.; Recupero, F.; Gambarotti, C.; Punta, C.; Paganelli, R. Tetrahedron Lett. 2003, 44, 6919-6922. doi:10.1016/S0040-4039(03)01687-3

259. Khan, K. M.; Maharvi, G. M.; Hayat, S.; Zia-Ullah; Choudhary, M. I.; Atta-ur-Rahman. Tetrahedron 2003, 59, 5549-5554. doi:10.1016/S0040-4020(03)00812-3

260. Iwata, S.; Hata, T.; Urabe, H. Adv. Synth. Catal. 2012, 354, 3480-3484. doi:10.1002/adsc.201200410

261. Macedo, A. G.; Fernandes, S. E. M.; Valente, A. A.; Ferreira, R. A. S.; Carlos, L. D.; Rocha, J. Molecules 2010, 15, 747-765. doi:10.3390/molecules15020747

262. Akhlaghinia, B.; Ebrahimabadi, H.; Goharshadi, E. K.; Samiee, S.; Rezazadeh, S. J. Mol. Catal. A: Chem. 2012, 357, 67-72. doi:10.1016/j.molcata.2012.01.020

263. Shaikh, T. M.; Sudalai, A. Tetrahedron Lett. 2005, 46, 5589-5592. doi:10.1016/j.tetlet.2005.06.033

264. Khenkin, A. M.; Neumann, R. J. Am. Chem. Soc. 2004, 126, 6356-6362. doi:10.1021/ja031710i

265. Occhipinti, G.; Liguori, L.; Tsoukala, A.; Bjørsvik, H.-R. Org. Process Res. Dev. 2010, 14, 1379-1384. doi:10.1021/op100185x

266. Cho, S.-D.; Kim, H.-J.; Ahn, C.; Falck, J. R.; Shin, D.-S. Tetrahedron Lett. 1999, 40, 8215-8217. doi:10.1016/S0040-4039(99)01713-X

267.Iwaoka, M.; Tomoda, S. J. Chem. Soc., Chem. Commun. 1992, 1165-1167. doi:10.1039/c39920001165 
268. Tiecco, M.; Testaferri, L.; Tingoli, M.; Bagnoli, L.; Santi, C. J. Chem. Soc., Chem. Commun. 1993, 637-639. doi:10.1039/C39930000637

269. Shibuya, K. Synth. Commun. 1994, 24, 2923-2941. doi:10.1080/00397919408010614

270.Chen, L.; Shi, E.; Liu, Z.; Chen, S.; Wei, W.; Li, H.; Xu, K.; Wan, X. Chem. - Eur. J. 2011, 17, 4085-4089. doi:10.1002/chem.201100192

271.Zhang, S.; Guo, L.-N.; Wang, H.; Duan, X.-H. Org. Biomol. Chem. 2013, 11, 4308-4311. doi:10.1039/C3OB40748A

272. Yu, H.; Shen, J. Org. Lett. 2014, 16, 3204-3207. doi:10.1021/ol5012168

273.Zhao, J.; Fang, H.; Zhou, W.; Han, J.; Pan, Y. J. Org. Chem. 2014, 79, 3847-3855. doi:10.1021/jo500192h

274.Barve, B. D.; Wu, Y.-C.; El-Shazly, M.; Korinek, M.; Cheng, Y.-B.; Wang, J.-J.; Chang, F.-R. Org. Lett. 2014, 16, 1912-1915. doi:10.1021/ol5004115

275.Park, J.; Han, S. H.; Sharma, S.; Han, S.; Shin, Y.; Mishra, N. K.; Kwak, J. H.; Lee, C. H.; Lee, J.; Kim, I. S. J. Org. Chem. 2014, 79, 4735-4742. doi:10.1021/jo500576x

276.Phan, N. T. S.; Vu, P. H. L.; Nguyen, T. T. J. Catal. 2013, 306, 38-46. doi:10.1016/j.jcat.2013.06.006

277.Murahash, S.-I.; Saito, T.; Naota, T.; Kumobayashi, H.; Akutagawa, S. Tetrahedron Lett. 1991, 32, 5991-5994. doi:10.1016/S0040-4039(00)79446-9

278.Murahashi, S.; Naota, T.; Kuwabara, T.; Saito, T.; Kumobayashi, H.; Akutagawa, S. J. Am. Chem. Soc. 1990, 112, 7820-7822. doi:10.1021/ja00177a067

279.Shu, X.-Z.; Xia, X.-F.; Yang, Y.-F.; Ji, K.-G.; Liu, X.-Y.; Liang, Y.-M. J. Org. Chem. 2009, 74, 7464-7469. doi:10.1021/jo901583r

280.Weinberg, N. L.; Brown, E. A. J. Org. Chem. 1966, 31, 4058-4061. doi:10.1021/jo01350a041

281.Liang, D.; Wang, M.; Dong, Y.; Guo, Y.; Liu, Q. RSC Adv. 2014, 4, 6564-6567. doi:10.1039/C3RA47282E

282.Liu, X.; Cheng, R.; Zhao, F.; Zhang-Negrerie, D.; Du, Y.; Zhao, K. Org. Lett. 2012, 14, 5480-5483. doi:10.1021/ol3025583

283.Liu, H.; Wang, X.; Gu, Y. Org. Biomol. Chem. 2011, 9, 1614-1620. doi:10.1039/С0ОВ00749H

284.Liu, H.; Xie, Y.; Gu, Y. Tetrahedron Lett. 2011, 52, 4324-4326. doi:10.1016/j.tetlet.2011.06.041

285.Jiang, Q.; Wang, J.-Y.; Guo, C. J. Org. Chem. 2014, 79, 8768-8773. doi:10.1021/j0501601u

286. Pelter, A.; Elgendy, S. M. A. J. Chem. Soc., Perkin Trans. 1 1993, 1891-1896. doi:10.1039/P19930001891

287.Fleck, A. E.; Hobart, J. A.; Morrow, G. W. Synth. Commun. 1992, 22, 179-187. doi:10.1080/00397919208021090

288. Mitchell, A. S.; Russell, R. A. Tetrahedron Lett. 1993, 34, 545-548. doi:10.1016/0040-4039(93)85123-E

289. Omura, K. Synthesis 2010, 208-210. doi:10.1055/s-0029-1217127

290.Chen, X.; Zhu, C.; Cui, X.; Wu, Y. Chem. Commun. 2013, 49, 6900-6902. doi:10.1039/c3cc43947j

291.Takemura, N.; Kuninobu, Y.; Kanai, M. Org. Lett. 2013, 15, 844-847. doi:10.1021/ol303533z

292. Halper, S. R.; Stork, J. R.; Cohen, S. M. Dalton Trans. 2007, 1067-1074. doi:10.1039/B615801C

293. Takuwa, A.; Soga, O.; Iwamoto, H.; Maruyama, K. Bull. Chem. Soc. Jpn. 1986, 59, 2959-2961. doi:10.1246/bcsj.59.2959

294.Kidwai, M.; Kumar, P.; Kohli, S. J. Chem. Res., Synop. 1997, 24-25. doi:10.1039/A601810F

295.Bansal, V.; Sharma, J.; Khanna, R. N. J. Chem. Res., Synop. 1998, 720-721. doi:10.1039/A803513J
296. Komiya, N.; Noji, S.; Murahashi, S.-I. Chem. Commun. 2001, 65-66. doi:10.1039/B006869L

297. Nomura, K.; Uemura, S. J. Chem. Soc., Chem. Commun. 1994, 129-130. doi:10.1039/C39940000129

298.Deno, N. C.; Messer, L. A. J. Chem. Soc., Chem. Commun. 1976, 1051a. doi:10.1039/C3976001051A

299. Moody, C. J.; O'Connell, J. L. Chem. Commun. 2000, 1311-1312. doi:10.1039/B003074K

300.Tran, B. L.; Driess, M.; Hartwig, J. F. J. Am. Chem. Soc. 2014, 136, 17292-17301. doi:10.1021/ja510093x

301. Gary, J. B.; Cook, A. K.; Sanford, M. S. ACS Catal. 2013, 3, 700-703. doi:10.1021/cs300786j

302. Tajima, T.; Fuchigami, T. Chem. - Eur. J. 2005, 11, 6192-6196. doi:10.1002/chem. 200500340

\section{License and Terms}

This is an Open Access article under the terms of the Creative Commons Attribution License

(http://creativecommons.org/licenses/by/2.0), which permits unrestricted use, distribution, and reproduction in any medium, provided the original work is properly cited.

The license is subject to the Beilstein Journal of Organic Chemistry terms and conditions: (http://www.beilstein-journals.org/bjoc)

The definitive version of this article is the electronic one which can be found at: doi:10.3762/bjoc. 11.13 